\title{
Dynamic expression of Mover in rodent endbulbs of Held
}

\author{
Dissertation \\ for the award of the degree \\ "Doctor rerum naturalium " (Dr. rer. nat.) \\ of the Georg-August-University of Göttingen
}

within the doctoral program Sensory and Motor Neuroscience of the Göttingen graduate School for Neuroscience, Biophysics and Molecular Biosciences of the Georg-August University School of Science (GAUSS)

submitted by

\section{Friederike Wetzel}

born in Wernigerode, Germany

Göttingen, 2015 

Members of the thesis committee

Prof. Dr. Thomas Dresbach, Center of Anatomy, Department of Anatomy and Embryology, University Medical Center Göttingen

Prof. Tobias Moser, Institute for Auditory Neuroscience, University Medical Center Göttingen

Prof.Dr. Nils Brose

Department of Molecular Neurobiology, Max Planck Institute of Experimental Medicine, Göttingen

Date of the oral examination: 


\section{Declaration}

This thesis has been written independently and with no other sources and aids than quoted.

Friederike Wetzel

Göttingen, May 4, 2015 


\section{Contents}

Declaration

Contents

List of Figures

List of Tables

1. Introduction

1.1 The auditory system and sound localization in the auditory brainstem .........1

1.2 Cell types and function in the ventral cochlear nucleus ..........................4

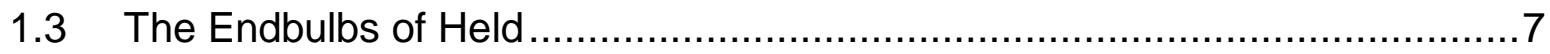

1.3.1 Short-term plasticity in endbulbs of Held .....................................

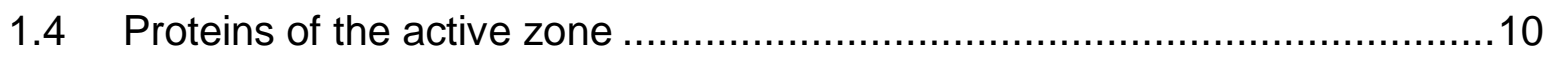

1.5 Mover, a novel presynaptic protein that is associated with Bassoon...........11

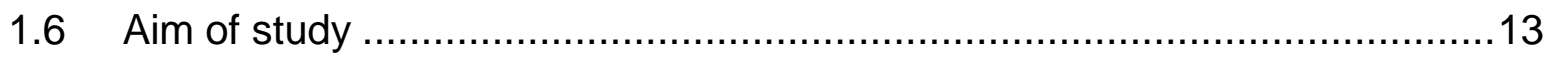

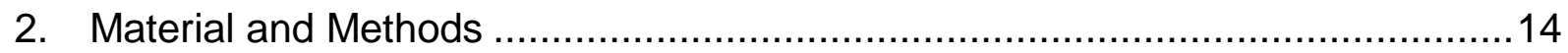

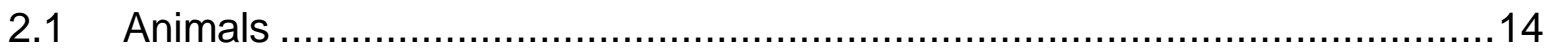

2.2 Generation of Mover knock-out mouse ................................................. 14

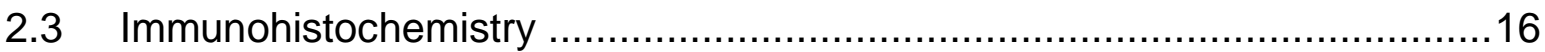

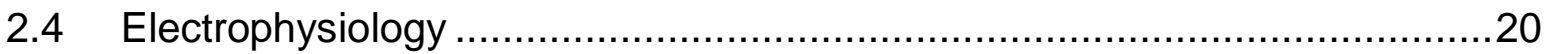

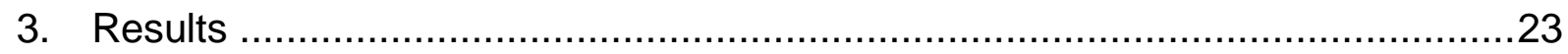

3.1 Tesing available antibodies against Mover ..........................................23

3.2 Mover immunolabeling in the auditory brainstem and ventral cochlear nucleus

3.2.1 Mover fluorescence intensities in the AVCN and calyx of Held ............30

3.3 Mover is associated with Bassoon at active zones ................................32

3.4 Mover fluorescence intensities in deaf Otoferlin knock-out mice.................33

3.5 Characterization of a Mover knock-out mouse.......................................37

3.5.1 3.5.1 Validation of the Mover knock-out ....................................... 37

3.5.2 Electrophysiological characterization of synaptic neurotransmission between bushy cells and endbulbs of Held in Mover knock-out mice................39

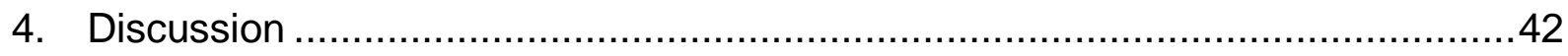


$4.1 \quad$ Methodological considerations ........................................................... 42

4.2 Mover immunofluorescence in AVCN ................................................43

4.3 Activity-dependent regulation of Mover in deaf mice ...............................46

4.4 Characterization of synaptic transmission at the endbulb bushy cell junction in a Mover knock-out mouse

4.5 Association of Mover with Bassoon .................................................... 51

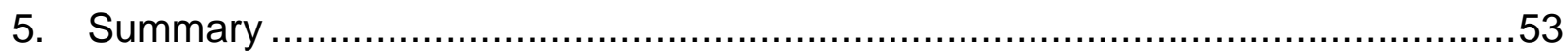

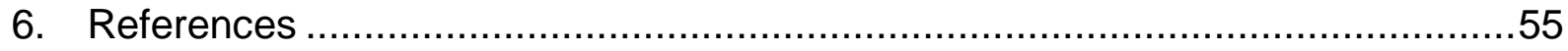

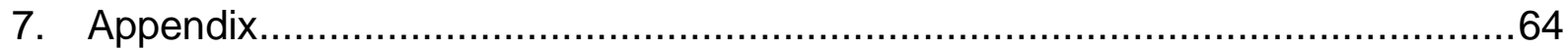

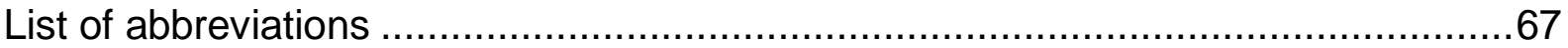

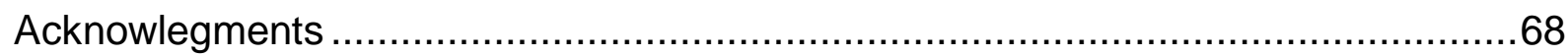

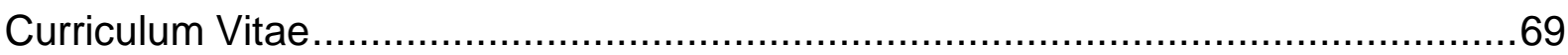




\section{List of Figures}

Figure 1.1 The ascending auditory pathway.

Figure 1.2. The cochlear nucleus.

Figure 2.1 Scheme illustrating Mover knock-out generation.

Figure 3.1 Mover antibody stainings in the anteroventral cochlear nucleus.

Figure 3.2 Mover is present in auditory brainstem nuclei.

Figure 3.3 Mover is a synaptic vesicle protein.

Figure 3.4 Mover is present in the endbulbs of Held.

Figure 3.5 Mover is present in inhibitory terminals in the AVCN.

Figure 3.6 Analysis of Mover antibody fluorescence intensities in the ventral cochlear nucleus and calyx of Held.

Figure 3.7 Mover associates with Bassoon.

Figure 3.8 Reduced intensities of Mover fluorescence signals in the endbulbs of Held in Otoferlin knock-out mice

Figure 3.9 Increased intensities of Mover fluorescence signals in the calyx of Held in Otoferlin knock-out mice.

Figure 3.10 Intensities of Mover signals remain unchanged in hippocampal mossy fiber terminals in Otoferlin knock-out animals.

Figure 3.11 Mover fluorescence signals are absent in brainstem and hippocampal slices in a Mover knock-out mouse.

Figure 3.12 Validation of Mover knock-out with DAB stainings in the auditory brainstem slices of a Mover knock-out mouse.

Figure 3.13 Identification of bushy and stellate cells in electrophysiological recordings

Figure 3.14 Increased quantal size in Mover knock-out mice.

Figure 4.1 Schematic illustration of the location of Mover at the active zone

Figure 7.1 Correlation of measured immunofluorescence intensities in Otoferlin mice.

Figure 7.2 Standard deviation of mean intensities from Mover immunosignals in rat.

Figure 7.3 Increased paired-pulse ratio in endbulbs of Mover knock-out mice. 


\section{List of Tables}

Table 2.1. Cre PCR - protocol

Table 2.2. multiplex PCR - protocol

Table 2.3 Primary antibodies

Table 2.4 Secondary antibodies

Table 2.5 Chemicals for electrophysiology

Table. 3.1 Analysis of miniature EPSCs

Table 7.1 Analysis of evoked EPSCs 


\section{Introduction}

Hearing allows animals and man to localize the sources of sound and to communicate with conspecifics. For animals sound source localization is important for detection and an appropriate response to danger and it allows predators to detect prey. The sense of hearing is mediated by the auditory system, which involves the cochlea and the spiral ganglion as peripheral parts, and sends signal to the central nervous system through auditory nerve fibres. To identify and make a percept of an acoustic event, the brain can use only a few acoustic cues. These acoustic cues are transformed into temporal firing patterns of the auditory nerve fibers and further processed and integrated at hierarchically organized stations of the ascending pathways. Sound location is computed at more central levels in the auditory pathway and is based entirely on neural representations of the spectral and temporal characteristics of the acoustic stimuli.

\subsection{The auditory system and sound localization in the auditory brainstem}

Auditory stimuli are created by moving objects (e.g. human speaking, snipping fingers, and flapping wings) that cause changes of pressure in the air or other elastic media. In this way, sound waves with certain characteristics are generated. The sound frequency is defined as the number of cycles of a sound wave per second. The frequency of a sound wave encodes the pitch of a tone. On the other hand, the intensity of a sound is assigned to the maximum deflections of the sound wave, the amplitude. The hearing (intensity) threshold, is described as the just perceptible sound pressure level and is dependent on the frequency.

Humans can detect sound between 16 and $20 \mathrm{kHz}$. In contrast, the hearing range of animals is more various with some specialized to low frequencies, e.g. gerbils (0.1-50 $\mathrm{kHz}$ ) and barn owls $(0.2-12 \mathrm{kHz})$, and others having a better high frequency hearing ability (cats: $0.1-90 \mathrm{kHz}$ and mice: $3-100 \mathrm{kHz}$, respectively) (Fay 1988).

The external ear collects sound waves and carries them down the ear canal, where the sound waves cause the vibration of the eardrum. The mechanical deflections of the eardrum are transmitted to the cochlea via the ossicles. These tiny bones act as 
an impedance-matching device effectively coupling the air-borne sound to the fluids of the inner ear. Vibrations of the ossicles cause the oval and round window at the base of the cochlea to move in opposite directions. This leads to a displacement of the cochlear fluids and consequently a wave starts travelling across the basilar membrane. As it moves the traveling wave increases in amplitude and reaches a peak deflection at a place that corresponds to the frequency of the sound. Hair cells in the organ of Corti are specialized for the transduction and resolution of sound frequency, i.e. mechanical energy is converted into bioelectric energy in form of membrane depolarization. This depolarization induces transmitter release, which triggers action potentials in spiral ganglion neurons. Their afferent nerve fibers transmit the action potentials to the central auditory system. High-frequency sounds produce deflections near the base of the cochlea, while low-frequencies deflect the membrane near the apex. In this way frequency is coded via a place-code with neurons at different places coding for different frequencies. Precise mapping of frequency to a position is known as tonotopic mapping which is preserved throughout the auditory pathway. The afferent auditory nerve fibers (ANF) arise from spiral ganglion cell axons and terminate in the cochlear nucleus (CN). Second-order neurons of the $\mathrm{CN}$ project in several parallel pathways to the inferior colliculus (IC). in the midbrain. Neurons from the dorsal cochlear nucleus (DCN) project directly to the contralateral IC. Some neurons from the ventral cochlear nucleus (VCN) pass across the midline to cells of the superior olivary complex (SOC), whereas others make connection with olivary cells of the same side. Nerve fibers from the VCN, SOC and DCN join the lateral lemniscus and end in the IC. Neurons of the IC project to the medial geniculate nucleus of the thalamus and from there to the auditory cortex in the temporal lobe. The ascending auditory pathway to the midbrain is illustrated and summarized in figure 1.1.

To perform sound localization, many mammals make use of two binaural cues, interaural time differences and interaural level difference (Grothe et al. 2010). Microsecond differences in the arrival time of a sound at the two ears (interaural time differences, ITDs) are the main cue for localizing low-frequency sounds in the horizontal plane. Sound waves arrive first at the ear which is turned towards the sound source but arrives delayed at the other ear. Neurons in the medial superior olive (MSO) compute ITDs in a sub-millisecond range. The relative arrival times are transmitted via two excitatory inputs deriving from the contralateral and the ipsilateral 
spherical bushy cells in the CN (Cant \& Casseday 1986). In addition, neuronal inhibition originating from the medial and lateral nucleus of the trapezoid body (MNTB and LNTB) (Grothe \& Sanes 1994) refines the ITD sensitivity (Grothe \& Pecka 2014; Grothe 2003)

For frequencies higher than $2 \mathrm{kHz}$, differences in sound level, or intensity, are analyzed in the lateral superior olive (LSO) which receives excitatory inputs from ipsilateral spherical bushy cells in the VCN and inhibitory inputs from the MNTB which itself is innervated by globular bushy cells the contralateral VCN (Cant and Casseday, 1986). Interaural level differences (ILDs) are created by a shadowing effect of the head which is produced at the ear further away from the sound source. For instance, sound coming from the left side is attenuated by the head, which lies between the contralateral ear and the sound-source, before it reaches the right ear. Significant ILDs occur when the wavelength is shorter than the head width (Grothe \& Pecka 2014).

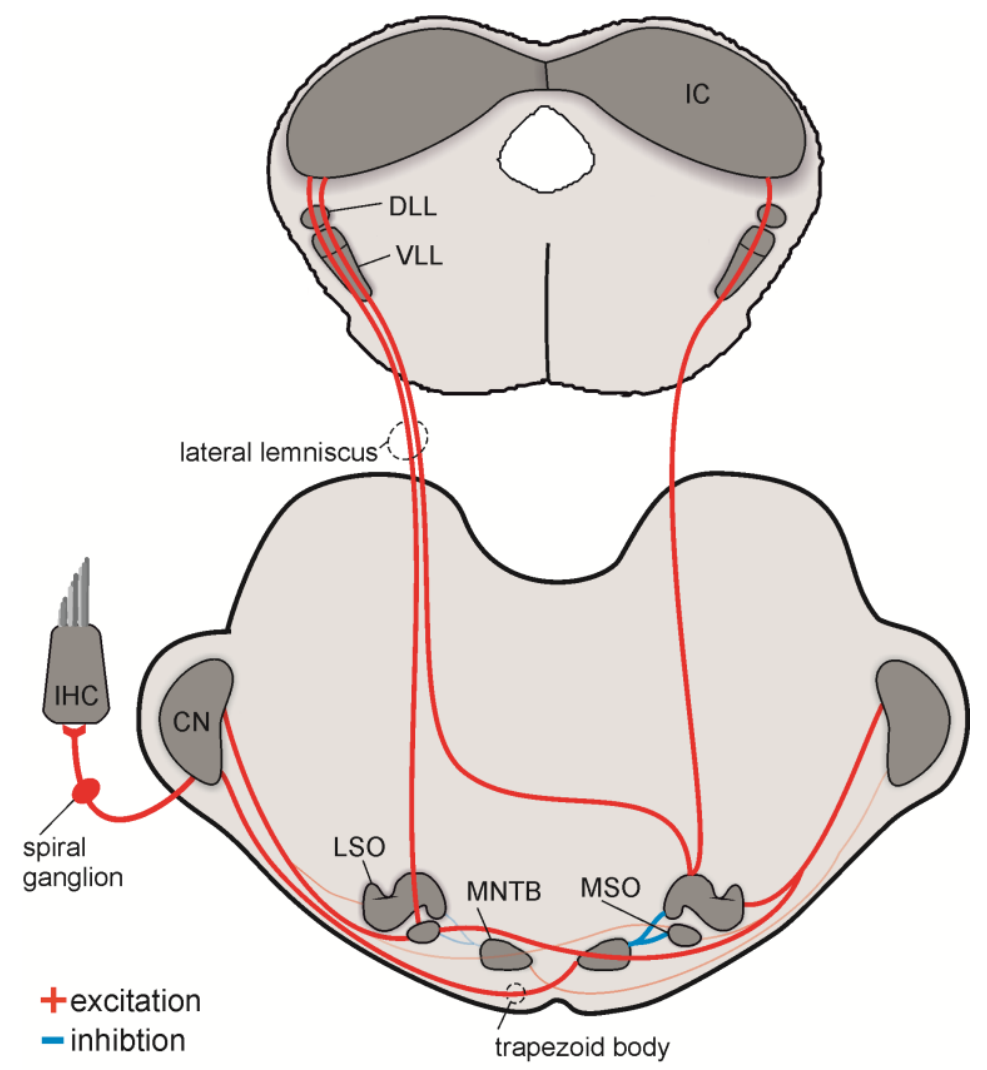

Figure 1.1 The ascending auditory pathway. Schematic coronal section of the auditory brainstem and midbrain. Selected afferent projections. IHC: inner hair cell, CN, cochlear nucleus, LSO: lateral superior olive, MNTB: medial nucleus of the trapezoid body, MSO: medial superior olive, VLL: ventral lateral lemniscus, DLL: dorsal lateral lemniscus. (adapted from Gersdorff \& Borst, 2002) 
The mechanisms described above emphasize that the processing of sound source information in both nuclei, MSO and LSO, are dependent on the accurate coincidence and integration of excitatory as well as inhibitory inputs. A precisely timed transmission of the binaural signals from the auditory nerve fibers via the $\mathrm{CN}$ is essential for appropriate detection of ITDs and ILDs in the brainstem (Grothe 2003; Oertel 1999).

\subsection{Cell types and function in the ventral cochlear nucleus}

The cochlear nucleus of the brainstem can be divided into a ventral and a dorsal part. Each part is topographically organized with regard to incoming ANFs. Consequently, high frequency information is transmitted in dorsal regions and low frequency processing takes place in ventral areas. The VCN is separated from the DCN by a cap that harbors the granule cells. The DCN serves as the initial site of multimodal signal integration along the ascending auditory pathway. It integrates audition with other sensory input and subsequently refers this information to the midbrain (Cant \& Benson 2003). The ventral cochlear nucleus can be further divided into an anterior and posterior subdivision based of the bifurcation zone of the auditory fibers (Cajal, 1909). The region where ANFs enter the brainstem marks the border between anterior the ventral cochlear nucleus (AVCN) and posterior the ventral cochlear nucleus (PVCN) (overview see figure 1.1). 


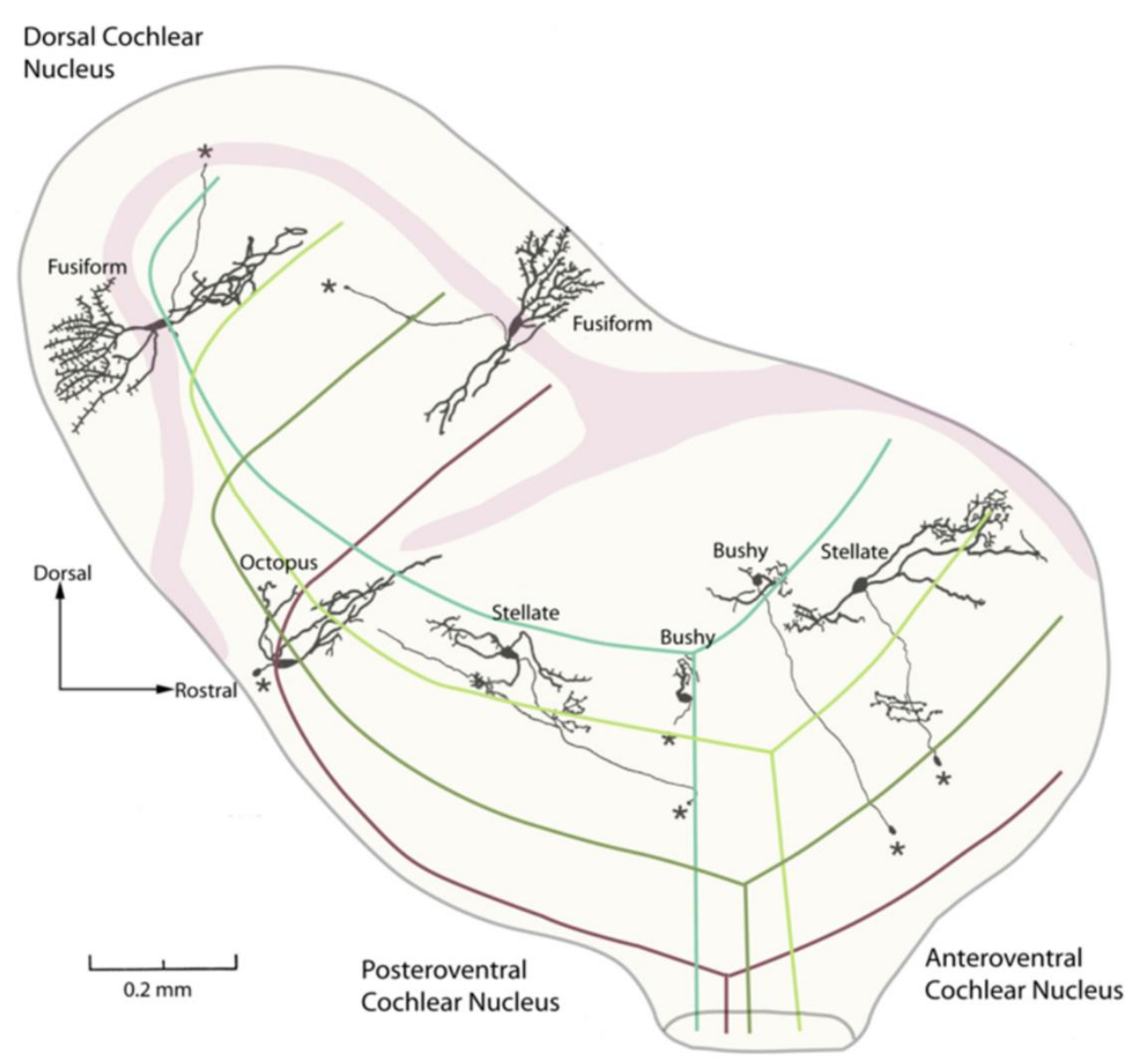

Figure 1.2. The cochlear nucleus. (adapted from Oertel and Kandel et al., 2013)

Bushy and T-stellate cells are the main cell types in the AVCN.

T-stellate cells occupy a region between the octopus cell area (in the most caudal and dorsal part of the PVCN) and the nerve root, and a few sit anterior to the nerve root (Oertel et al. 2011). They receive many small inputs from ANF, i.e. 6.5 on average (Cao \& Oertel 2010). T-stellate cells respond to tone bursts with regular, tonic firing of action potentials (AP). Hence, the response pattern was termed as chopping (Smith \& Rhode 1989). The tonic firing rate increases monotonically with intensity (Oertel et al. 2011). This makes T-stellate cells well suited for encoding the envelope of sounds and (as a population) for the spectrum of complex sound, cues that are used for the sound localization (Blackburn \& Sachs 1990) and speech processing (Shannon et al. 1995), respectively. T-stellate cells innervate numerous auditory nuclei in the brainstem including DCN, LSO, VNTB, the nuclei of the lateral 
lemniscus (NLL), and the IC (Cant \& Benson 2003). Their axons project through the trapezoid body, hence, they were called T stellate cells (Oertel et al. 2011).

Bushy cells can be divided into two subtypes (spherical bushy cells and globular bushy cells) based on the distribution of response properties and patterns of inputs and projections (Cao \& Oertel 2010; Lauer et al. 2013). Spherical bushy cells (SBCs) give rise to an excitatory bilateral projection to the MSO and to the ipsilateral LSO (Cant \& Casseday 1986). Globular bushy cells (GBCs) sent their axons to the contralateral MNTB (Smith et al. 1991) where they form a large synaptic ending, the calyx of Held.

In cats, spherical and globular bushy cells occupy different parts of the VCN. SBCs were primarily found in the more rostral regions of the AVCN (Osen 1969) whereas GBSs were located in the posterior part of AVCN and near the root of the auditory nerve (Osen 1969). In contrast, a recent anatomical study from Lauer et al. (2013) in the mouse AVCN revealed that bushy cells do not occupy distinct regions. Instead differences in inputs to bushy cell bodies were obvious at the electron microscopic level. In a physiological study Cao et al. (2010) found that bushy cells can be separated into two groups that differ in converging excitatory inputs with SBCs generally receiving1 to 3 and GBCs receiving 4 to 6 excitatory inputs.

Bushy cells respond rapidly at the onset of a tone followed by a decline in rate to a steady state response. The phasic firing pattern of bushy cells is very similar to that of ANFs; hence the firing pattern was called primary-like (Rhode \& Smith 1986). In that way, bushy cells preserve the timing of the stimulus onset by integrating temporal information from multiple ANF (Liberman 1991; Sento \& Ryugo 1989; Spirou et al. 2005). Accordingly, they convey information about the fine structure of sounds (Joris et al. 1998; Kopp-Scheinpflug et al. 2002) which is important for the localization of sound sources (Joris \& Yin 2007) and pitch identification (Shofner 2008). Furthermore, bushy cells report the phase of a sound wave by firing an AP at a certain time during the cycle of a wave, a phenomenon called phase-locking. At low frequency phase-locking is an important cue for coding sound frequency (Joris et al. 1994).

In addition to their excitatory inputs from ANFs both bushy and T-stellate cells receive inhibitory inputs from narrowly tuned tuberculaventral (TBV) cells originating in the DCN (Wickesberg \& Oertel 1990) and broadly tuned D-stellate cells of the VCN. D 
stellate cells are the major source of inhibition in the VCN (Smith \& Rhode 1989; Campagnola \& Manis 2014). These local circuits within the $\mathrm{CN}$ are either glycinergic, GABAergic, or use both transmitters.(Kolston et al. 1992). Other sources of inhibitory inputs include the LNTB, VNBT, MNTB and the superior paraolivary nucleus (SPN) (Schofield 1991; Schofield 1994). Time course of inhibition to bushy cells is much slower than the excitation (Xie \& Manis 2013; Nerlich et al. 2014). Functionally, the glycinergic synapses provide a tonic inhibition that can increase the temporal precision of spikes in bushy cells (Kuenzel et al. 2011; Xie \& Manis 2013).

\subsection{The Endbulbs of Held}

Within the AVCN, auditory nerve fibers produce large axo-somatic terminals, the so called endbulbs of Held, on bushy cells (Held 1893). These giant synapses exhibit highly branched aborizations and a strong fenestration of synaptic specializations which can have complex shapes and extend over a considerable distance. Moreover the converging terminals appeared to be well separated from each other around the cell soma. Functionally, these arrangements support efficient neurotransmitter clearance (Nicol \& Walmsley 2002). Each endbulb has a high number, 400 to 1500 , of closely spaced release sites as calculated through serial section electron microscopy (Nicol \& Walmsley 2002). In addition, the pool of readily releasable vesicles (RRP) that can be released upon an action potential was estimated at $\sim 1050$ vesicles from capacitance measurements (Lin et al. 2011).

Immunohistochemical studies in the AVCN of mature animals demonstrated the presence of mainly a-amino-3-hydroxy-5-methyl-4-isoxazole propionic acid (AMPA) receptor at the postsynaptic site inferring that the endbulb of Held is a glutamatergic synapse. The AMPA receptor complexes are composed of the rapid desensitizing 'flop' isoforms GluR4 and GluR3 that contribute to fast the kinetics of excitatory postsynaptic potentials (EPSCs) in bushy cells (Petralia et al. 2000; Wang et al. 1998). In addition to AMPA receptors N-Methyl-D-aspartate (NMDA) receptors are expressed and contribute to synaptic transmission during development. In mature bushy cells only low levels of NMAR receptors remain but they promote firing probability and improve temporal precision (Pliss et al. 2009). 
The fast kinetics of EPSPs is also determined by the intrinsic properties of bushy cells. They express a low voltage-activated potassium conductance at the resting potential that assures fast repolarization and prevents repetitive firing. Furthermore, a hyperpolarization-activated conductance near rest leads to low input resistances and short membrane time constants (Cao et al. 2007; Cao \& Oertel 2010).

Thus, excitatory postsynaptic potentials (EPSPs) in bushy cells are brief and have rapid kinetics. As a consequence, action potentials occur reliably and with little temporal jitter, endbulb depolarization produces only one (or few) postsynaptic spike, and the refractory period is short. Hence, bushy cells exhibit the ability to 'follow' repeated stimulation up to $300 \mathrm{~Hz}$ which is near the maximum firing rate of auditory nerve fibers (Ryugo \& Spirou 2010).

\subsubsection{Short-term plasticity in endbulbs of Held}

Synapses adapt their strength to the preceding activity level and/or to postsynaptic alterations. This ability is referred to as synaptic plasticity. Short-term plasticity acts on a time scale of milliseconds to seconds and is thought to contribute to information processing. Synaptic strength can change in two directions, a decrease is called depression and increase is called facilitation.

During high frequency endbulbs are subjected to dynamic regulation of neurotransmitter release and receptor sensitivity. In the AVCN, ANF terminals on bushy cells show strong depression while on T-stellate cells depression is lower or facilitation occurs. Thus, bushy cells adapt faster to high frequency stimulation (Cao \& Oertel 2010; Chanda \& Xu-Friedman 2010). Wang et al. (2010) concluded that the endbulb synapses are chronically depressed by spontaneous activity, and are more resistant to further depression when challenged with a higher rate of activity. Thus, short-term synaptic depression at the endbulbs is activity dependent at high stimulation rates of 100 to $300 \mathrm{~Hz}$ (Oleskevich \& Walmsley 2002; Wang \& Manis 2008; Yang \& Xu-Friedman 2008). Mechanisms contributing to depression include depletion, postsynaptic receptor desensitization and saturation (Xu-friedman \& Regehr 2004). In the endbulb of Held the depression results from desensitization (Oleskevich, Clements, and Walmsley 2000; Yang and Xu-Friedman 2008) and vesicle depletion (Wang \& Manis 2008; Yang \& Xu-Friedman 2008). Release probability and the amount of depression vary between endbulbs that converge on 
different bushy cells (Oleskevich and Walmsley 2000; Yang and Xu-Friedman 2009). Interestingly, endbulbs which terminate on the same bushy cell have similar plasticity (Yang \& Xu-Friedman 2009; Yang \& Xu-Friedman 2012), suggesting that plasticity is closely regulated between converging endbulbs. In dynamic clamp experiments depression was particularly important in suppressing highly active inputs that may carry less precise temporal information this indicates an important role in preserving and enhancing temporal firing precision of bushy neurons (Yang \& Xu-Friedman 2009).

The role of activity in regulating synaptic transmission has been intensively studied by the effects of eliminating or reducing ANF activity i.e. deafness and hearing loss. Studies have been performed in congenitally deaf $(\mathrm{dn} / \mathrm{dn}$, deafness) mutant mice (Oleskevich \& Walmsley 2002) and DBA mice which develop with normal hearing thresholds, but begin to show elevated hearing thresholds by P30 (Wang \& Manis 2005; Wang \& Manis 2006). In both cases, auditory nerve fibers survive and can be electrically stimulated. Moreover, the intrinsic membrane properties of VCN neurons seem to be resistant to sensory deprivation (Lu et al. 2007; Wang \& Manis 2005; Wang \& Manis 2006; Cao et al. 2008). In deaf mice, synaptic transmission was found to be similar to control mice in many aspects, implying that many parameters of synaptic transmission develop normally in these animals. In $\mathrm{dn} / \mathrm{dn}$ mutants, only two significant differences were found. Deaf mice had higher release probability $(\operatorname{Pr})$ and stronger depression and showed delayed-release (asynchronous) after stimulation with a train of action potentials. Both changes could be reversed by the addition of EGTA-AM, suggesting that endogenous calcium buffering may be impaired (Oleskevich \& Walmsley 2002). Surprisingly, no changes in the synaptic transmission were found in the calyx of Held of deaf mice.

In contrast, in DBA mice which exhibit age-related hearing loss, Wang \& Manis (2005) showed that the spontaneous miniature EPSC frequency is greatly reduced and $\operatorname{Pr}$ is lower in endbulbs after the onset of hearing loss. However, synaptic depression at different stimulation rates $(100$ to $300 \mathrm{~Hz}$ ) is unchanged, indicating that other compensatory changes may be occurring in these hearing-impaired animals.

Yet, molecular mechanisms underlying the adaption to lacking activity are not known. Also it is still not clear whether activity in the auditory nerve contributes to regulate e.g. $\operatorname{Pr}$ and synaptic plasticity in endbulbs. Oleskevich et al. (2000) raised the possibility of a relationship between AN activity and $\operatorname{Pr}$ at endbulb terminals. They 
suggested that the varying $\operatorname{Pr}$ in endbulbs is due to morphological differences between endbulbs. Morphological adaptions to different levels of activity in ANFs have been revealed earlier. Endbulbs arising from highly active auditory nerve fibers exhibit larger endbulbs with more and smaller synaptic specializations than endbulbs from less active auditory nerve fibers. This indicates that, the synapse structure of endbulbs is subject to activity-related change (Ryugo et al. 1996). Moreover, in deaf cats that lack spontaneous and evoked activity the extent and complexity of endbulb branching were much less pronounced (Ryugo et al. 1997; Ryugo et al. 1998).

All in all, the auditory pathway offers a good system to investigate the mechanisms underlying activity-dependent changes in synaptic plasticity.

\subsection{Proteins of the active zone}

An incoming action potential evokes calcium influx in the presynaptic nerve terminal which triggers the fusion of synaptic vesicles (SV) with the presynaptic membrane and leads to neurotransmitter release into the synaptic cleft. At the postsynaptic site transmitters bind to specific receptors and cause ionic channels in the membrane to either open or close. When these channels open, depolarization occurs triggering further action potential generation. The SV exocytosis occurs exclusively at a small area of the presynaptic neuron, the active zone (AZ), which appears as an electrondense structure opposite the postsynaptic density. The active zone harbors a rich network of proteins that is referred to as the cytomatrix of the active zone (CAZ). Five protein families have been characterized that are enriched in the CAZ: Munc-13s, RIMs, ELKSs (ERC/CAST), liprins-as and piccolo and bassoon (Schoch \& Gundelfinger 2006). CAZ proteins serve diverse functions including: determining the structure of the AZ; docking and priming of SVs; recruitment of $\mathrm{Ca}^{2+}$ channels; and mediating short-term plasticity (Südhof 2012). Among these proteins RIM, Munc13, RIM-BP, liprin- $\alpha$, and ELKSs are evolutionary conserved proteins as well as the trans-SNARE plasma membrane proteins syntaxin, SNAP-25, synaptobrevin mediating the SV exocytosis and synaptotagmins acting as a calcium sensor. The latter proteins are not enriched at the AZ but are distributed all over the plasma membrane. In addition to these conserved proteins there are only a few presynaptic proteins that are specific for vertebrates including synuclein, a SV-associated protein, 
and the large scaffolding proteins bassoon and piccolo. Piccolo mainly seems to play a role in connecting the CAZ to the cytoskeleton forming a link between endo- and exocytosis of synaptic vesicles (Schoch \& Gundelfinger 2006). Bassoon shown to be important for vesicle replenishment (Frank et al. 2010; Hallermann et al. 2010; Mendoza Schulz et al. 2014) and SV clustering (Mukherjee et al. 2010). Interestingly, in cultured piccolo- and bassoon-deficient neurons no electrophysiological phenotype was detected although electron microscopy revealed a strong reduction in the number of SVs in the presynaptic terminals (Mukherjee et al. 2010). Furthermore, partial deletion of only bassoon in cultured hippocampal neurons led to reduction of normal synaptic transmission attributed to a silencing of a fraction of glutamatergic synapses but did not affect SV number (Altrock et al. 2003). Bassoon disruption in the endbulb of Held revealed increased quantal size and a reduced number of readily releasable vesicles accompanied by an increased release probability and stronger short-term depression but slower vesicle replenishment. As a result these opposing effects did not alter the reliability of synaptic transmission possibly due to homeostatic plasticity (Mendoza Schulz et al. 2014).

\subsection{Mover, a novel presynaptic protein that is associated with Bassoon}

The only known vertebrate-specific interaction partner of Bassoon is the novel presynaptic protein Mover. Mover was identified as a Bassoon binding partner in a yeast-two-hybrid assay using the C-terminus of Bassoon as bait. Mover is a $30 \mathrm{kDa}$ protein consisting of 266 amino acids that is named after its localization to mossy fiber terminals in the hippocampus and its exclusive expression in vertebrates (Kremer et al. 2007). Mover associates with SV membranes confirmed by subcellular fractionation with SVs where it was highly enriched in the purified SV fraction. Moreover, Mover was shown to be present on SV by mass spectrometry and by immunogold electron microscopy in these fractions. Flotation and carbonate stripping and the absence of a transmembrane domain indicated that Mover is a peripheral membrane protein (Kremer et al. 2007; Ahmed et al. 2013).

Mover has also been identified as SV associated protein (SVAP30) in an analysis of the synaptic vesicle proteome (Burré et al. 2006). The corresponding mouse gene 
was called TPRGL1 in a gene expression study where it was found in many tissues including the brain (Antonini et al. 2008). Mover is highly expressed in the hippocampal CA1, CA3 and dentate gyrus areas, the cerebellar purkinje cell layer, superficial layers of neocortex, and in restricted areas of the striatum, while lower levels are present in most brain areas (Allen Mouse Brain Atlas; http://www.brainmap.org). Protein levels of mover are highest in the brain. Furthermore, Mover is also expressed in testis while there is relatively weak expression in heart, spleen and liver. Immunofluorescence signal of the Mover protein was detected in the hippocampus, cerebellar cortex and auditory brainstem (Kremer et al. 2007). In detail, in the hippocampal CA3 region, Mover is present at glutamatergic mossy fiver terminals and absent from inhibitory synapses in the stratum pyramidale, whereas it is present at inhibitory synapses in all cell layers in the cerebellum. Moreover, Mover shows punctate staining that co-localizes with synaptophysin in the calyx of Held in the brainstem (Kremer et al. 2007).

Recently, an in vivo knock-down (75\%) of Mover using AAV-mediated shRNA expression in globular bushy cells of the VCN was generated to study the function of Mover in the calyx of Held (Körber 2011). The knock-down resulted in increased EPSC amplitudes as well as increased vesicular release probability and an enhanced and accelerated STD and recovery from depression during high frequency stimulation. Spontaneous synaptic transmission, the RRP and presynaptic calcium currents remained unaltered. However, the calcium sensitivity of SV fusion was increased in calcium uncaging experiments. Hence, the authors suggest that Mover acts as a negative regulator of $\operatorname{Pr}$ by decreasing the $\mathrm{Ca}^{2+}$ sensitivity of neurotransmitter release. This effect is mediated by a calcium-dependent interaction of Mover with calmodulin indicated by a pull-down of Mover and calmodulin in the presence of calcium (Körber 2011). In line with the proposed regulatory role of Mover, a recent Bassoon knock-out study revealed an increase in $\mathrm{Pr}$ in addition to a stronger and faster STD in the endbulb of Held synapse which was associated with a 20\% reduction in Mover expression (Mendoza Schulz et al. 2014). Furthermore, upon treatment with TTX for $48 \mathrm{~h}$ neuronal activity was blocked in cultured cortical neurons and a reduction of Mover was observed in a western blot (Kremer 2008) indicating that mover protein expression may be influenced by synaptic activity or inactivity. 
In summary, Mover is a peripheral membrane protein that is associated with SVs. It exists in a phosphorylated form and self-interacts. Throughout the brain, Mover is differentially expressed at presynapses, for example in the hippocampus, the cerebellum and the MNTB. Mover might be expressed in an activity-dependent way. In the calyx of Held, Mover likely regulates the release probability by decreasing the $\mathrm{Ca}^{2+}$ sensitivity of neurotransmitter release. Mover interacts with Bassoon and Calmodulin.

\subsection{Aim of study}

A recent study used a knock-down approach in the calyx of Held to investigate the role of Mover (Körber 2011). Still the picture of Mover's role is not complete. The present study aimed to further elucidate the function of Mover. Therefore, a Mover knock-out mouse line was generated to investigate changes in synaptic transmission at the endbulb-bushy cell-junction in Mover knock-out animals and test whether Mover has the same function in endbulbs of Held as suggested in the calyx of Held. Initially, the location and distribution of Mover in the ventral cochlear nucleus, in general, and in particular in the endbulbs of Held will be revealed here. Moreover, preliminary data from Kremer (2008) indicated an activity-dependent regulation of Mover upon blocking neuronal activity with TTX in cell cultures. This issue is addressed again by analyzing the Mover fluorescence intensities in endbulbs of Held in deaf mice. 


\section{Material and Methods}

\subsection{Animals}

All animals used in this study were housed on a $12 \mathrm{~h}$ light/dark cycle with food and water ad libitum.

All experiments performed in this study complied with national animal care guidelines and were approved by the Board for Animal Welfare the University of Göttingen and the Animal Welfare Office of the State of Lower Saxony.

For immunohistochemistry, wistar rats of the postnatal day (P) 21 and Otoferlin knock-out mice and wild-type littermates between P16 to P19 were used. Genotyping for Otoferlin mice was performed by polymerase chain reaction (PCR). For generation of Otoferlin knock-out (see Reisinger et al. 2011). Mover knock-out mice and their wild-type littermates were used for immunohistochemistry and electrophysiology between P15 to P19. The Animals were derived from heterozygous breeding. Genotyping was performed by PCR.

\subsection{Generation of Mover knock-out mouse}

A conditional targeting vector harboring Exons 1 to 3 of the Mover flanked by lox Psites and a frt flanked Neomycin selection cassette between Exon 3 and 4 was generated by PolyGene AG (Schweiz). This targeting vector was electroporated into 1290la ES-cells. The extracted DNA from ES cell clones, which contained the conditional targeting vector of Mover, was injected into blastocysts of C57BL/6J mice to generate chimeric mice. Heterozygous offspring from one chimera (50\%) was bred with C57BL/6J mice and subsequently bred with a flp-recombinase expressing mouse line to excise the neomycin cassette. The progeny has a Mover gene that is flanked by loxP sites; hence mice were named 'flox mice'. These 'floxed' mice were bred with a mouse line that has a cre-recombinase under the E2a promotor to allow a global knock-out of Mover in the early mouse embryo and in nearly all tissue (Lakso et al., 1996). Finally, the heterozygote offspring were inbred to generate Mover knock-out mice. See figure 2.1. for a summary and scheme of derived alleles. 
Genotyping. Global Mover knock-out mice were verified by genotyping using a multiplex PCR (see table 2.2). Additionally, the presence of a cre-recombinase was verified using a cre PCR (see table 2.1)

Table 2.1 Cre PCR - protocol

\begin{tabular}{|c|c|c|c|c|c|}
\hline \multicolumn{3}{|c|}{ To identify the presence of Cre } & \multicolumn{3}{|c|}{ PCR conditions } \\
\hline DMSO & $\overline{1 \mu l}$ & & $95^{\circ} \mathrm{C}$ & $03: 00$ & \\
\hline DNA & $\frac{1 \mu l}{1 \mu l}$ & & $95^{\circ} \mathrm{C}$ & $00: 30$ & \multirow{3}{*}{$35 x$} \\
\hline 24365 & $1 \mu \mathrm{l}$ & $5 \mathrm{pmol} / \mu \mathrm{l}$ & $61^{\circ} \mathrm{C}$ & $00: 30$ & \\
\hline 24366 & $1 \mu \mathrm{l}$ & $5 \mathrm{pmol} / \mu \mathrm{l}$ & $72^{\circ} \mathrm{C}$ & $00: 30$ & \\
\hline $\mathrm{H} 2 \mathrm{O}$ & $8.5 \mu \mathrm{l}$ & & $72^{\circ} \mathrm{C}$ & 07:00 & \\
\hline $2 X \mathrm{MM}$ & $12.5 \mu \mathrm{l}$ & & $4^{\circ} \mathrm{C}$ & pause & \\
\hline \multicolumn{6}{|c|}{24365 GCG GTC TGG CAG TAA AAA CTA TC } \\
\hline \multirow{2}{*}{\multicolumn{6}{|c|}{ 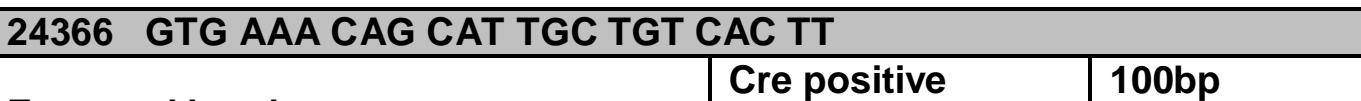 }} \\
\hline & & & & & 100bp \\
\hline \multicolumn{3}{|c|}{ Expected bands } & Cre negative & \multicolumn{2}{|l|}{ no band } \\
\hline
\end{tabular}

Table 2.2 Multiplex PCR - protocol

\begin{tabular}{|c|c|c|c|c|c|}
\hline \multicolumn{3}{|c|}{ To identify the knock-out allele } & \multicolumn{3}{|c|}{ PCR conditions } \\
\hline DMSO & $\overline{1 \mu l}$ & & $98^{\circ} \mathrm{C}$ & $03: 00$ & \\
\hline DNA & $1 \mu \mathrm{l}$ & & $98^{\circ} \mathrm{C}$ & $00: 30$ & \multirow[t]{3}{*}{$35 x$} \\
\hline B008-P4 & $1 \mu \mathrm{l}$ & $\mid 5 \mathrm{pmol} / \mu \mathrm{l}$ & $55^{\circ} \mathrm{C}$ & $00: 30$ & \\
\hline E-4001 & $1 \mu \mathrm{l}$ & $5 \mathrm{pmol} / \mu \mathrm{l}$ & $72^{\circ} \mathrm{C}$ & $00: 30$ & \\
\hline E-3001 & $1 \mu \mathrm{l}$ & & $72^{\circ} \mathrm{C}$ & $10: 00$ & \\
\hline $\mathrm{H} 2 \mathrm{O}$ & $7.5 \mu \mathrm{l}$ & & $10^{\circ} \mathrm{C}$ & pause & \\
\hline $2 X \mathrm{MM}$ & $12.5 \mu \mathrm{l}$ & & & & \\
\hline \multicolumn{6}{|c|}{ B008-P4 CCAATCACAAGGCGAACGAG } \\
\hline \multicolumn{6}{|c|}{ E-3001 CATTCAGTGGGACAAGCAGA } \\
\hline E-4001 & \multicolumn{5}{|c|}{ CAAGGCTCTCCTGATCCAAG } \\
\hline \multirow{4}{*}{\multicolumn{3}{|c|}{ Expected bands }} & Wild-type & \multicolumn{2}{|l|}{$867 \mathrm{bp}$} \\
\hline & & & Knock-out & \multicolumn{2}{|l|}{$697 \mathrm{bp}$} \\
\hline & & & flox & \multicolumn{2}{|l|}{$1106 \mathrm{bp}$} \\
\hline & & & heterozygous & \multicolumn{2}{|c|}{$867 \mathrm{bp} \& 697 \mathrm{bp}$} \\
\hline
\end{tabular}




Exon 1 Exon 2 Exon 3 wild-type allele

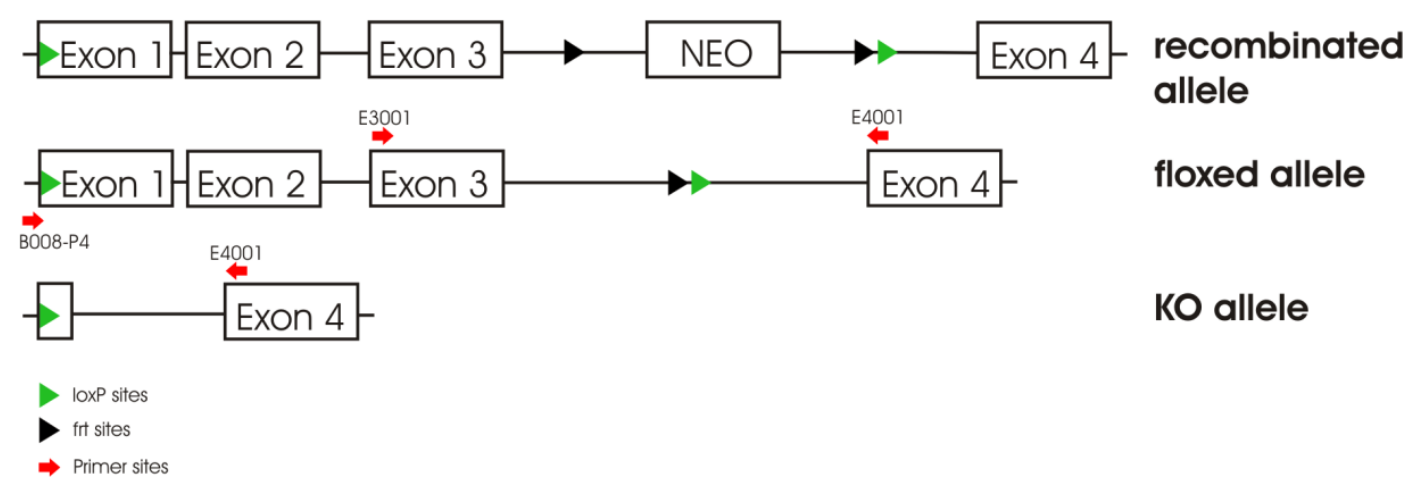

Figure 2.1 Scheme illustrating Mover knock-out generation.

The Mover wild-type allele consists of 4 exons. LoxP-sites and a Neo cassette flanked with frt-sites were inserted. The neo cassette was removed with a flp-recombinase resulting in the floxed allele. Exon 1 to 3 were excised by a cre-recombinase resulting in a knock-out (KO) allele.

\subsection{Immunohistochemistry}

Fluorescence stainings. The animals were transcardially perfused with $0.9 \%$ sodium chloride and fixed with $2 \%$ paraformaldehyde (PFA). After decapitation and removal of the brain the tissue was postfixated in $2 \%$ PFA over night at $4^{\circ} \mathrm{C}$. The brain was embedded in $3 \%$ agarose and sections of $50-30 \mu \mathrm{m}$ thickness were cut on a vibrating microtome (Thermo Scientific Microm HM $650 \mathrm{~V}$ ) and collected in a 24-well plate in phosphate buffer (PB). For immuhistochemical stainings free-floating slices were blocked in a solution containing $5 \%$ of normal goat serum (NGS) and $1 \%$ of Triton X100 (in PB) for 90 minutes at room temperature. Primary and secondary antibodies (see table) were diluted in a solution consisting of $1 \%$ NGS and $0.2 \%$ Triton X-100 (in PB) and were applied over night at $4{ }^{\circ} \mathrm{C}$. A washing step of $3 \times 10$ minutes with a $2 \%$ NGS (in PB) solution followed. Secondary antibodies incubated for 90 minutes at room temperature in the dark followed by washing with 1\% NGS (in PB) for $3 \times 10$ minutes. Eventually sections were stained for DAPI, 2 minutes at RT. Finally, the slices were mounted on Superfrost $\circledast$ Plus (Thermo Scientific) slides with Mowiol and DABCO (both Carl Roth GmbH\&Co. KG, Germany) and covered with a glass cover slip.

3,3'-Diaminobenzidine (DAB) stainings. The Universal Immuno-enzyme Polymer (UIP) method was applied using a Polymer Detection System from Nichirei 
Biosciences Inc., Japan. In order to block and inactivate endogenous peroxidases the sections were treated with Triton- $\mathrm{X} 100$ and $\mathrm{H}_{2} \mathrm{O}_{2}$. Antibodies were diluted in a ... solution and incubated over night at $4^{\circ} \mathrm{C}$. The polymer solution (N-Histofine ${ }^{\circledR}$ Simple Stain Max PO) which corresponds to the secondary antibody was applied in a third step. The solution must be against animal species in which the primary antibody has been raised (mouse or rabbit were used here). The sections incubated for 30 minutes in the polymer solution and were rinsed $3 x$ in PB for 5 minutes afterwards. The DABsolution was prepared of $2 \mathrm{ml}$ DAB in $84 \mathrm{ml} 0.1 \mathrm{M}$ Tris and $20 \mu \mathrm{l} \mathrm{H}_{2} \mathrm{O}_{2}$ were added just before the DAB-reaction. The reaction was stopped by washing the sections with distilled water. The sections were mounted on Superfrost@Plus (Thermo Fischer Scientific, Germany) slides with Mowiol covered with a glass cover slip.

The following tables summarize the antibodies used for immunohistochemistry:

Table 2.3 Primary antibodies

\begin{tabular}{|c|c|c|c|}
\hline antibody & host & dilution & company \\
\hline Mover 9a* & rabbit & $1: 1000$ & Synaptic Systems, Germanny \\
\hline Mover $9 c^{\star \star}$ & rabbit & $1: 1000$ & Synaptic Systems, Germanny \\
\hline Mover $1 c^{\star \star *}$ & rabbit & $1: 1000$ & Synaptic Systems, Germanny \\
\hline Mover (commercial) ${ }^{\star \star \star \star}$ & guinea pig & $1: 250$ & Synaptic Systems, Germanny \\
\hline gp Mover pool $1^{+}$ & guinea pig & $1: 250$ & Synaptic Systems, Germanny \\
\hline gp Mover pool $2^{++}$ & guinea pig & $1: 250$ & Synaptic Systems, Germanny \\
\hline VGLUT1 & guinea pig & $1: 1000$ & Synaptic Systems, Germanny \\
\hline VGLUT1 & mouse & $1: 250-1: 500$ & Abcam, United Kingdom \\
\hline VGAT & guinea pig & $1: 1000$ & Synaptic Systems, Germanny \\
\hline VGAT & mouse & $1: 600$ & Synaptic Systems, Germanny \\
\hline Synapsin 1,2 & mouse & $1: 500$ & Synaptic Systems, Germanny \\
\hline Bassoon & mouse & $1: 1000-1: 2000$ & Enzo Life Science, Germany \\
\hline GlyT2 & guinea pig & $1: 1000$ & Synaptic Systems, Germanny \\
\hline GAD 65 & mouse & $1: 500$ & Synaptic Systems, Germanny \\
\hline VGLUT2 & guinea pig & $1: 1000$ & Synaptic Systems, Germanny \\
\hline GFAP & mouse & $1: 1000$ & Synaptic Systems, Germanny \\
\hline
\end{tabular}

* Anti-Mover9a: raised against GST-Mover, purified using GST-Mover95-266

** Anti-Mover9c: raised against His-Mover, purified using GST-Mover95-266 
*** Anti-Mover1c: raised against GST-Mover, purified using His-Mover

**** Anti-Mover commercial: raised against His-Mover, purified using His-Mover

+ Anti-Mover pool 1: raised against GST-Mover, purified using His-Mover

${ }^{++} \quad$ Anti-Mover pool 2: raised against GST-Mover, purified using His-Mover

Table 2.4 Seondary antibodies

\begin{tabular}{llll}
\hline antibody & host & dilution & company \\
\hline Alexa 488 & Donkey anti-mouse & $1: 2000-1: 4000$ & $\begin{array}{l}\text { Invitrogen; Life technologies, } \\
\text { Germany }\end{array}$ \\
Alexa 488 & Goat anti-guinea pig & $1: 2000$ & $\begin{array}{l}\text { Invitrogen; Life technologies, } \\
\text { Germany }\end{array}$ \\
Alexa 568 & Goat anti-guinea pig & $1: 1000$ & $\begin{array}{l}\text { Invitrogen; Life technologies, } \\
\text { Germany }\end{array}$ \\
Alexa 647 & Goat anti-rabbit & $1: 1000$ & $\begin{array}{l}\text { Invitrogen; Life technologies, } \\
\text { Germany }\end{array}$ \\
Cy3 & Donkey anti-mouse & $1: 4000$ & $\begin{array}{l}\text { Dianova, Germany } \\
\text { Cy3 }\end{array}$ \\
\hline
\end{tabular}

\section{Preparation of Mowiol}

Mix 2.4g Mowiol and $6 \mathrm{~g}$ Glycerol by vortexing. Add $6 \mathrm{ml}$ of $\mathrm{H}_{2} \mathrm{O}$ and mixed again. Incubate for $2 \mathrm{hr}$ at RT. Add $12 \mathrm{ml}$ of $0.2 \mathrm{M}$ Tris $\mathrm{pH} 8.5$ and heat at $50^{\circ} \mathrm{C}$ for $10 \mathrm{~min}$. Centrifuge at $5000 \mathrm{~g}$ for $15 \mathrm{~min}$. A final concentration of $2.5 \%$ DABCO was added. Aliquote and store at $-20^{\circ} \mathrm{C}$.

\section{Preparation of Phosphate buffer $0.1 \mathrm{M}$}

Weigh $35.61 \mathrm{~g} \mathrm{Na2HPO} 4 \times 2 \mathrm{H} 2 \mathrm{O}$ and dilute in 1 liter aqua bi-dest (solution X). Weigh $27.6 \mathrm{~g}$ $\mathrm{Na} 2 \mathrm{HPO} 4 \times 2 \mathrm{H} 2 \mathrm{O}$ and dilute in 1 liter aqua bi-dest (solution $\mathrm{Y}$ ). Mix $385 \mathrm{ml}$ of solution $\mathrm{X}$ and $115 \mathrm{ml}$ of solution $\mathrm{Y}$ and add $500 \mathrm{ml}$ aqua bi-dest.

Confocal microscopy. Confocal images were acquired using a laser-scanning confocal microscope (Leica TCS SP5, Leica Microsystems CMS, Germany) equipped with $488 \mathrm{~nm}(\mathrm{Ar})$ and 561/633 $\mathrm{nm}(\mathrm{He}-\mathrm{Ne}$ ) lasers for excitation of the respective Alexa fluorophores and a $63 x$ / 1.4 NA oil- immersion objective. All images were 
acquired with identical settings. For all experiments, the pinhole was set to 1 airy unit (AU) and the scan speed to $400 \mathrm{~Hz}$.

Single section images for analysis were acquired with a zoom between $1 \mathrm{x}$ and $10 \mathrm{x}$ resulting in pixel sizes between $126 \mathrm{~nm}$ and $24.6 \mathrm{~nm}$. The zoom factor was kept constant for the respective set of images. Images comprised 1024*1024 pixels and were obtained from 4 frame averages.

Overview images of the brainstem were acquired with a 40x, zoom factor $1 \mathrm{x}$ and $2 \mathrm{x}$, $1024^{*} 1024$ image size and 4 frame averages.

Bright-field microscopy. DAB Images were acquired with a AxioCam MRc5 from Zeiss on an inverted microscope (Observer Z.1, Zeiss, Germany) with 10x, 20x, and $63 x$ objectives.

Data analysis. Confocal images were analyzed with ImageJ (FIJI version) using the following procedure: The scale was set. Background noise was subtracted automatically $(100 \mathrm{px})$ from raw images with the background subtraction macro based on the "rolling ball" algorithm (described in Stanley Sternberg's article, "Biomedical Image Processing", IEEE Computer, 1983). A threshold was applied to the image of the 'control protein' (e.g. VGLUT1 representing endbulbs of Held or VGAT representing inhibitory synapses) and a mask was created from the suprathreshold pixels. Region of interests (ROls) were defined with the Analyze Particles option in the Analyze menu. Areas of $60 \mathrm{~nm}$ (represent background puncta in Mover stainings ) were excluded from the analysis. The ROls were used as a mask which was applied to the respective fluorescence double or triple staining. With the Measure option parameters such as area, mean intensity, standard deviation and maximum intensity were measured.

Pearson's correlation coefficient as a measure for colocalization was analyzed with the JACOP plugin (Bolte \& Cordelières 2006).

Figures were assembled for display in the CorelCRAW Graphics Suite 11 (Corel Corporation).

Intensity values were normalized to the mean VGLUT1 intensity levels (of wild-type animals). 
All statistical tests were performed on GraphPad Prism 5 software. Means are presented with their standard errors (SEM), statistically significant differences between groups were determined by using unpaired, two-tailed t-tests or ANOVA for mort ah 2 groups (if data was distributed normally).

\subsection{Electrophysiology}

Preparation of slices and solutions. Parasagittal slices of the cochlear nucleus, $180 \mu \mathrm{m}$ thick, were cut from the brain stem with a vibrating microtome (Thermo Scientific Microm HM 650 V) in an ice-cold high-sucrose extracellular saline solution that contained (in mM) $99 \mathrm{NaCl}, 3 \mathrm{KCl}, 1.2 \mathrm{KH} 2 \mathrm{PO} 4,1 \mathrm{CaCl} 2 \times 2 \mathrm{H} 20,1.3$ MgSO4x7H2O, 20 NaHCO3 , 3 HEPES, 10 glucose, and 72 sucrose, pH 7.3-7.4.. Afterwards slices incubated for 30 minutes in a normal physiological saline at $33^{\circ} \mathrm{C}$ and recovered for another 30 minutes at room temperature. The physiological extracellular saline comprised (in $\mathrm{mM}$ ) $130 \mathrm{NaCl}, 3 \mathrm{KCl}, 1.2 \mathrm{KH} 2 \mathrm{PO} 4,2.4 \mathrm{CaCl} 2$, $1.3 \mathrm{MgSO} 4,20 \mathrm{NaHCO} 3$, 6 HEPES, 10 glucose, and 0.4 ascorbic acid, pH 7.3. The osmolality was between 305 and $310 \mathrm{mOsm} / \mathrm{kg}$ (OM 801 Osmometer, Vogel). Slices were transferred to a heated recording chamber ( $\mathrm{PH}-1$, Warner Instruments) and were superfused with the pre-warmed physiological extracellular saline (through a heated Perfusion Tube HPT-2 from Alascience). All salines were saturated with 95\% O2-5\% CO2. The internal pipette solution for voltage- and current-clamp recordings contained (in mM) 108 potassium gluconate, 9 HEPES, 9 EGTA, $4.5 \mathrm{MgCl} 2 \times 6 \mathrm{H} 2 \mathrm{O}$, 14 phosphocreatinine (Tris salt), 4 ATP ( $\mathrm{Na}$ salt), and 0.3 GTP (Tris salt), final osmolarity was between 297 and 303 mosM. The $\mathrm{pH}$ was adjusted to 7.4 with $\mathrm{KOH}$. The final holding potentials were corrected for a $-12 \mathrm{mV}$ junction potential. All measurements of EPSCs were made in the presence of $1 \mu \mathrm{M}$ strychnine to block inhibition (Cao et al., 2010). Miniature EPSCs (mEPSCs) were measured in the absence of TTX since no difference in the mEPSCs was noted when compared with and without TTX (Isaacson \& Walmsley 1996). After mEPSC recordings the cell type was identified and confirmed by evoking synaptic transmission.

The temperature was measured and controlled with a Temperature controller (T-20$\mathrm{W} 1, \mathrm{npi})$ to remain at 32 or $33^{\circ} \mathrm{C}$.

Electrophysiological recordings. Whole cell patch-clamp recordings were made with a EPC 10 amplifier (HEKA) under the control of PatchMaster software. The tissue was 
visualized through a Olympus BX51WI microscope with a 40x water immersion objective and CCD Camera (Hamamatsu) with the image displayed on a screen. Patch electrodes were made from borosilicate glass (GB150F-8P, Science Products) and had resistances between 3 and $8 \mathrm{M} \Omega$. Recordings of evoked excitatory postsynaptic currents (eEPSCs) were made at $-70 \mathrm{mV}$ and sampled at $50 \mathrm{~Hz}$, low pass filtered at $10.000 \mathrm{kHz}$ and further filtered by a $2.9 \mathrm{kHz}$ Bessel filter. Compensation for the capacitance and series resistance of electrodes was done with the automatic features of the amplifier. The series resistance was compensated 50$80 \%$ with a $100 \mu$ s lag. EPSCs were evoked by current stimulation through a Linear Stimulus Isolator (A395, WPI) and delivered through an extracellular saline- filled glass pipette (2 M $\Omega$ tip). The stimulating pipette was placed in the vicinity of the recorded bushy cell.

Table 2.5 Chemicals for electrophysiology

\begin{tabular}{ll}
\hline Chemical & company \\
\hline $\mathrm{NaCl}$ & BioFroxx, AppliChem \\
$\mathrm{KCl}$ & Sigma-Aldrich \\
$\mathrm{KH} 2 \mathrm{PO} 4$ & ChemCruz \\
$\mathrm{CaCl} 2$ x 2H20 & Sigma-Aldrich \\
$\mathrm{MgSO} 4$ x 7H2O & Roth \\
NaHCO3 & AppliChem \\
HEPES & Sigma-Aldrich \\
glucose & BioFroxx, AppliChem \\
sucrose & BioFroxx, AppliChem \\
\hline ascorbic acid & Merck \\
\hline potassium gluconate & Sigma-Aldrich \\
\hline EGTA & AppliChem \\
\hline MgCl2 6 6H2O & AppliChem \\
Phosphocreatinine (Tris salt) & Sigma-Aldrich \\
ATP (Na salt) & Sigma-Aldrich \\
GTP (Tris salt) & Sigma-Aldrich \\
\hline strychnine & Sigma-Aldrich \\
\hline
\end{tabular}


Data analysis. Analysis of miniature EPSCs was performed with the MiniAnalysis program from Synaptosoft Inc. Evoked EPSCs were analyzed with a custom written Igor procedure (Igor Pro v6.32). All statistical tests were performed on GraphPad Prism 5 software and are given as means \pm SEM. 


\section{Results}

\subsection{Testing available antibodies against Mover}

Polyclonal antibodies generated against purified Mover protein fused to polyhistidin (His-Mover) or glutathione-S-transferase (GST-Mover) respectively and additionally affinity purified using various antigen columns were available in the laboratory.

Overview of available antibodies against Mover:

- Rabbit Anti-Mover9a: raised against GST-Mover, purified using GST-Mover95-266

- Rabbit Anti-Mover9c: raised against His-Mover, purified using GST-Mover95-266

- Rabbit Anti-Mover1c: raised against GST-Mover, purified using His-Mover

- Rabbit Anti-Mover commercial: raised against His-Mover, purified using His-Mover

- Guinea pig Anti-Mover pool 1: raised against GST-Mover, purified using His-Mover

- Guinea pig Anti-Mover pool 2: raised against GST-Mover, purified using His-Mover

In order to identify the antibody with the best fluorescence signal in the endbulbs of Held immunohistochemical stainings of coronal brainstem sections of the anterior the ventral cochlear nucleus (AVCN) were employed and are summarized in figure 3.1.

As a co-label an anti-VGLUT1 antibody was used as a maker for glutamatergic synapses (in the anteroventral cochlear nucleus, particularly for endbulbs of Held). The glutamate transporter 1 (VGLUT1) is associated with the SV membrane and responsible for the uptake of glutamate into SV in excitatory neurons. Figure 3.1 gives an overview of example confocal single sections for each tested rabbitantibody. Merged images with the co-labeled marker and grey scale images for the respective labeled protein are displayed. Surprisingly, Mover9a IF signals do not appear as small or large puncta as assumed for a synaptic vesicle marker (compare with VGAT or VGLUT1 IF signals, Fig. 3.1, A, B right) but rather appears as elongated red stripes indicating that an antigen is recognized in nerve fibers (Fig. 3.1, A). Moreover, IF signals for Mover9a do not co-localize with signals from the vesicular GABA transporter (VGAT), which is expressed in both GABAergic and glycinergic inhibitory neurons in the AVCN (Chaudhry et al. 1998) and used as a marker for inhibitory synapses. IF signals from anti-Mover1c antibodies are very dim (Fig. 3.1, B) in VGLUT1-positve synapses. Instead, bright IF signals are seen in VGLUT1-negative synapses, probably inhibitory, next to endbulbs and around small round cells which were not determined further. 

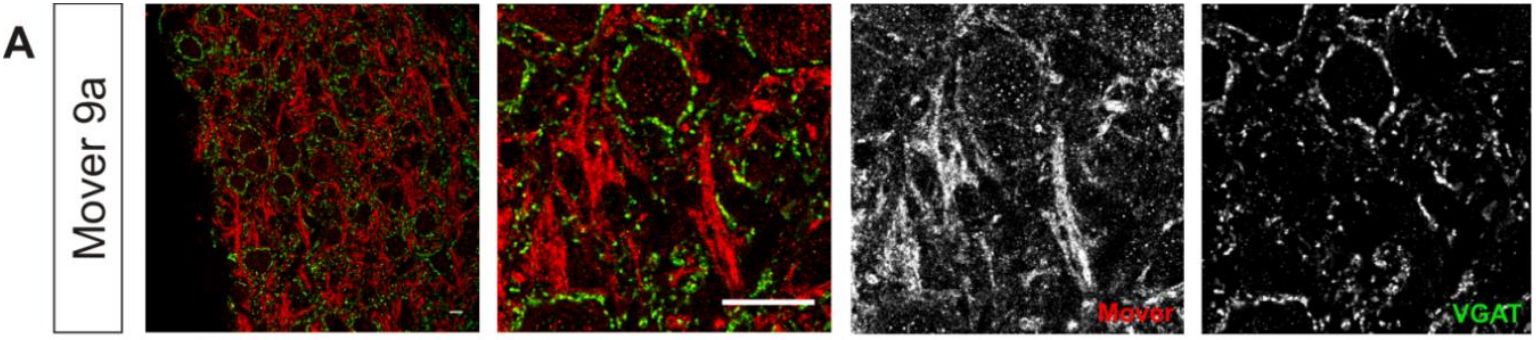

B
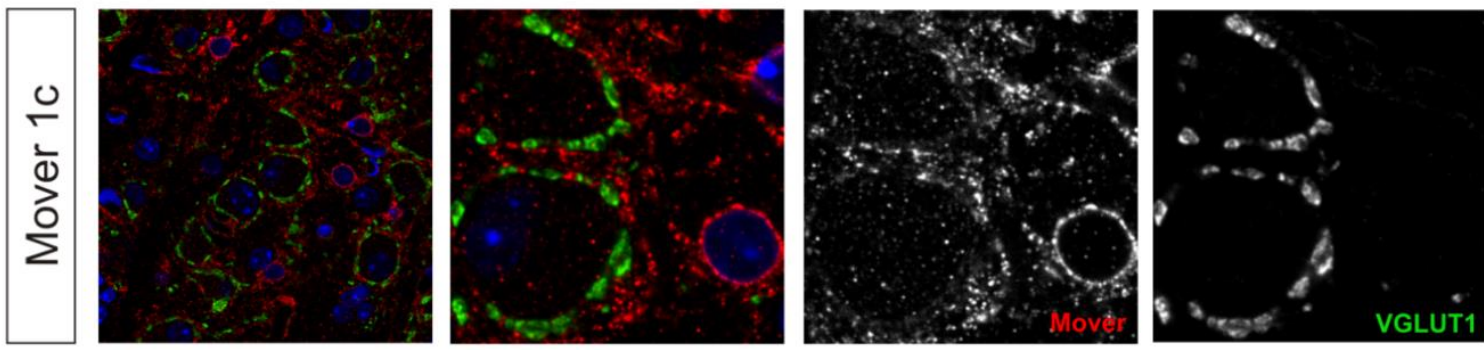

C
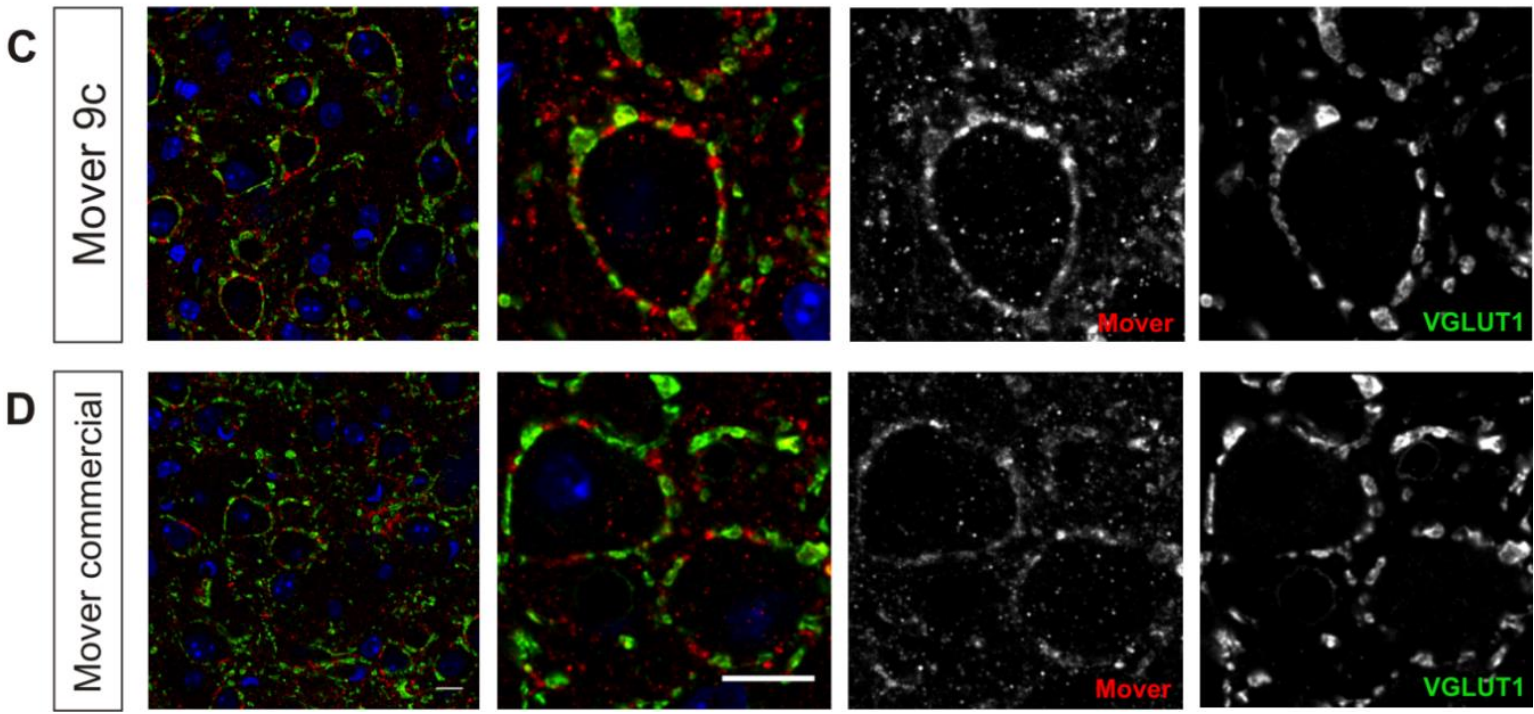

Figure 3.1 Mover antibody stainings in the anteroventral cochlear nucleus. Immunohistochemical stainings with several polyclonal antibodies against Mover and VGAT or-VGLUT1 as marker for and inhibitory synapses or glutamatergic synapses (endbulb), respectively, in brain slices of the anteroventral cochlear nucleus (AVCN). A-D. Single confocal sections labeled for Mover, VGAT or VGLUT and DAPI (blue) counterstaining. A. The anti-Mover9a antibody does not label inhibitory synapses but labels structures that are likely nerve fibers. B. Immunofluorescence signals from Mover1c are very weak in endbulbs (labeled with VGLUT1) and brighter in VGLUT1-negative synapses, probably inhibitory synapses. C and D. Mover9c and commercial Mover labels co-localize with VGLUT1 in the endbulbs but also label VGLUT1-negative synapses, probably inhibitory synapses. All scale bars: $10 \mu \mathrm{m}$.

Next, I immunostained AVCN sections using the two antisera raised against HisMover. Single confocal images from brainstem slices immunostained with the antiMover9c or commercial anti-Mover antibody and a VGLUT1 antibody reveal co- 
localization of Mover and VGLUT1 labels indicated by the yellow color in the merged image. The Mover IF signal at VGLUT1-positive sites is light and spread over the whole endbulb terminal. However, Mover immunoreactivity is more pronounced at VGLUT1-negative sites (probably inhibitory synapses) around a bushy cell. This is reminiscent of the staining pattern observed with anti-Mover1c. Nuclei of these cells are indicated with DAPI stainings. Both antibodies raised against His-Mover gave stronger fluorescence compared to anti-Mover1c, which was raised against GSTMover. The IF signals from the commercial anti-His-Mover antibody showed slightly higher co-localization with VGLUT1 IF signals. For that reason I chose the commercial anti-Mover antibody for all further experiments. In the following, the commercial anti-Mover antibody is referred to as anti-Mover. It is commercially available from Synaptic Systems, Germany.

\subsection{Mover immunolabeling in the auditory brainstem and ventral cochlear nucleus}

The distribution of Mover in the all auditory brainstem nuclei, single confocal sections comprising brainstem nuclei including the anteroventral cochlear nucleus (AVCN) is illustrated in figure 3.2, A-C. Mover IF signals appear homogeneously distributed in the brainstem and can be detected in the AVCN and several other nuclei including the medial superior olive (MSO), medial, lateral and ventral nucleus of the trapezoid body (MNTB,LNTB and VNTB), superior olivary nucleus (SPN) (Fig.3.2, C) and lateral superior olive LSO (Fig.3.2, A). Demarcations of the nuclei were made with the help of the VGLUT1 and VGAT co-labels (not shown). The nuclei in figure $3.2 \mathrm{~A}$ and $\mathrm{C}$ are projection areas of bushy cell terminals arising in the AVCN. There, the Mover immunolabels appear in a ring-like shape likely around the principal cells which are bushy and few stellate cells (Fig.3.2, B). In AVCN slices co-labeled with a Mover and a VGLUT1 or VGAT antibody, Mover labels co-localizes with VGLUT1 labels (Fig. 3.2, D) as well as with VGAT labels (Fig., 3.2, E) all over the nucleus. This is a first indication that Mover is present in excitatory and inhibitory synapses.in the AVCN and, in addition, is present in nerve terminals that project from the AVCN to nuclei in the ascending auditory pathway. 

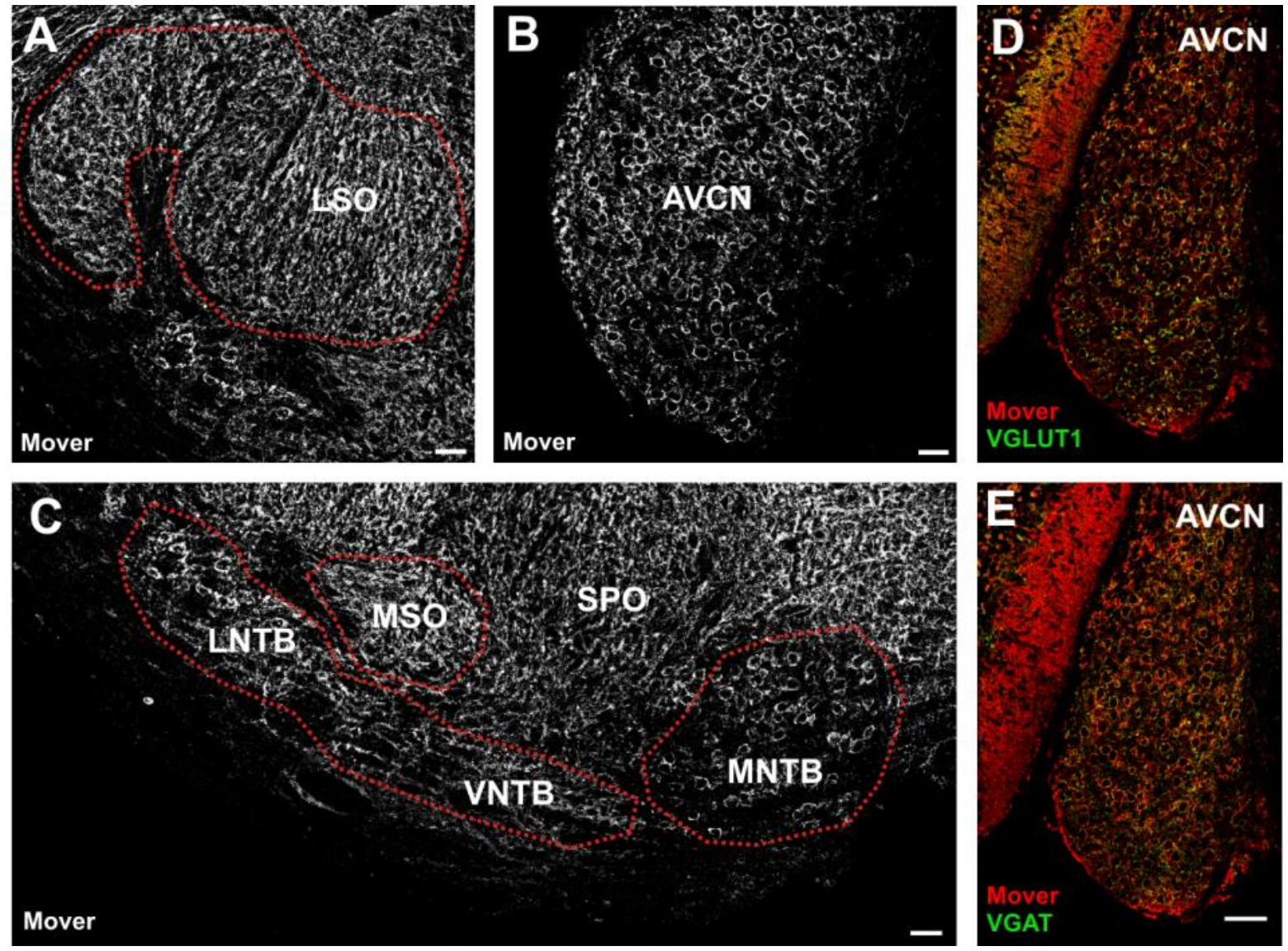

Figure 3.2 Mover is present in auditory brainstem nuclei.

A-C. Confocal single sections of a rat brainstem slice immunolabeled for Mover. Mover fluorescence signals can be detected in the anteroventral cochlear nucleus (AVCN) (B) and in several nuclei that are innervated from bushy in the AVCN. Nuclei include lateral superior olive (LSO) (A), medial nucleus of the trapezoid body (MNTB), medial superior olive (MSO), LNTB and VNTB (lateral and ventral nucleus of the trapezoid body) and superior olivary nucleus (SPN) (C). D-E. Confocal single sections of AVCN slices co-labeled for Mover and VGLUT1 (D) or VGAT (E). Mover immunosignals appear as ring like structures that colocalize with immunosignals from the marker protein. All scale bars: $100 \mu \mathrm{m}$.

Mover is a peripheral synaptic vesicle (SV) protein that is associated with the SV membrane similar to the SV protein Synapsin (Ahmed et al. 2013). VGLUT1 and VGAT are proteins in the SV membrane in either glutamatergic or inhibitory nerve terminals. All four proteins can be used as SV marker. 3,3'-Diaminobenzidine (DAB) stainings with an antibody against Mover, Synapsin, VGLUT1 and VGAT were performed for comparison of the staining patterns (Fig.3.3. B-E). The small punctate pattern of brown Mover label resembles those of Synapsin and VGAT. These SV proteins mostly localize around a cell body (indicated with asterics) of a bushy cell. In contrast, the VGLUT1 DAB signal is more clustered in probably endbulb terminals. Additionally, co-localization of Mover and Synapsin IF labels was analyzed from 
confocal images of rat brainstem slices of co-labeled for Mover and Synapsin (images not shown). Fluorescence signals from both proteins overlap to $62 \%$. The co-localization coefficient is $0.6248 \pm 0.03 \quad(n=20)$ (Fig.3.3, A). For Pearson's coefficients of VGLUT1 and VGAT see Fig.3.6, D. These results support the notion that Mover is localized to synaptic vesicles in synapses in the AVCN.

A

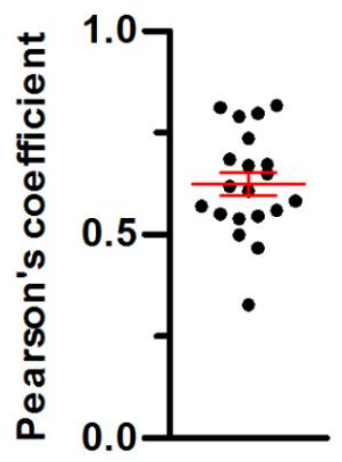

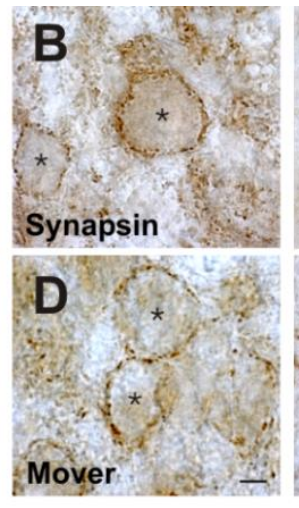

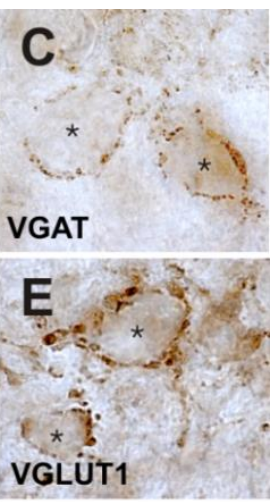

Figure 3.3 Mover is a synaptic vesicle protein.

Staining pattern of the Mover antibody resembles those of synaptic vesicle markers. A. Immunolabels for Mover and Synapsin co-localize to 62.5\%. B-D. In addition, the staining pattern of Synapsin (B) and VGAT (D) is similar to the Mover patterns (C). E. VGLUT1 signal appears clustered in synaptic structures, probably endbulb terminals. Scale bar: $10 \mu \mathrm{m}$.

Figure 3.3 and 3.4 display confocal images of immunostainings with the antibody against Mover and against several antibodies that label excitatory and inhibitory synapses. An overview image is displayed on the left side. Next to it is an example cell from the overview area shown as merge and single color images. The Mover IF signals appear in small or larger bright puncta and as broad clusters of weaker signal. Immunosignals from VGLUT1 appear as large synaptic structures of diverse shapes (Fig 3.4, D) and immunosignals from Mover appear as either large bright puncta or weaker signal clusters where they overlap with VGLUT1 signals (Fig. 3.3, C). As indicated by the yellow color in merged images, Mover and VGLUT1 immunolabels overlap strongly around bushy cells (Fig. 3.4, A). In addition, the Mover label co-localizes with VGLUT2 labels (Fig. 3.4, B). Some labels are more and some less co-localized depending on how strong the Mover immunosignal is. Thus, it Mover is present in the endbulbs of Held. Because co-localization of Mover labels and VGLUT1 labels appeared more homogenous and stronger only VGLUT1 was used for the following experiments. The glial fibrillary acidic protein (GFAP) is expressed in astrocytes and served as glial cell marker. IF signals from stainings with 
an antibody against GFAP show a divergent pattern and no co-localization with Mover signals is seen (Fig. 3.4, C). Therefore, it can be concluded that Mover is located to Mover is not present in glia cells in the AVCN.

A

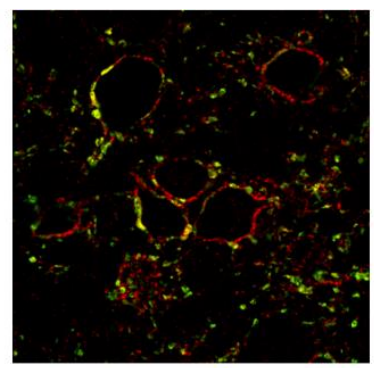

B

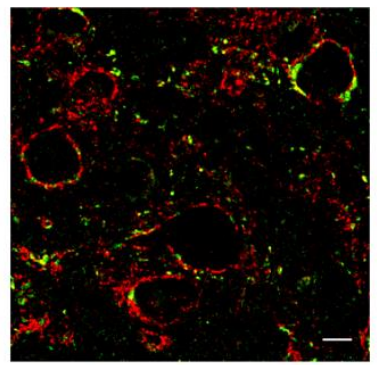

C

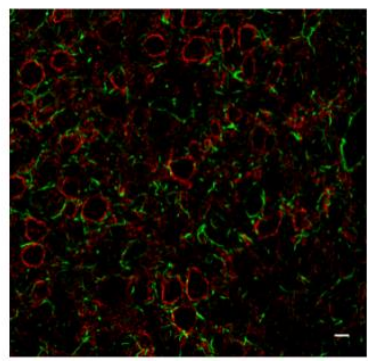

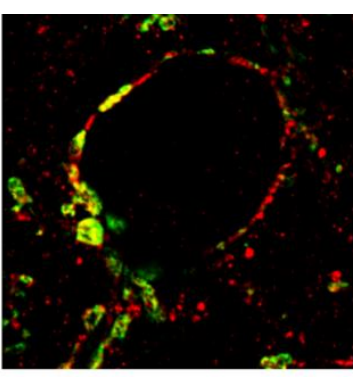
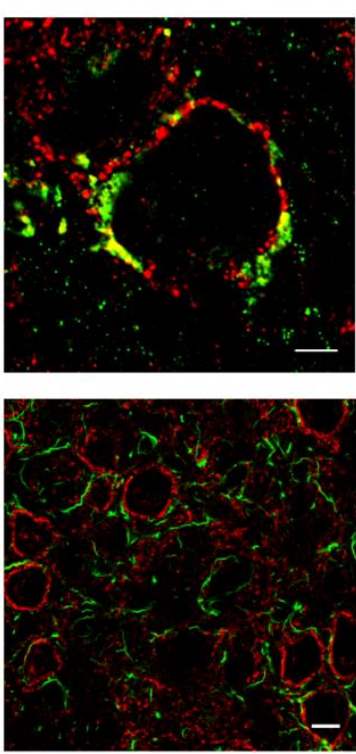
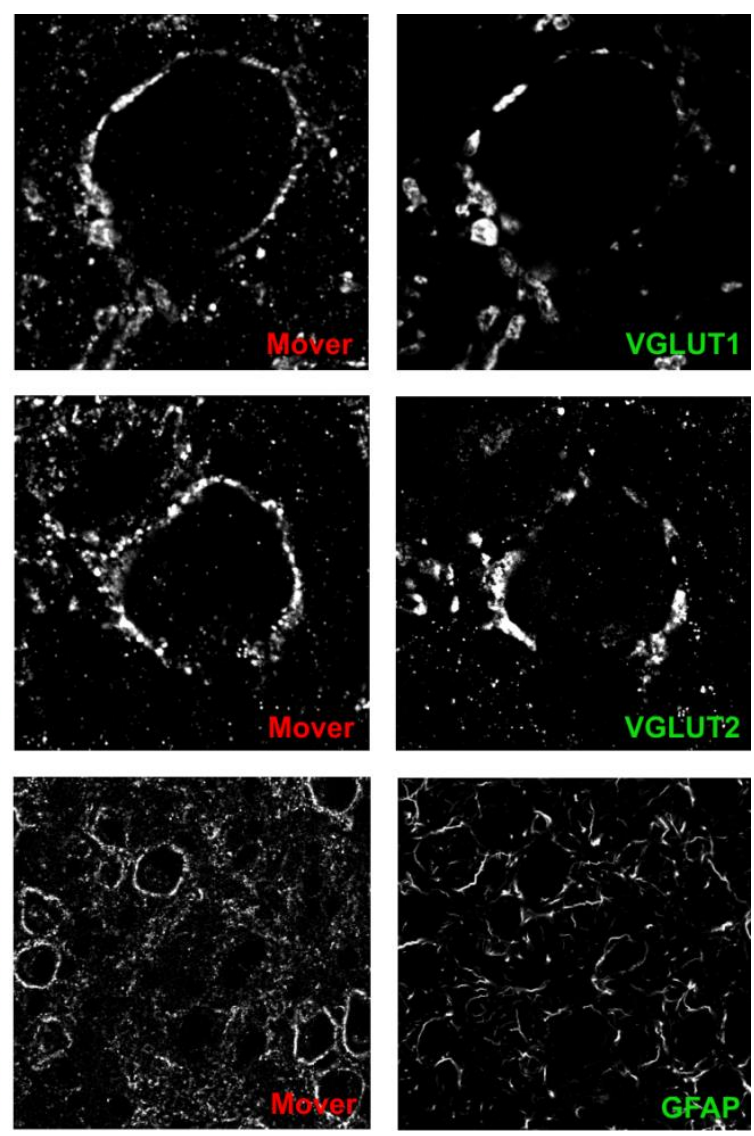

Figure 3.4 Mover is present in the endbulbs of Held.

A-B. Brainstem slices immunolabeled with anti-Mover and anti-VGLUT1 (A), anti-VGLUT2 (B) antibodies. Mover immunolabeling overlaps with immunolabels of VGLUT1 (A) and VGLUT2 (B). Co-localization with VGLUT1 labels appears stronger. C. Antibodies against Mover and the astrocyte marker glial fibrillary acidic protein (GFAP) stain different structures, thus, Mover is not present in astrocytes. All scale bars: $10 \mu \mathrm{m}$

Apart from positive VGLUT1-co-localization Mover IF signals are detected in VGLUT1-negative synapses around bushy cells. These are probably inhibitory terminals which can be stained with VGAT. Mover and VGAT immunosignals appear in shapes which are round and smaller compared to the shape of IF signals (Fig. 3.5, $C$ and D). The VGAT and Mover labels strongly co-localize at most of the VGATpositive spots indicated by the yellow color in merged confocal images. But there are few VGAT spots where the Mover immunosignal seems weak.

Next, markers for each of the inhibitory neurotransmitter (glycine and GABA) in the AVCN were used. The glycine transporter 2 (GlyT2) is a membrane protein which 
mediates glycine uptake of inhibitory synaptic terminals. GlyT2 IF signals surround and/or overlap with Mover signals in terminals that can be determined as glycinergic terminals now (Fig. 3.5, E-H). GAD65 is an isoform of the glutamate decarboxylase that mediated the synthesis of gamma-aminobutyric acid (GABA) in nerve terminals. The GAD65 IF signals appear as small puncta (Fig 3.5, L). Only few GAD65 immunolabels co-localizes with the Mover immunolabels (Fig. 3.5, I and J) indicating that Mover is mainly present in glycinergic nerve terminals in the AVCN.

A
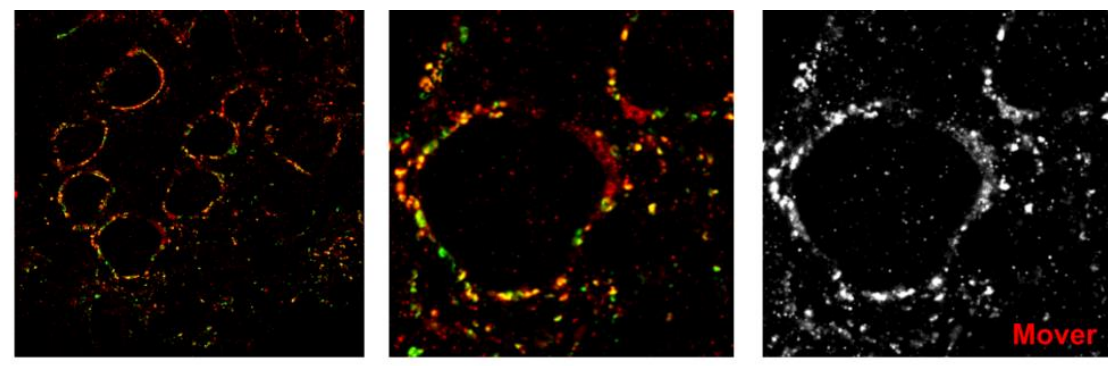

B

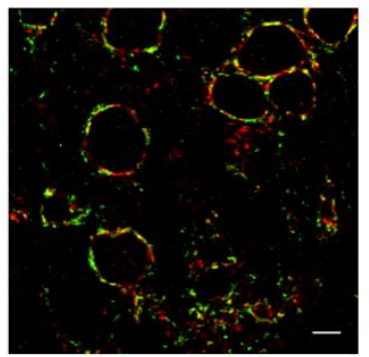

C

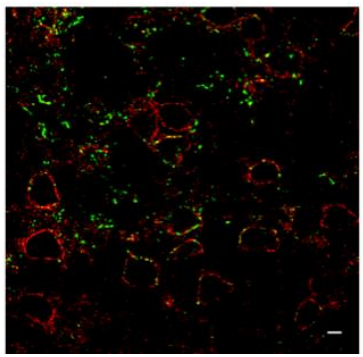

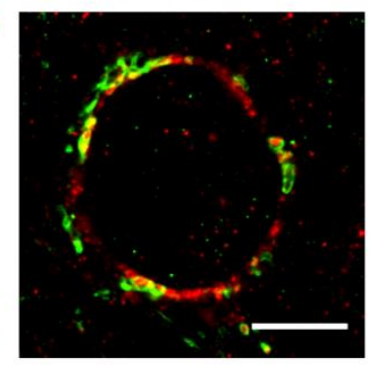

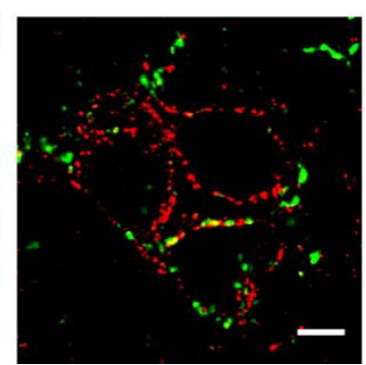

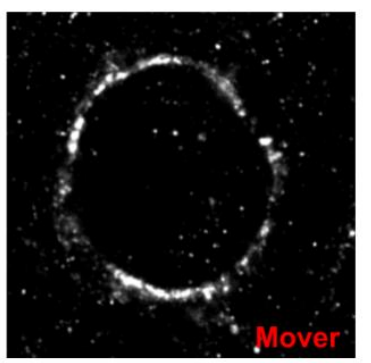

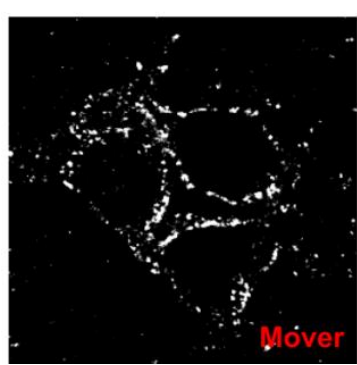

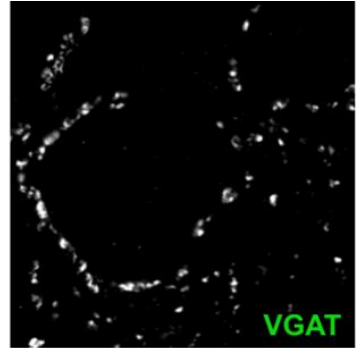
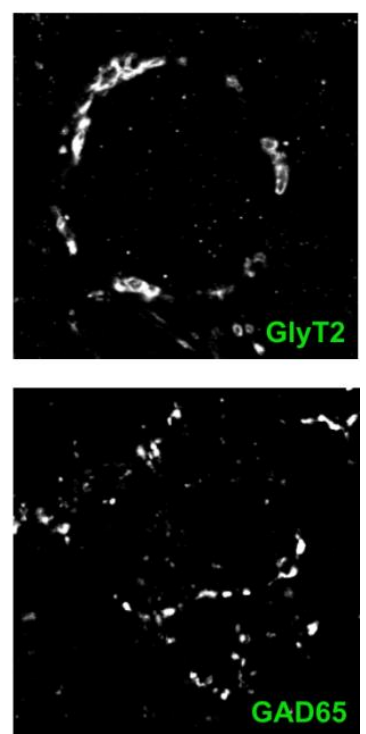

Figure 3.5 Mover is present in inhibitory terminals in the AVCN.

Three different antibodies were used to label the glycine transporter 2 (GlyT2), an isoform of the glutamate decarboxylase (GAD65) and VGAT in glycinergic, GABAergic and both nerve terminals in brainstem slices. A. Mover labels co-localize strongly with VGAT. B. GlyT2 labels overlaps and surrounds Mover labels. C. GAD65 and Mover labels co-localize rarely. All scale bars: $10 \mu \mathrm{m}$

In summary, immunolabeling for Mover and markers for excitatory and inhibitory synapses suggest that Mover is present in excitatory glutamatergic as well as in inhibitory, mainly glycinergic, nerve terminals in the AVCN. Mover antibody signals co-localize with signals from antibodies that label vesicular neurotransmitter 
transporters in SV supporting that Mover is associated with SV in those nerve terminals.

\subsubsection{Mover fluorescence intensities in the AVCN and calyx of Held}

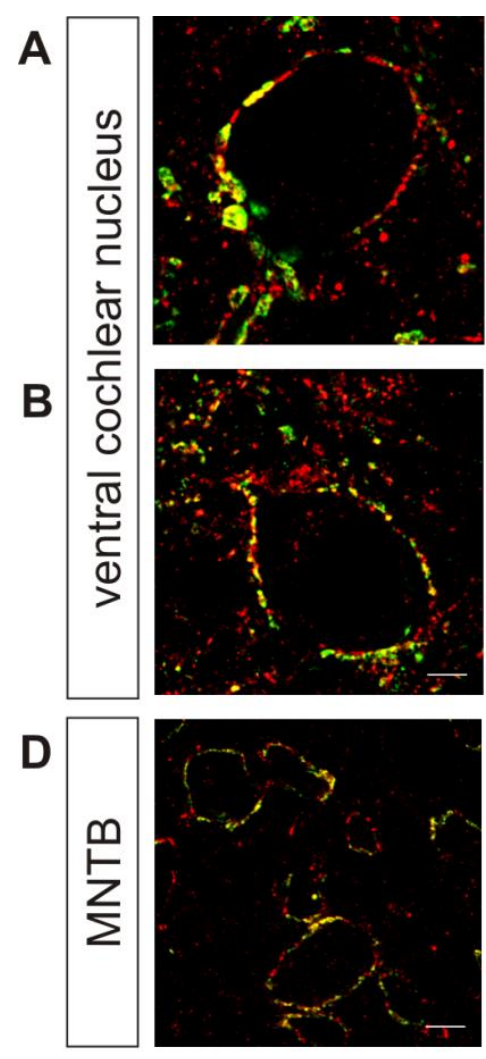

$\mathbf{F}$

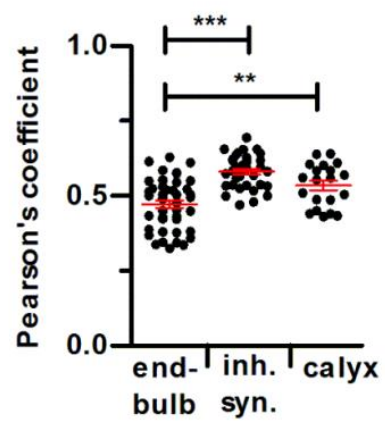

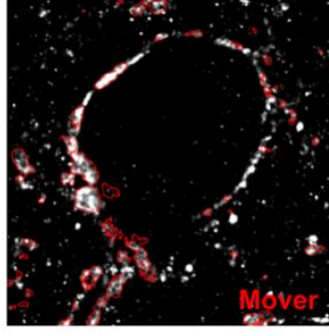
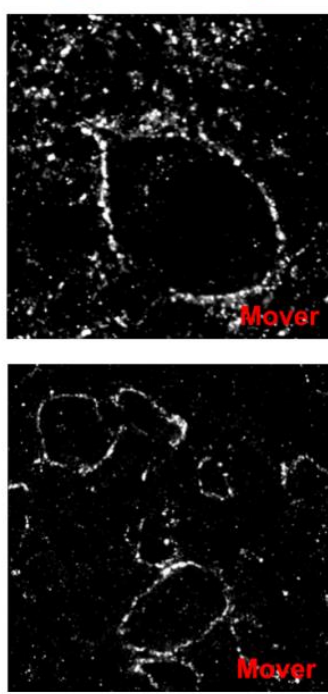

G

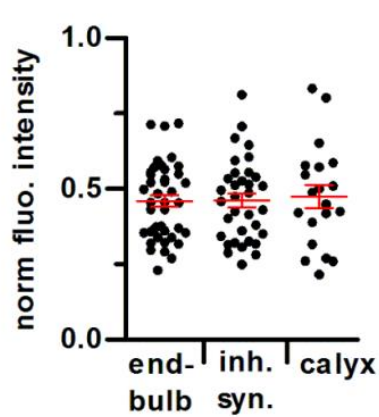

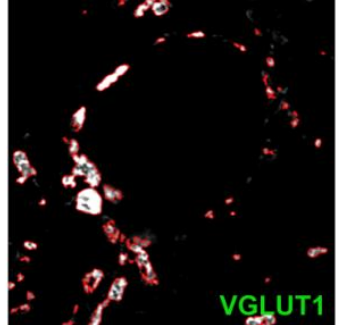
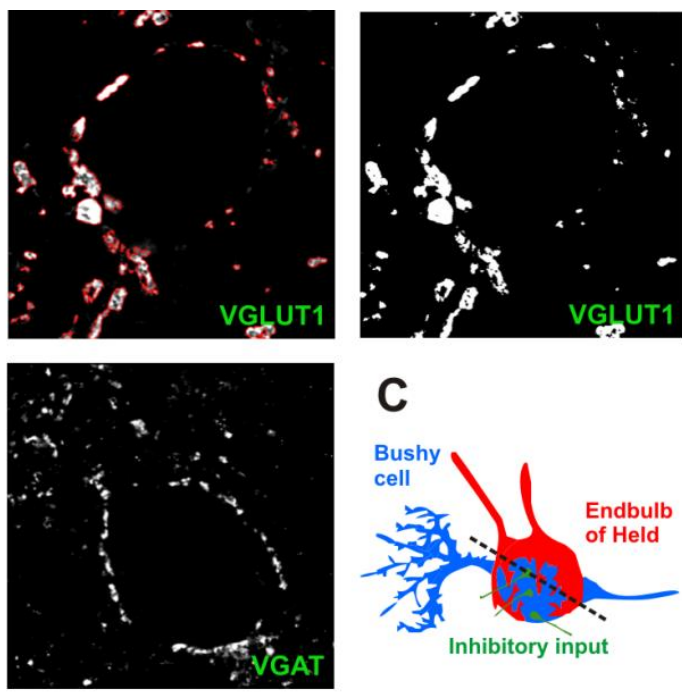

\section{C}
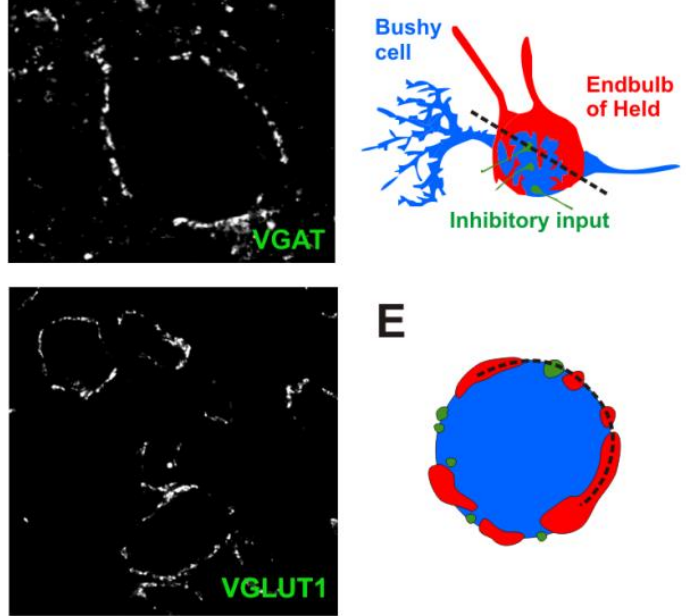

E

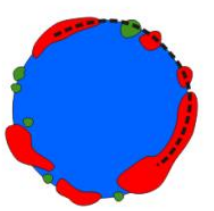

H

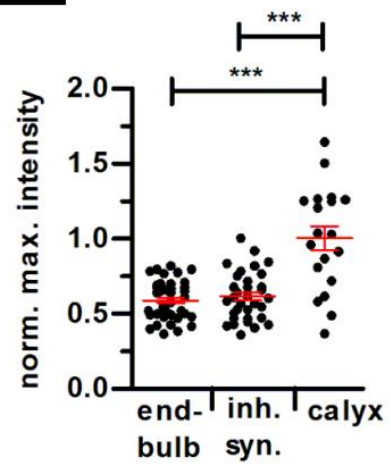

Figure 3.6 Analysis of Mover antibody fluorescence intensities in the ventral cochlear nucleus and calyx of Held.

A. Illustration of the region of interests (red) that were obtained from a suprathreshold VGLUT1 mask and applied to Mover and VGLUT1 images for analysis of intensities in specific areas. Same procedure was applied to confocal images labeled with VGAT and Mover (B). Single confocal sections for example cells labeled for VGLUT1 (A) or VGAT (B) and Mover. C. A simple model visualizing endbulbs of Held and inhibitory inputs converging on a bushy cell soma and (E) the appearance of a transverse cut through a bushy cell in confocal sections. F. Pearson's coefficient is significantly higher in inhibitory synapses in 
VCN and the calyx in the MNTB when compared to endbulbs. G. Normalized mean intensities of Mover signals are not different from each other in the three nerve terminals. $\mathbf{H}$. Normalized maximum intensities of Mover signals are significantly higher in the calyx compared to maximum intensities of Mover signals in the ventral cochlear nucleus. Scale bars: $10 \mu \mathrm{m} .{ }^{* \star} p<0.01,{ }^{* \star *} p<0.0001$

As the Mover IF signals that co-localized with VGAT IF signals seemed to be brighter the intensity of Mover IF signals in endbulbs and inhibitory synapses was analyzed and compared in confocal images. Co-stainings with anti-Mover and anti-VGLUT1 or anti-VGAT antibodies, respectively, were performed in rat AVCN slices. For illustration figure 3.6, C shows a simplified model how endbulbs and inhibitory synapses arrange around a bushy cell and figure 3.6, E displays the top view of a transverse cut through a bushy cell as it appears in a confocal section. Fluorescence intensities were analyzed as described in the methods chapter. Briefly, a suprathreshold mask (Fig. 3.6., A, rightmost image) from VGLUT1 or VGAT pixels are generated. This mask was used to create regions of interest (ROI, red selections in Fig. 3.6, A). These selections were applied to the VGLUT1 or VGAT and Mover image and the fluorescence intensities within the ROls were measured. Example confocal images labeled for Mover and VGLUT1 and VGAT are displayed in figure 3.6, A-C. The co-localization of Mover IF signals with VGLUT1 or VGAT IF signals, respectively, is indicated as Pearson's coefficient measures the pixel-by-pixel covariance in the signal levels. A Pearson's coefficient of 1 denotes a perfect colocalization and 0 denotes no co-localization. For this method a threshold has to be applied to the VGLUT1 and the Mover pixels. The Pearson's coefficient is significantly lower $(0.47 \pm 0.01)$ in images labeled for Mover and VGLUT1 compared to images labeled for Mover and VGAT $(0.58 \pm 0.01 ; p<0.001)$. This means that Mover IF signals co-localize stronger with VGAT IF signals in inhibitory synapses while Mover IF signals co-localizes less with VGLUT1 IF signals in the endbulbs of Held (Fig. 3.6, F). The result confirms the visual observation of brighter Mover IF signals in inhibitors nerve terminals. In contrast, the mean intensities of Mover IF signals have similar values in endbulbs $(0.46 \pm 0.02, n=42)$ and inhibitory synapses $(0.46 \pm 0.02, n=34$; $\mathrm{p}=0.93$ ) (Fig. 3.6, G). These opposing results may be attributed to the fact that for the calculation of the Pearson's coefficient a threshold is set for Mover pixels which neglects Mover signals that are below the threshold but are still inside VGLUT1 selections. Another possibility can be that the maximum intensities of Mover IF signals in inhibitory synapses are higher and thus the Mover signal appears stronger. 
But maximum intensities of Mover IF signals are also similar in endbulbs $(0.59 \pm 0.02$, $\mathrm{n}=42$ ) and inhibitory synapses (0.62 $\pm 0.03, \mathrm{n}=34 ; \mathrm{p}=0.38$ ) (Fig. 3.6, H). Mean intensities of Mover IF signals in the calyx of Held $(0.47 \pm 0.038, n=20)$ are not significantly different from the intensities of Mover IF signals in endbulbs of Held $(p=0.69)$. However, the Pearson's coefficient is higher in the calyx of Held $(0.54 \pm$ $0.02, n=20 ; p=0.006$ ). This may be a consequence of the significantly higher maximum intensities detected in the calyx of Held $(1.00 \pm 0.08, n=20)$ compared to the endbulbs of Held $(p<0.0001)$ and inhibitory synapses $(p<0.0001)$.

\subsection{Mover is associated with Bassoon at active zones}

Figure 3.7 A and D show overview images of two bushy cell labeled for Mover and the active zone marker Bassoon. With higher magnification it can be seen that Mover signals overlap partially with the Bassoon signals at active zone sites (see Fig. 3.7, B,C,E,F). In endbulb of Held terminals, (Fig. 3.7, E,F) where the Mover IF signals are distributed more broadly over the large terminal, the overlap is visually less obvious. An overlap is indicated by the yellow color. Hence, confocal images confirm the association of Mover with the active zone protein Bassoon. However, there are Bassoon spots lacking any Mover IF signal (arrow heads).
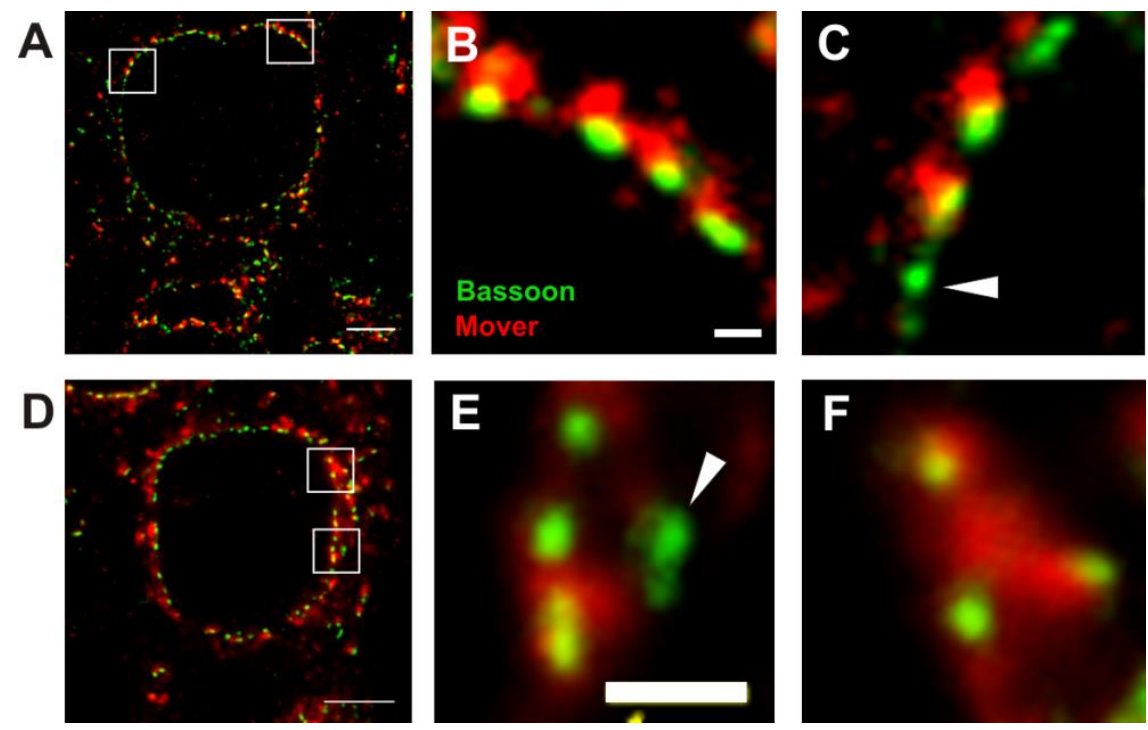

Figure 3.7 Mover associates with Bassoon.

Mover immunosignals overlaps partially with the active zone marker Bassoon. A and $\mathbf{D}$. Example bushy cells in a brain sections labeled for Mover (red) and Bassoon (green). B-C. Association of Mover and Bassoon is indicated by the overlap of their fluorescence signals (yellow color). E-F. In endbulb areas the Mover signal is weaker and the signal overlap with Bassoon is less clear. Arrow heads in C and E point out active zones lacking Mover signal. 


\subsection{Mover fluorescence intensities in deaf Otoferlin knock-out mice}

In order to examine how reduction or loss of activity in auditory nerve fibers (ANF) affect Mover expression in the endbulbs of Held Mover IF signals were studied in deaf Otoferlin knock-out mice which lack ANF activity. AVCN sections from wild-type (wt) and Otoferlin knock-out (ko) mice were stained with an anti-VGLUT1 antibody to label the endbulbs, with an anti-VGAT antibody to label inhibitory synapses and with an anti-Mover antibody to check for changed Mover fluorescence signals. The analysis of confocal images from these stainings was performed as described before. The intensities of Mover IF signals are reduced by $35 \%$ in endbulbs in Otoferlin knock-out mice $(0.75 \pm 0.03, n=65, N=3 ; p<0.0001)$ (Fig. 3.8, C). Interestingly, the intensities of Mover IF signals are lower $(0.97 \pm 0.03 ; p=0.02)$ in the inhibitory synapses of these knock-out mice as well. Hence, the loss of activity in ANF leads to a down-regulation of Mover in endbulbs and in inhibitory synapses. Moreover, the area of VGLUT1 ROls is smaller in Otoferlin knock-out mice when compared to Otoferlin wild-type mice (wt: $0.61 \pm 0.04 \mu \mathrm{m}^{2} ;$ ko: $0.36 \pm 0.03 \mu \mathrm{m}^{2} ; \mathrm{p}<0.0001$ ). Additionally, the area of VGAT ROIs is smaller in Otoferlin knock-out mice, as well $\left(0.38 \pm 0.02 \mu \mathrm{m}^{2}\right.$, wt: $\left.0.27 \pm 0.01 \mu \mathrm{m}^{2} ; p<0.0001\right)$. This indicates that the size of endbulbs and inhibitory synapses which is represented by the area of VGLUT1 or VGAT ROIs is decreased in the AVCN in Otoferlin knock-out mice.

The comparison of Mover IF signal intensities in wild-type mice revealed no difference between endbulbs $(0.58 \pm 0.02 \quad(n=81, N=3)$ and inhibitory synapses $(0.62 \pm 0.02 ; p=0.11)$ comparable to the result in rat $A V C N$. 
A
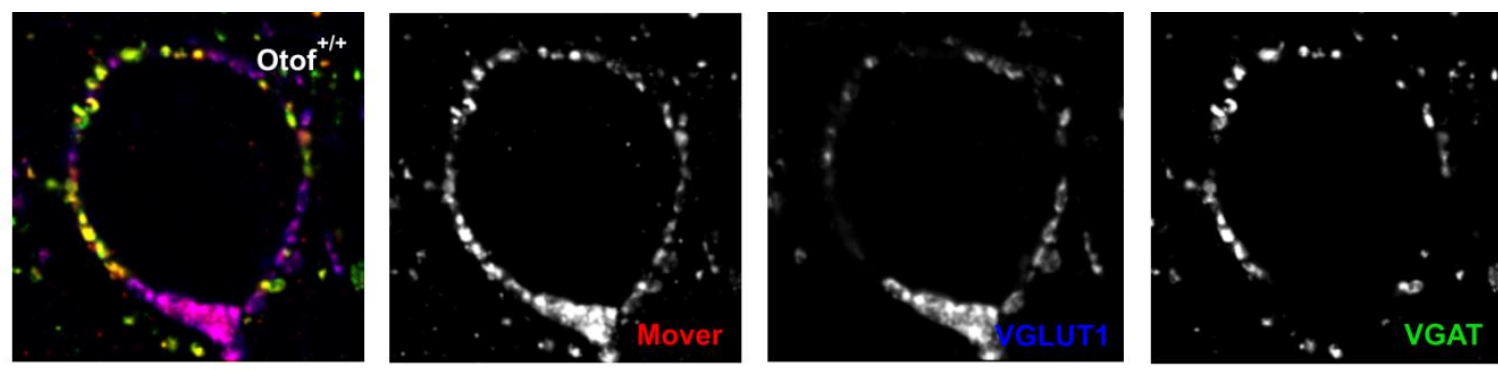

B
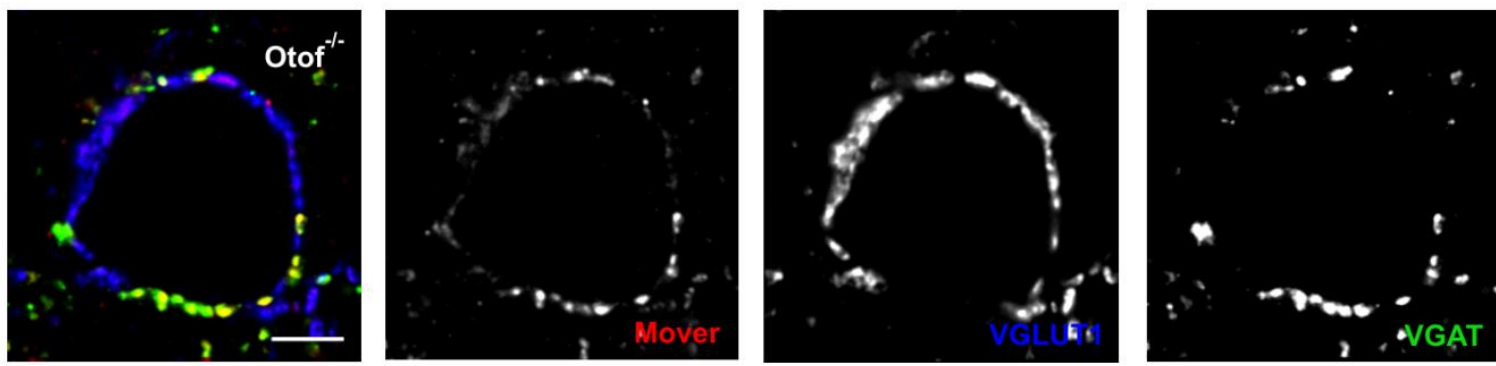

C
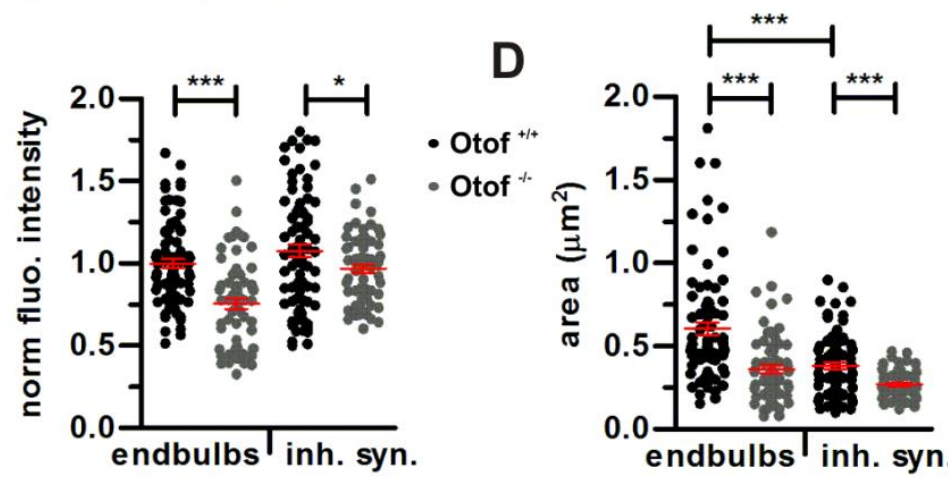

E

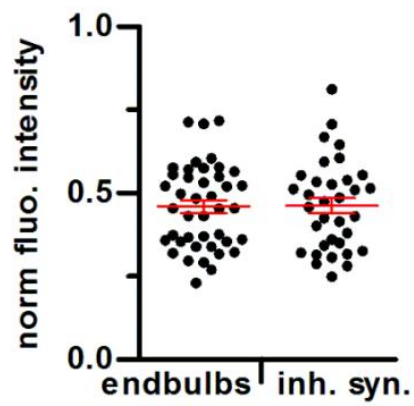

Figure 3.8 Reduced intensities of Mover fluorescence signals in the endbulbs of Held in Otoferlin knock-out mice.

A-B. Single confocal section of a bushy cell in an Otoferlin wild-type mouse (A) and knockout mouse (B) labeled for VGLUT1 (blue), VGAT (green) and Mover (red). C. Normalized Mover fluorescence levels are reduced in endbulbs as well as in inhibitory synapses of knock-out mice. D. The size of endbulbs, represented by the area of VGLUT1 labels, and the size of inhibitory synapses, represented by the area of VGAT labels, is decreased in Otoferlin knock-out mice. E. In wild-type mice, normalized mean intensities of Mover signals are similar in endbulbs and in inhibitory synapses. Scale bar: $10 \mu \mathrm{m} .{ }^{*} p<0.05,{ }^{* *} p<0.01,{ }^{* * *}$ $\mathrm{p}<0.0001$

Further it was tested whether the reduction of Mover IF signals in endbulbs of Held lead to a subsequent modification of Mover IF signals at the next station in the auditory pathway, the MNTB. There globular bushy cell axons form the large nerve terminal the calyx of Held. The analyzed intensities of Mover IF signals in the calyx of Held (labeled with VGLUT1) are higher in a knock-out mouse $(1.44 \pm 0.03, n=42, N=1)$ in comparison to wild-type mice $(p<0.0001)$. These results reveal an opposite change of Mover IF signal intensities in the calyx of Held. The area of VGLUT1 ROls in the 
MNTB is not changed in Otoferlin knock-out mice (wt: $0.81 \pm 0.02 \mu \mathrm{m}^{2}, \mathrm{n}=53$; ko: $\left.0.74 \pm 0.02 \mu \mathrm{m}^{2}, n=59 ; p=0.12\right)$ indicating that the size of calyces has not changed.

A
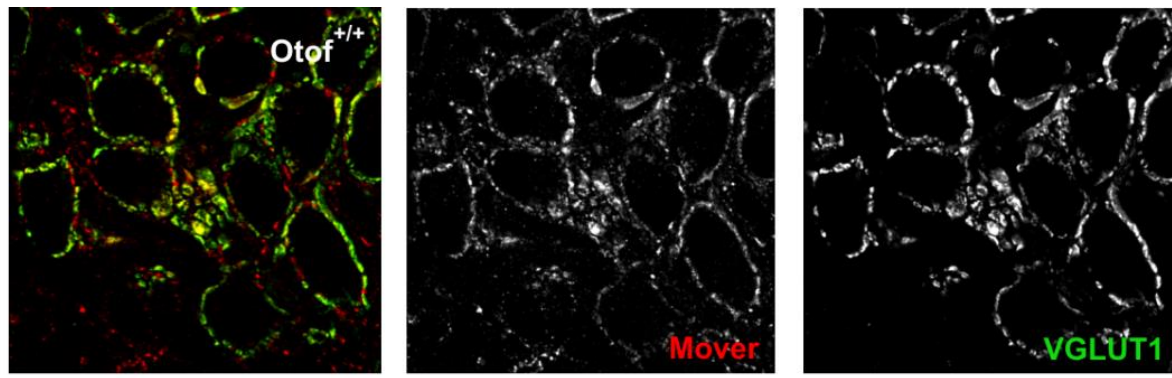

B
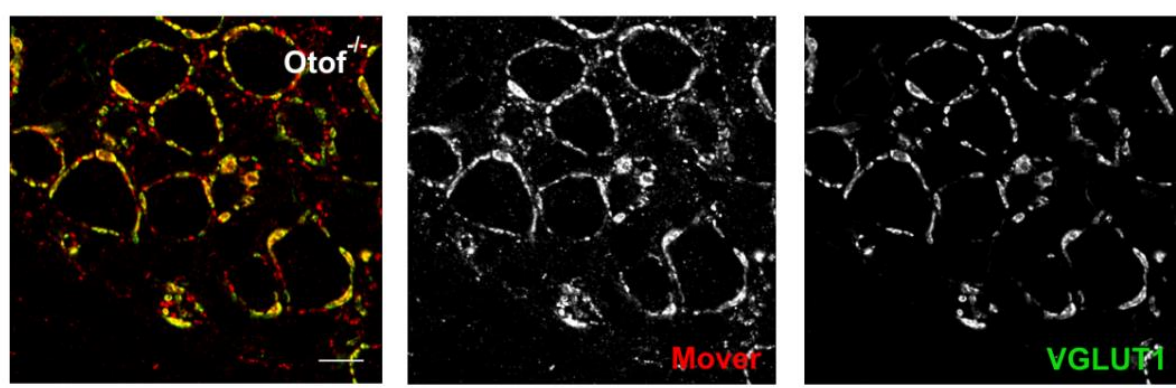

C
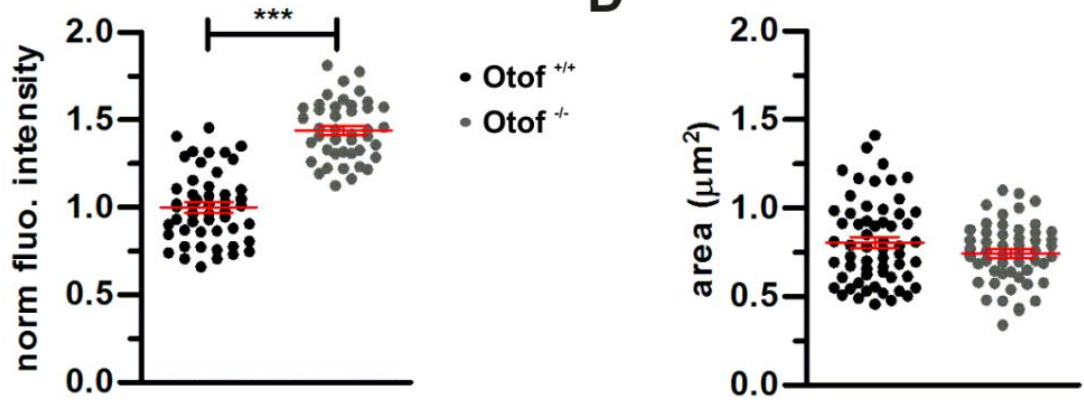

Figure 3.9 Increased intensities of Mover fluorescence signals in the calyx of Held in Otoferlin knock-out mice.

A-B. Single confocal sections of calyces of Held in the MNTB labeled for VGLUT1 (green) and Mover (red) in wild-type (A) and knock-out (B) Otoferlin mice. C. Mover fluorescence levels are increased in Otoferlin knock-out mice compared to Otoferlin wild-type mice. D. The area of VGLUT1 ROIs in the MNTB, representing the size of calyces of Held, remained changed in Otoferlin knock-out mice. Scale bar: $5 \mu \mathrm{m} .{ }^{* \star *} p<0.0001$

The CA3 region of the hippocampus was chosen as a control region since the lack of Otoferlin did not to affect presynaptic function in hippocampal autaptic cultures revealed in electrophysiological experiments (Reisinger et al. 2011). Therefore, it is assumed that the Mover IF signals remains unchanged in mossy fiber terminals where Mover was identified earlier (Kremer et al. 2007). To analyze Mover fluorescence intensities in these excitatory terminals hippocampus slices were 
stained with an anti-VGLUT1 and an anti-Mover antibody. In wild-type and in knockout IF signals from both antibodies show a strong co-localization of Mover and VGLUT1 in mossy fiber terminals indicated by the yellow color (Fig. 3. 10, A). Fluorescence intensities of Mover immunosignals were analyzed in 3-5 areas of $100 \times 100$ pixels in the stratum pyramidale where mossy fibers form presynaptic terminals at the dendrites of pyramidal cells. VGLUT1 suprathreshold pixels were used as mask and to create ROls. Intensities of Mover and VGLUT1 IF signals were measured within the ROls (Fig. 3.10, A2). The analysis of Mover and VGLUT1 fluorescence intensities in the mossy fiber terminals revealed that Mover levels are changed in Otoferlin knock-out mice compared with the wild-type animals $(p=0.38)$ (Fig. 3.10, B). Mover intensity was $1.00 \pm 0.02$ in wild-type $(n=32, N=2)$ mice and $0.97 \pm 0.03(n=25, N=2)$ in knock-out mice.
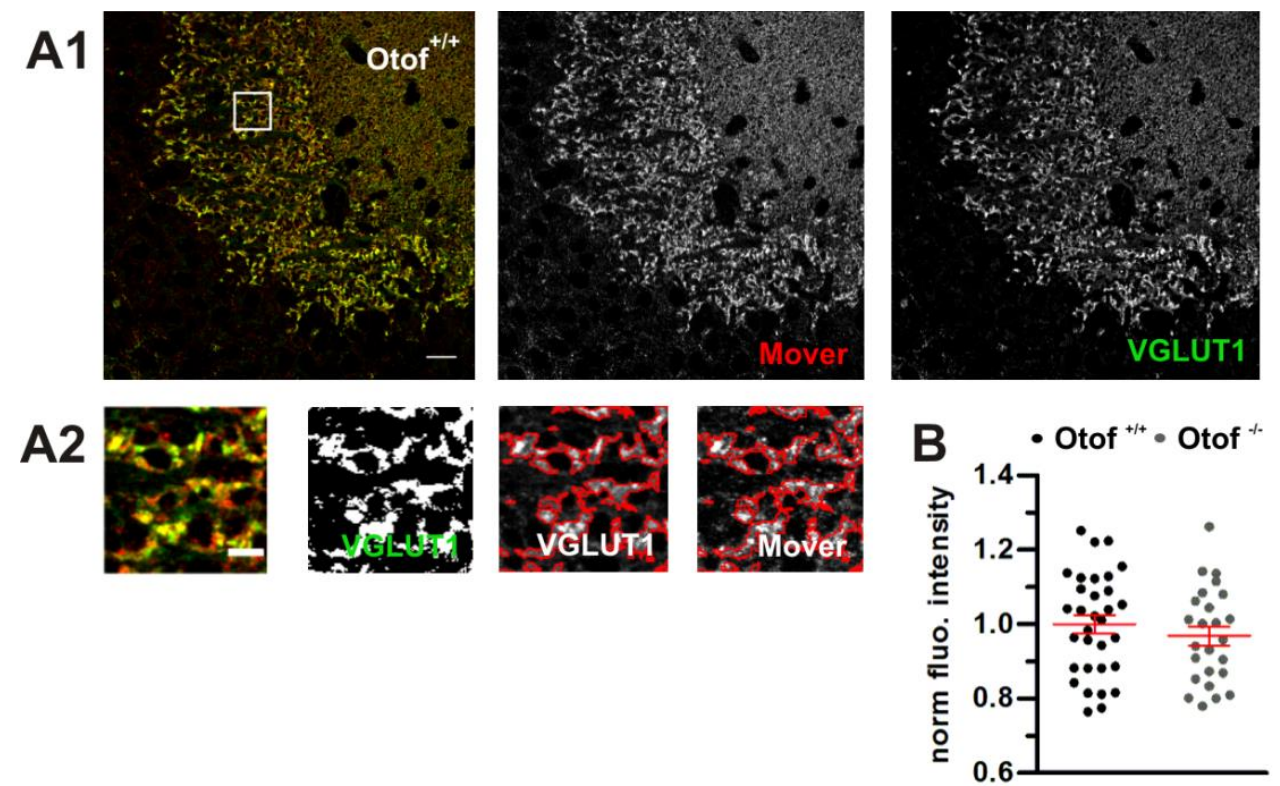

Figure 3.10 Intensities of Mover signals remain unchanged in hippocampal mossy fiber terminals in Otoferlin knock-out animals.

A1. Single confocal section of the hippocampus CA3 region labeled for VGLUT1 (green) and Mover (red). Scale bar $10 \mu \mathrm{m}$. Three to five areas were picked for the intensity analysis. A2. Blow-up of a 100x100 pixel area from A1. A suprathreshold mask was created from VGLUT1 pixels and region of interests (red selections) were selected for intensity measurements. B. No changes in VGLUT1 and Mover fluorescence intensity are detected. Scale bar $0.5 \mathrm{~nm}$. 


\subsection{Characterization of a Mover knock-out mouse}

\subsubsection{Validation of the Mover knock-out}

A Mover knock-out mouse was generated to study and determine the changes that occur when Mover is lacking in the brain.

Initially, the global knock-out of Mover was validated using immunofluorescence stainings. For this, brain slices of the VCN and hippocampus were stained with an anti-Mover and an anti-VGLUT1 antibody. The results are illustrated in figure 3.11, AD. Mover fluorescence signals disappeared from endbulbs (labeled with VGLUT1) in (Fig. 3.11, A, B) and also from VGLUT1-negative synapses in knock-out animals confirming the knock-out of Mover in the VCN. Co-immunolabeling of Mover and VGLUT1 in the hippocampal CA3 region revealed strong co-localization of both immunosignals in the stratum pyramidale which harbors the mossy fiber terminals (Fig 3.11, C). In contrast, no Mover fluorescence signal and thus no co-localization are observed in the Mover knock-out mice (Fig. 3.11, D). Both in the VCN and hippocampus VGLUT1 fluorescence signals do not show obvious changes in the labeled glutamatergic terminals.

$D A B$ stainings were used to confirm the knock-out of Mover with a second staining method. A dark brown DAB signal from the Mover antibody is detected in brainstem nuclei (LSO, MSO, VNTB, LNTB and SPN) and in the AVCN (Fig. 3.12, A, B) in Mover wild-type mice. In the AVCN, the Mover signals exhibit a punctate staining pattern around bushy cells (Fig. 3.12, C, asterics). In Mover knock-out mice a light brown signal remains in the brainstem and the AVCN. This signal Possibly reflects background signal of the Mover antibody.

In summary, immunofluorescence and DAB stainings confirmed the global knockdown of Mover. 
A
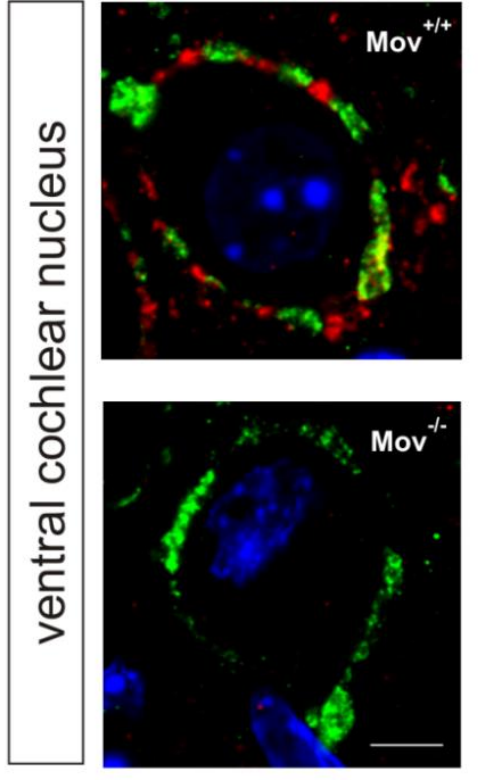

C

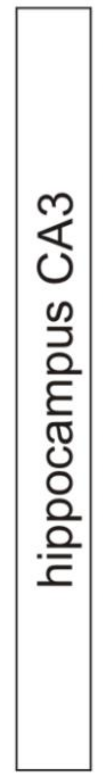

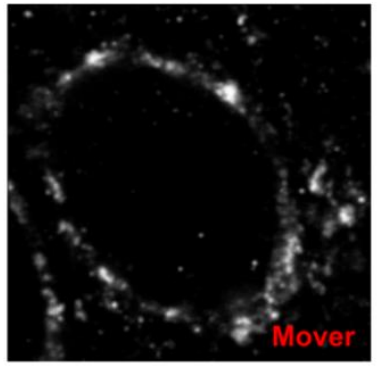
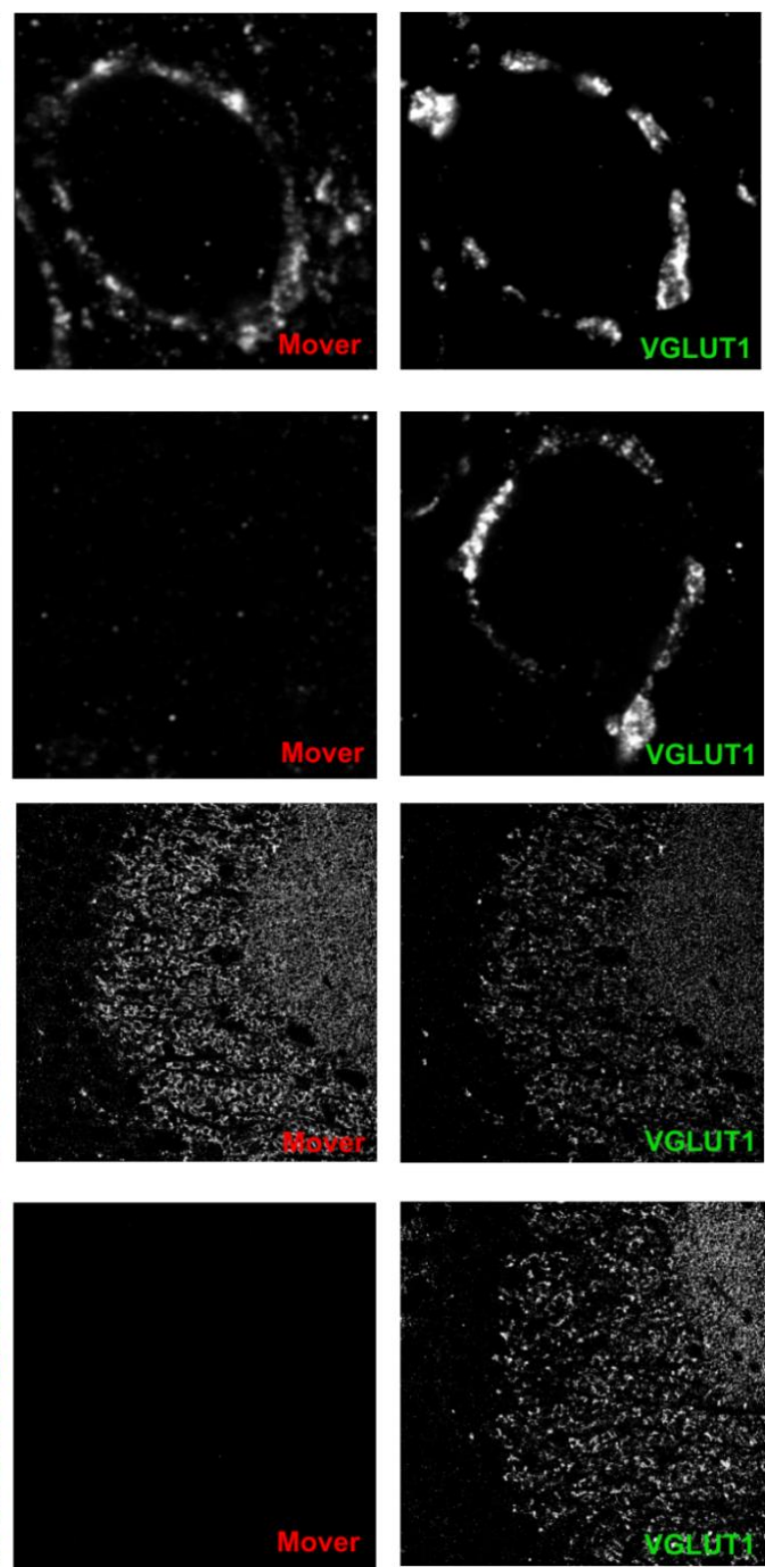

Figure 3.11 Mover fluorescence signals are absent in brainstem and hippocampal slices in a Mover knock-out mouse.

A-D. Single confocal sections from VCN and hippocampus brain slices labeled for Mover and VGLUT1. A. Mover labels co-localizes with VGLUT1 labels in endbulbs of Held. B. Complete absence of Mover signals and remaining VGLUT1 signals in the VCN in a Mover knock-out mouse. Scale bar: $10 \mu \mathrm{m}$ C. Mover labels and VGLUT1 labels strongly co-localize in the stratum pyramidale in the hippocampus in Mover wild-type mice. D. The Mover fluorescence signal disappeared. The VGLUT1 signals remains. Scale bar: $100 \mu \mathrm{m}$ 


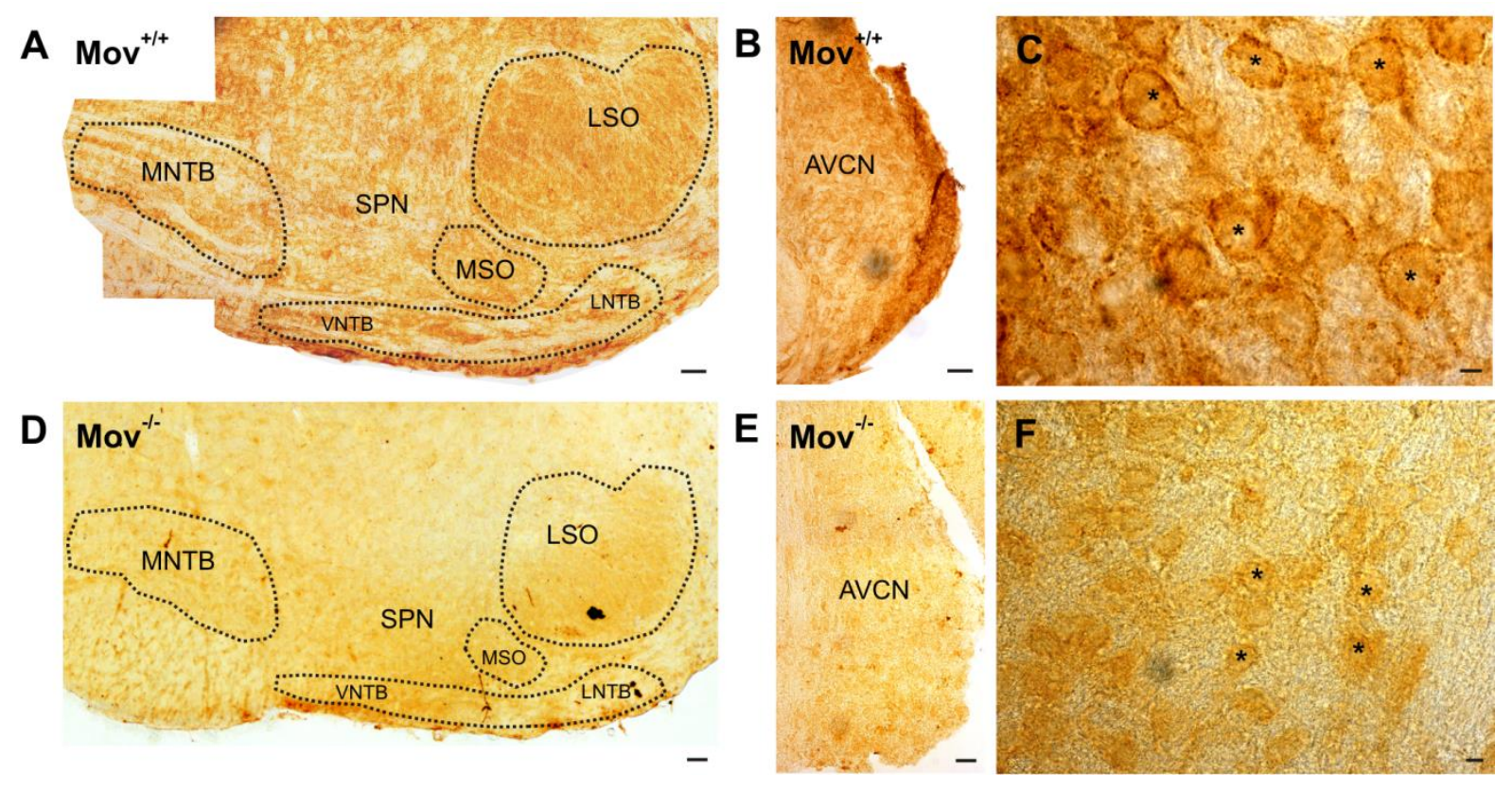

Figure 3.12 Validation of Mover knock-out with DAB stainings in the auditory brainstem slices of a Mover knock-out mouse.

A. A dark brown Mover DAB signal appears in several brainstem nuclei including the lateral superior olive (LSO), medial nucleus of the trapezoid body (MNTB), medial superior olive (MSO), LNTB and VNTB (lateral and ventral nucleus of the trapezoid body) and superior olivary nucleus (SPN) as well as in the anteroventral cochlear nucleus (AVCN) (B) in wildtype mice. C. Higher magnification of (B) shows a punctate Mover signal around bushy cells (asterics) in AVCN. D-F. Mover DAB signal is absent in Mover knock-out mouse brainstem slices. The light brown signal that remains possibly reflects background staining from the Mover antibody.

\subsubsection{Electrophysiological characterization of synaptic neurotransmission between bushy cells and endbulbs of Held in Mover knock-out mice}

Here, I started to characterize the synaptic transmission between endbulbs and bushy cells in global Mover knock-out mice in order to understand the function of Mover. In electrophysiological recordings bushy cells can be distinguished from stellate cells based on their firing pattern in current clamp recordings (also see introduction). Bushy cells fire one or few spikes at the onset of an injected depolarizing current. In response to hyperpolarizing current pulses bushy cells show typical sag due to hyperpolarization-activated conductance (Fig. 3.13, C). In contrast, stellate cells lack a hyperpolarization-activated conductance and fire tonically in the depolarizing voltage range (Fig. $3.13, \mathrm{~F}$ ). In addition, miniature EPSCs (mEPSC) from both cell types differ in kinetics and amplitude. Bushy cell mEPSCs usually have higher amplitudes and decay faster than mEPSCs in stellate cells (compare B and E in Fig. 3.13). This can be used to differentiate between cell types in voltage clamp 
recordings. A superimposed trace of mEPSCs from a bushy cell and a stellate cell are displayed in figure $3.13(A$ and $D)$.

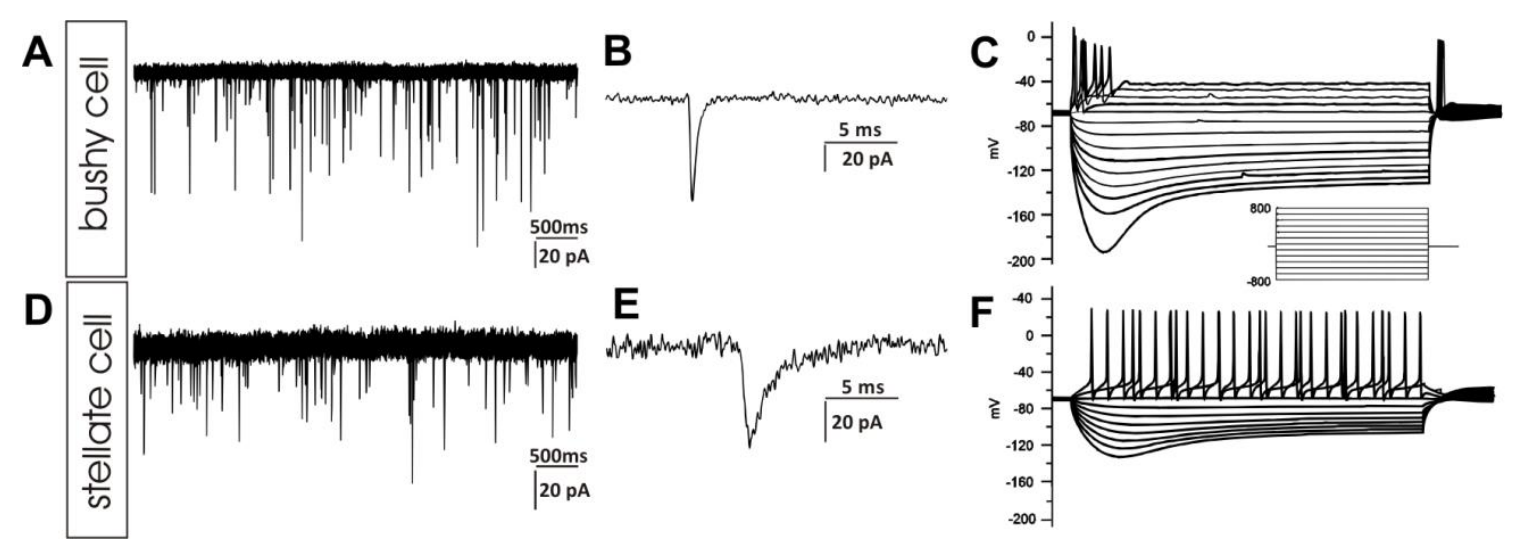

Figure 3.13 Identification of bushy and stellate cells in electrophysiological recordings.

A and D. A superimposed miniature EPSC trace from a bushy cell (A) and a stellate cell (D). B and E. A superimposed miniature EPSC spike. mEPSCs typically differ in amplitude and decay time. $\mathbf{C}$ and $\mathbf{F}$. As response to current injections bushy and stellate cells show characteristic firing pattern.

To test whether the basal synaptic transmission is changed mEPSCs were recorded from bushy cells in acute sagittal slice preparations of Mover wild-type and knock-out animals. The analysis revealed a significant increase in the amplitude and area of mEPSCs in knock-out mice. The frequency and kinetics of mEPSCs remained unchanged in knock-out mice (Fig.3.14 and table 3.1). The amplitude of mEPSCs can be used as a measure for the quantal size. Thus, also the quantal size increased in Mover knock-out animals. 


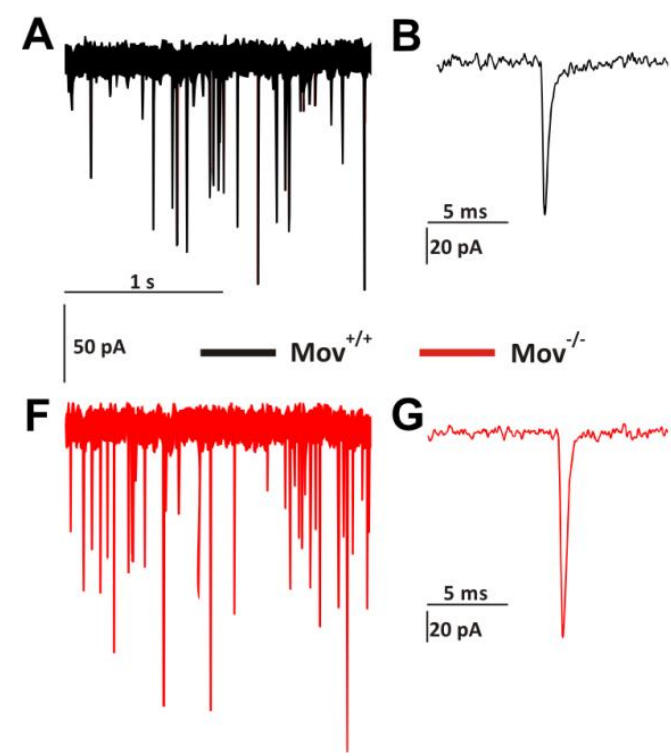

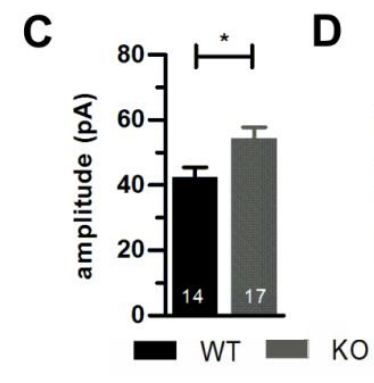

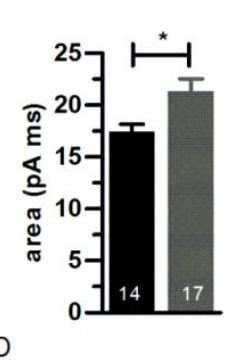

E

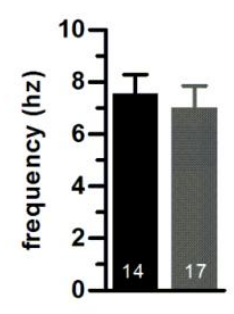

H
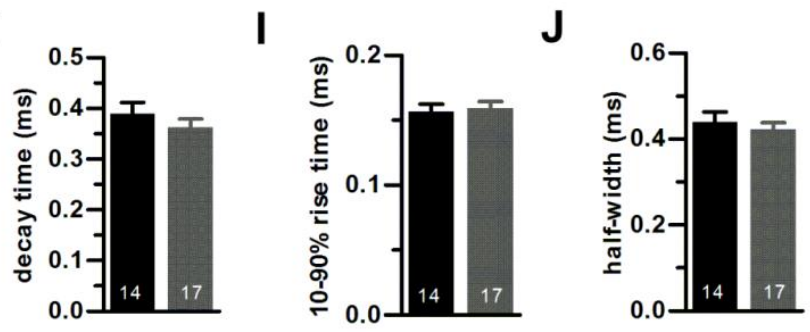

Figure 3.14 Increased quantal size in Mover knock-out mice.

$\mathbf{A}$ and $\mathbf{E}$. A typical trace of a miniature EPSCs in a wild-type (A, B, black) and knock-out (F, G, red) animal. C-E. mEPSC amplitude and area are significantly increased while the frequency remained unchanged in Mover knock-out mice. H-J. mEPSC kinetics such as decay time $(\mathbf{H})$, rise time $(\mathbf{I})$ and half-width $(\mathbf{J})$ are not altered in Mover knock-out mice.

Table. 3.1 Analysis of miniature EPSCs

\begin{tabular}{lccc}
\hline & $\begin{array}{c}\text { Mov }^{+/+} \\
\mathrm{n}=14\end{array}$ & $\begin{array}{c}\text { Mov }^{-/-} \\
\mathrm{n}=17\end{array}$ & p value \\
\hline Amplitude (pA) & $43.34 \pm 2.94$ & $54.27 \pm 3.58$ & 0.029 \\
Tau decay time (ms) & $0.39 \pm 0.023$ & $0.36 \pm 0.017$ & 0.34 \\
10-90\% rise-time (ms) & $0.16 \pm 0.006$ & $0.16 \pm 0.005$ & 0.87 \\
Frequency (Hz) & $8.16 \pm 0.93$ & $7.00 \pm 0.85$ & 0.37 \\
Half-width (ms) & $0.44 \pm 0.024$ & $0.42 \pm 0.015$ & 0.52 \\
Area (pAms) & $17.45 \pm 0.70$ & $21.32 \pm 1.24$ & 0.016 \\
\hline
\end{tabular}




\section{Discussion}

In the present study, the location and distribution of the synaptic protein Mover was studied in the anterior ventral cochlear nucleus (AVCN). It could be shown that Mover is expressed in the endbulbs of Held as well as in inhibitory synapses. Within the endbulbs, fluorescence signal intensities of antibodies generated against Mover were broadly distributed over bushy cells. Using immunohistochemical approaches, activity dependent regulation of Mover expression was studied in a deaf mouse model that lacks Otoferlin a calcium sensor proposed to regulate synaptic vesicle exocytosis. It could be shown that Mover signal intensities were significantly reduced in these mice compared to control animals suggesting that is activity-dependently regulated. Finally, in order to see if the absence of Mover in synapses affects synaptic transmission global knock-out of the mover gene in mice was studied, revealing an increased quantal size in endbulbs.

\subsection{Methodological considerations}

An indirect immunofluorescence method was used for fluorescence stainings. Here, a primary antibody binds directly to the antigen in the probe. The secondary antibodies bind indirectly through the primary antibody to the target protein. The detection of the bound antibody is due to a fluorophore that is conjugated to the secondary antibody. Emission of fluorescence is triggered by a laser light in the confocal microscope. In general, indirect immunofluorescence is the most common and cost effective approach to label proteins in a specimen. Secondary antibodies are available in a wide spectrum of colors allowing the use of several secondary antibodies (in combination with any primary antibody that they are reactive to) at the same time. Hence, several proteins can be labeled in the same specimen and their localization in relation to each other can be studied. Indirect immunofluorescence offers a high level of sensitivity and signal amplification because more than one secondary antibody can bind to each primary antibody. Nevertheless there are a number of pitfalls that can affect a sufficient signal and accurate localization of immune complexes, i.e. nonspecific binding and cross-reactivity of the secondary antibodies, high concentrated antibodies and auto-fluorescence of the fixed tissue are possible 
causes for a high background in immunofluorescence images. Problems that occur with the Mover fluorescence signal and/ or antibody are high background, high signal variability and low signal at particular regions of interest. Various adaptions of the staining protocol were tested to approach these problems. Blocking of nonspecific binding to identical or similar epitopes on non-target antigens was performed with normal serum from the same species of the secondary antibody. Higher concentration of normal serum with and without bovine serum albumine did not improve the staining. Cross-reactivity of anti-mouse and anti-rabbit secondary antibodies was prevented by using antibodies raised in different species. The fixation was reduced to $2 \%$ of paraformaldehyde (PFA) (instead of commonly used $4 \%$ PFA) to avoid high background and auto-fluorescence. Fixation with methanol, cryosectioning of PFA-fixed brains or of freshly frozen brains in 2-methylbutane led to very low or no Mover signals. Thus PFA fixation is the most suitable for Mover immunostainings. To improve the affinity and specificity of the primary antibody, all of our Mover antibodies were affinity purified to an immobilized antigen column. Antibody concentration and incubation times were adapted to obtain specific signals. Thin brain slices of $30 \mu \mathrm{m}$ were cut to achieve an optimal antibody penetration of the tissue. In order to amplify the weak Mover immunosignal the Universal Immunoenzyme Polymer (UIP) method developed by NICHIREI BIOSCIENCES was applied in DAB stainings. This is a simplified chromogenic, indirect immunofluorescence staining method which uses a complex of amino acid polymers, peroxidases and Fab' fragments of the secondary antibody instead of a horse radish peroxidase coupled secondary antibody. When adding $D A B$ and hydrogen peroxide to the bound polymer, the DAB is oxidized and a brown, alcohol-insoluble precipitate at the site of enzymatic activity (site of labeled protein).

While imaging stacks of confocal sections and using high magnification Mover fluorescence signals bleached mainly in endbulb regions. For that reason only confocal single sections were considered for analysis of Mover fluorescence intensities in endbulbs.

\subsection{Mover immunofluorescence in AVCN}

Fluctuations in Mover signal may result from difficulties with the antibody or the applied experimental protocol. However, one has to take into consideration that the varying signal intensity may also reflect variation in Mover protein level. 
When comparing the Mover fluorescence signal intensity in inhibitory terminals, which appeared brighter and smaller, to the Mover signal intensity in excitatory endbulbs, which appeared weaker and more widespread, similar mean and maximum intensity values were detected in both terminals in the rat AVCN. However, the Pearson's coefficient, as a read-out for co-localization, was different between Mover and VGLUT or VGAT signals, respectively. For the co-localization analysis overlapping suprathreshold pixels were analyzed meaning that the lower signal below the threshold is cut off. As a result, the Pearson's coefficient of Mover and VGLUT1 signal is lower than the Pearson's coefficient of Mover and VGAT signal. In the calyx Mover mean fluorescence signal intensity is similar to that in the endbulb. Additionally, the Pearson's coefficient is higher in the calyx. In this case the higher maximum fluorescence signal intensity of Mover in the calyx may account for the difference between both structures. In contrast, in Otoferlin wild-type mice mean and maximum fluorescence signal intensity and Pearson's coefficient of Mover in endbulbs and inhibitory synapses are not different. But Mover mean signal intensity in the calyx is higher than in endbulbs indicating that Mover expression is higher in calyx terminals. The different intensities of Mover fluorescence signals in the calyx in rat and mouse brain might result from species differences and/or different functional roles for Mover. Or it is due to a different Mover antibody specificity in rat and mouse brain. Note, that the Mover antibody dilution was slightly higher for the rat stainings.

Standard deviation (SD) of the mean quantifies variability of the values in a data set. For example a low SD means that the values are close to the mean of the data set on average, and vice versa. A better way of looking at SD is by plotting the distribution as a histogram of values. For example a distribution with a high SD would display as a wide shape while a distribution with a low SD would display as a narrow shape. The intensity analysis of Mover and VGLUT signals in endbulbs revealed a higher SD for Mover mean signal intensities when compared to VGLUT1 signal intensities, in endbulbs in rat and mouse. Furthermore, histograms of Mover signals in endbulbs have a broad distribution whereas those of VGLUT1 have a narrow distribution (see appendix, figure 7.2. A,B). The variability of fluorescence signals might be a result of variability in specific antibody binding and staining or it has physiological reasons, for example different protein levels due to physiological differences or changes. This is further discussed below. 
In the calyx of Held the role of Mover was associated with the synaptic vesicle release probability ( $\operatorname{Pr})$ (Körber 2010). The author suggests a negative correlation between Mover expression and Pr because the knock-down of Mover in the calyx of Held resulted in an enhanced and accelerated short-term depression and a higher $\mathrm{Pr}$. In general, estimates of $\mathrm{Pr}$ in endbulbs are rather high: 0.55 in rats $(2.0 \mathrm{mM}$ calcium, P10-12; S Oleskevich, Clements, and Walmsley 2000), 0.5 in CBA mice (2.0 mM calcium, P11-16; (Oleskevich \& Walmsley 2002), 0.65 in normal-hearing young DBA/2j mice (2.0 mM calcium, P17-25; Yong Wang and Manis 2005), 0.49 in Bassoon $^{\Delta E \times 4-5}$ wild-type mice (1.5 mM calcium, P15-P23; Mendoza Schulz et al. 2014). The Pr can be estimated in different ways. Oleskevich and Walmsley used a variance-mean analysis to examine the $\operatorname{Pr}$. Interestingly the mean $\operatorname{Pr}$ (at $2.0 \mathrm{mM}$ calcium) varied from 0.3 to 0.95 in 10 endbulbs (Oleskevich et al. 2000). This variance was observed in other studies as well (e.g. (Yang \& Xu-Friedman 2009; Cao \& Oertel 2010) Another way to estimate Pr is to quantify the paired-pulse ratio (PPR). This is defined as the amplitude ratio of the second and the first evoked EPSC after stimulation with two consecutive pulses. The extent of PPR, i.e. the degree of depression or facilitation, depends among others factors on the initial Pr of a synapse (Regehr 2012). In the endbulbs of Held synapse a linear correlation between PPR and $\operatorname{Pr}$ was observed (Oleskevich et al. 2000). Bushy cells with high Pr had a low PPR and vice versa. A recent study revealed that endbulbs converging on the same bushy cell have similar PPRs. Whereas the PPR was more divergent in randomly chosen endbulbs terminating on different bushy cells (Yang \& Xu-Friedman 2009). This was also true for responses during low-frequency trains. Later experiments with a use-dependent NMDA-receptor blocker MK-801 confirmed that presynaptic $\operatorname{Pr}$ is similar in converging endbulbs (Yang \& Xu-Friedman 2012). Moreover, the results from that study indicate that plasticity is tightly regulated on a cell-by-cell basis. Yet, underlying mechanisms or involved molecules in the coordinated plasticity in the AVCN are not known.

A correlation between auditory nerve activity and endbulb morphology was described in cats (Ryugo et al. 1996). Auditory nerve terminals were found to have high and low spontaneous activity. Those terminals that converge on the same bushy cell have similar spontaneous rates (Ryugo \& Sent 1991) and exhibit similar shapes (Ryugo et 
al. 1996). Endbulbs with low spontaneous rates are smaller and more complex in shape while endbulbs with high spontaneous rates are larger (Ryugo et al. 1996).

An obvious question arising from these findings is whether activity in the auditory nerve is contributes to the regulation of $\mathrm{Pr}$ in endbulbs. Currently Xu-Friedman and colleagues are addressing this question. Preliminary data yield to a correlation between activity and $\operatorname{Pr}$ in a way that higher activity in ANF led to lower $\operatorname{Pr}$ in endbulbs (Xu-Friedman, talk, German Neuroscience society conference, 2015).

In the following it will be discussed that the findings mentioned above and the results from the present study support an earlier suggested correlation between Mover level and the Pr of synapse.

The broad distribution of Mover mean fluorescence signals may reflect the varying $\operatorname{Pr}$ between endbulbs at different bushy cells. And changes in the Mover level could correlate to the observed differences in $\mathrm{Pr}$. Thus it is conceivable that higher Mover levels are detected when endbulbs have lower $\mathrm{Pr}$ and vice versa. Moreover, the SD of Mover mean intensities in endbulbs from one cell is lower than the SD for VGLUT1 intensities indicating similar Mover levels in endbulbs that converge onto one bushy cell. This is consistent with the finding that `sibling 'endbulbs have similar $\operatorname{Pr}$ (Yang \& Xu-Friedman 2012). Certainly; the correlation of fluorescence signals with $\operatorname{Pr}$ is only indirect in this particular instance. In order to prove a direct correlation, electrophysiological recordings would have to be performed followed by immunostainings of the recorded cell. Then the measured Mover fluorescence can be compared or correlated with the measured Pr. This seems to be a very tedious approach. Instead, we chose to generate a Mover knock-out mouse model for further studying its function in synaptic plasticity (see 4.4).

\subsection{Activity-dependent regulation of Mover in deaf mice}

Otoferlin appears in inner hair cells $(\mathrm{IHC})$ at $\mathrm{P} 4$ after which it is important for calciumdependent exocytosis (Beurg et al. 2010) and involved in SV replenishment in IHC (Pangrsic et al. 2010). In mice that lack Otoferlin exocytosis in the IHC is almost completely abolished (Roux et al. 2006)and ABRs are absent (Roux et al. 2006; Wright et al. 2014) indicating that the transmission from $\mathrm{IHC}$ to the brainstem is impaired. However, the auditory nerve responded to electrical stimulation and electrically evoked brainstem responses (eEBRs) could be elicited suggesting that 
the afferent auditory pathway is functional and the hearing impairment in these mice is probably due to defective IHCs (Roux et al. 2006). A recent study by Wright et al. (2014) examined the synaptic transmission between endbulbs of Held and bushy cells in mice with a mutation in Otoferlin. They revealed a decrease in the pairedpulse ratio indicating a higher release probability. Moreover, bushy cells from the mutant mice show stronger and faster synaptic depression in response to a train of stimuli. Furthermore, they could show that bushy cells in deaf mutant mice received a greater number of inputs that were smaller in morphology.

Analysis of Mover fluorescence signal intensities in endbulbs in Otoferlin knock-out mice revealed reduced intensity of Mover signals indicating an activity-dependent regulation of Mover in deaf mice. This result supports previous experiments in cultured cortical neurons where neuronal activity was blocked with TTX and a downregulation of Mover was detected with western blot. The observed reduction of Mover level in the current study is in line with the higher Pr found in Otoferlin mutants assuming that Mover correlates with Pr in a negative way. In addition, the reduced endbulbs size (represented by the VGLUT1 labeled area) that was measured here matches with a smaller endbulb morphology reported in the Otoferlin mutant study. Moreover, in Otoferlin knock-out animals a decreased VGLUT1 fluorescence was observed which correlated with the area of VGLUT1 fluorescence signals and Mover signal intensities. The reduction in VGLUT1 level (4\%) is much smaller than the reduction in Mover level and both fluorescence intensities correlate negatively (see appendix, figure 7.1), making it unlikely that the VGLUT1 reduction account for the changed intensity of Mover signals. However, the decreased VGLUT1 fluorescence may be related to the decreased VGLUT1 area due to a positive correlation of both parameters. VGAT fluorescence signal area represents the inhibitory terminal size and was also reduced in deaf Otoferlin knock-out. A loss of glycinergic terminals surrounding bushy cells was observed after bilateral cochlear ablation (Asako et al. 2005). This suggests that a loss or reduction of ANF activity affects not only the excitation to bushy cells but also leads to changes at inhibitory synapses. This possibly results in lower Mover level in inhibitory synapses. Increased $\operatorname{Pr}$ and greater depression in bushy cells was also found in a congenitally deaf $(\mathrm{dn} / \mathrm{dn})$ mouse which lack normal synaptic activity (Oleskevich \& Walmsley 2002; Oleskevich et al. 2004). Similarly, stronger depression indicating higher $\operatorname{Pr}$ was revealed in T-stellate and octopus cells in deaf jerker mice in which IHC start to degenerate around the onset of 
hearing (Cao et al. 2008). In contrast, Pr is lower in 'old` DBA mice exhibiting hearing loss by the age of 5 weeks (Wang \& Manis 2005). In Otoferlin mutant and jerker mice it was reported that the size of endbulbs is reduced (Cao et al. 2008; Wright et al. 2014). Moreover, morphological and structural abnormalities in deaf cat endbulbs were reported by Ryugo et al. (1998). Interestingly, changes in cats suffering from hearing loss exhibited intermediate features (Ryugo et al. 1998).

The partial auditory deprivation in $B s n^{\Delta E \times 4-5}$ mice, arising from defective $\mathrm{IHC}$ and a reduced ANF spike rate, had as a consequence an increased $\mathrm{Pr}$ and an enhanced and stronger depression in endbulbs. The loss of Bassoon was accompanied by a $\sim 20 \%$ reduction of Mover in endbulbs and mossy fiber terminals in hippocampus (Mendoza Schulz et al. 2014). In the first place, this supports the association of Mover with Bassoon at the active zone and with a regulatory role of Mover in $\operatorname{Pr}$ adaptation. Secondly, the lower Mover level might be a result of a down-regulation of Mover upon reduced ANF activity. The present study revealed that the fluorescence intensities of the Mover signal remained unchanged in hippocampus in Otoferlin knock-out mice. Moreover, these results are in line with results from electrophysiological recordings in autaptic hippocampal cultures that revealed normal synaptic transmission and synaptic properties (Reisinger et al. 2011).

Homeostatic plasticity is a phenomenon in which neurons modify their intrinsic or synaptic properties to maintain a target level of electrical activity on a local and/or circuit level. Many cellular mechanisms that counteract or compensate for changes in the activity level have been observed and studied including pre- and postsynaptic forms of synaptic plasticity, such as synaptic scaling, the balancing of excitation and inhibition, compensatory changes in synapse number, the activity-dependent regulation of intrinsic neuronal firing and several others (Turrigiano 2012). The increase of $\mathrm{Pr}$ in Otoferlin mutant, deafness and Bassoon mutant mice can partly be attributed to presynaptic homeostatic adaptations upon the loss of activity in ANF (Oleskevich \& Walmsley 2002; Wright et al. 2014; Mendoza Schulz et al. 2014). In addition, higher evoked EPSC amplitudes but unchanged quantal content in Otoferlin mutant possibly result from an AMPA receptor up-regulation (Wright et al. 2014) in line with expected homeostatic mechanisms. In contrast, changes in synaptic transmission mice with age-related hearing loss seem to contradict those from completely deaf mice and Bassoon mutant mice. 
In the present study an increase of Mover signal intensities at the calyx of Held level was detected suggesting a compensatory and homeostatic adjustment on the protein level. Interestingly, no differences in synaptic transmission (Oleskevich et al. 2004) but an increase in excitability due to changes in potassium currents and hyperpolarization-activated currents were found at the calyx of Held in deafness mice (Leao et al. 2004). This leads to the assumption that other mechanisms act in mice that undergo a normal auditory development and have to face changes in activity level later on.

It would be interesting to study if the Mover level increases in endbulbs of mice which were exposed to noise in order to increase the ANF activity. In the future we will proceed with such experiments in order to confirm an activity-dependent regulation of Mover. A first attempt $(\mathrm{N}=1)$ did not reveal any changes probably because the acoustic and experimental conditions were not efficient or optimal. Note, that electrical stimulation of auditory nerve fibers with cochlear implants can ameliorate the phenotype of deaf (O'Neil et al. 2011). Thus, adaptions to activity changes are plastic.

In summary, the present study supports the notion that Mover is regulated by activity. Furthermore, recent studies indicate that activity is involved in the regulation of Pr.. The correlation between Mover and afferent activity complements the arising picture of a functional involvement of Mover in the regulation of Pr.

\subsection{Characterization of synaptic transmission at the endbulb bushy cell junction in a Mover knock-out mouse}

The Mover knock-out mouse model was used to study if and how a loss of Mover affects synaptic transmission in the brain. A mouse line was generated that allows to knock out Mover in the entire brain (global knock-out) or to conditionally knock out Mover in specific brain regions or synapses. Initially, we bred flox-Mover mice with mice from a E2A-cre mouse line. This resulted in a global knock of Mover in the brain. These knock-out mice are viable and do not exhibit obvious behavioral abnormalities. The knock-out of Mover was validated with immunostainings and confirmed the absence of Mover fluorescence signals in the AVCN and hippocampus. The present study focused on the examination of synaptic transmission between endbulbs and bushy cells in the AVCN in the knock-put mice. 
Acute brainstem slice preparations were used to record from bushy cells and stimulate the ANF. Miniature excitatory postsynaptic currents (mEPSC), which are produced in response to spontaneous release of a single vesicle, were analyzed to study the basal synaptic transmission of the synapse. An increase in quantal size and the average charge transferred in each mEPSC was revealed in Mover knock-out animals. Kinetics and shapes of mEPSCs were unchanged suggesting that the composition of AMPA receptors is similar in knock-out and wild-type animals. The larger size of mEPSCs might be due to the action of spontaneous events on more AMPA receptors or a larger postsynaptic density (PSD) size (Xu-friedman \& Regehr 2004). An enlargement of the PSD can be quantified with electron microscopy. An up-regulation of AMPA receptors can be measured by isolating the AMPA receptor response with AP5 (NMDA receptor blocker) and calculate the ratio of the AMPA receptor and NMDA receptor response. The ratio should be larger if more AMPA receptors are present in knock-out mice.

Further experiments are necessary to elucidate causes and consequences from the observed changes in basal synaptic transmission in endbulbs in Mover knock-out mice.

Preliminary data from experiments of evoked EPSC indicate changes in synaptic transmission upon stimulation of auditory nerve fibers in the vicinity of the recorded bush cell that are contradictory to those observed upon a knock-down of Mover in the calyx of Held (see appendix, figure 7.3). To date one can only speculate on effects that cause these surprising changes. We cannot rule out that Mover is present in IHC and that the knock-out of Mover affects synaptic transmission in IHC. Thus, the effects that are measured in bushy cell recordings are caused by an impaired signal transmission from IHC to spiral ganglion neurons which can lead to changes in the firing rate of auditory nerve fibers. Such changes can be higher or reduced activity in the auditory nerve. As revealed from studies with hearing-impaired and deaf animals a reduced activity results in an increase in $\mathrm{Pr}$ in endbulbs of Held. Increased activity leads to forms of tinnitus. There are several options to clarify whether the Mover knock-out affects $\mathrm{IHC}$ synaptic transmission. One is to use immunostaining with Mover antibody to test if Mover is present in $\mathrm{IHC}$ and how the immunosignals are changed in Mover knock-out animals. Additionally, the spike rate of auditory nerve fibers can be determined with in vivo recordings from auditory nerve fibers indicating higher or reduced activity of these nerve fibers. Furthermore one can use the 
conditional Mover mouse model to selectively knock-out Mover in endbulbs by breeding the flox-Mover mice with a vglut1:cre mouse line. As IHCs express only vglut3 the knock-out of Mover would not affect synaptic transmission at IHC. Then effects of the absence of Mover in endbulbs can be studied and are more clearly.

One can also take into account that Mover has synapse specific roles, thus a knockout would show different effect at different synapses which could explain different changes of PPR in the calyx of Held and endbulb of Held.

\subsection{Association of Mover with Bassoon}

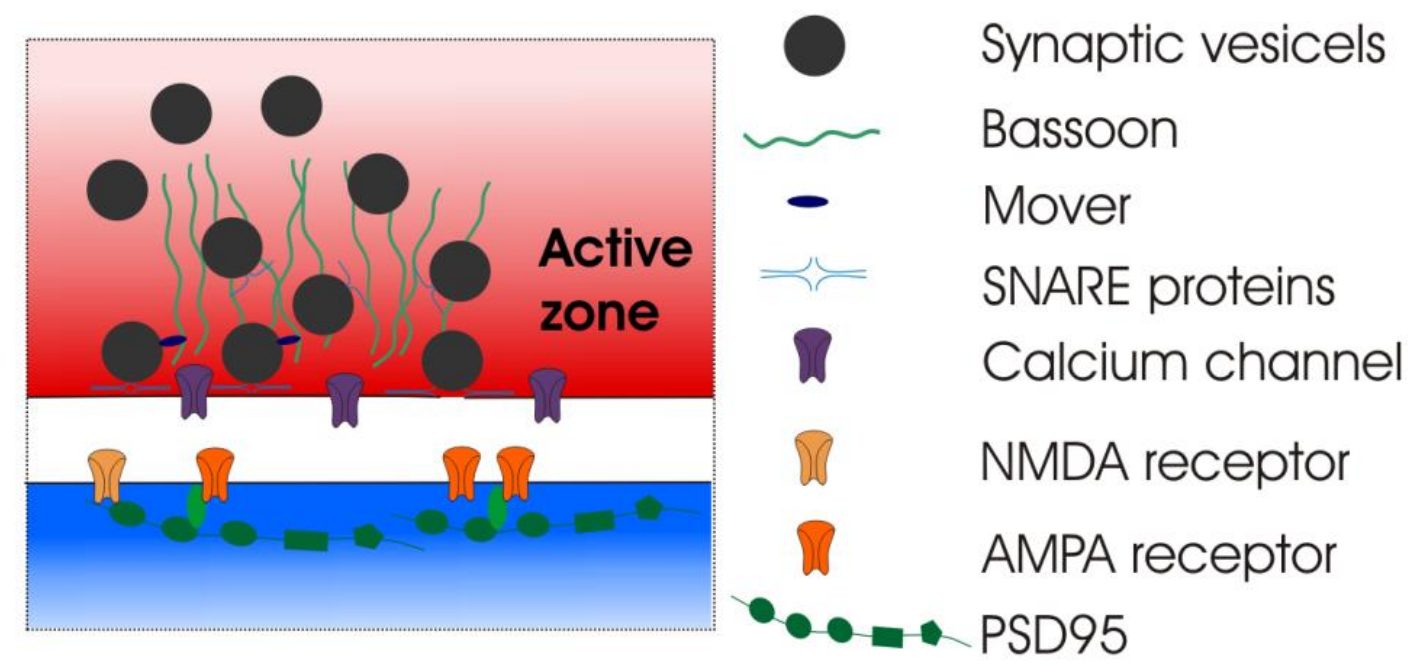

Figure 4.1 Schematic illustration of the location of Mover at the active zone

A direct association of Mover with Bassoon was found in a yeast-to-hybrid assay with the C-terminus of Bassoon (Kremer et al. 2007). Moreover, the C-terminus was found to be required for an association of Bassoon with CAZ whereas the $\mathrm{N}$-terminus is not incorporates into the CAZ but is rather involved in binding synaptic organelles such as SV (Dresbach et al. 2003). In more detail, the C-terminus of Bassoon was found to be located at a distance of 35 to $50 \mathrm{~nm}$ from the presynaptic plasma membrane in a conventional synapse (Limbach et al. 2011; Dani et al. 2010) and the N-terminus was detected at a distance of around $70-80 \mathrm{~nm}$ from the presynaptic plasma membrane (Dani et al. 2010). Immuno-gold electron microscopy confirmed that Mover is attached to SV (Körber 2011; Ahmed et al. 2013). Now, the promising assumption 
arises that Mover binds to docked vesicles since they are thought to be associated to the plasma membrane and approximately located in the same area as the $\mathrm{C}$-terminus of Bassoon - giving a SV diameter of $38 \mathrm{~nm}$ (Limbach et al. 2011). In an integrative approach combining quantitative immunoblotting and mass spectrometry Wilhelm et al. (2014) determined the protein copy number of Bassoon as 400 in a synaptic bouton containing roughly $400 \mathrm{SVs}$. A copy number of 80 molecules was calculated for Mover (personal communication T. Dresbach and S. Rizzoli) meaning that Mover is associated to $20 \%$ of the vesicles (and Bassoon molecules) given that one Mover molecules bind to one SV. This is in line with an electron microscopy analysis of a SV fraction where $16.4 \%$ percent of the SVs were positive for Mover whereas $98 \%$ of the SVs were positive for Synaptophysin (Ahmed et al. 2103). Combining these facts a model for the location of Mover can look illustrate in figure 4.1.

On the contrary, Mover immuno-gold signals in the calyx of Held were detected at a distance of around $100 \mathrm{~nm}$ away from the active zone plasma membrane which resembled the signal location of the labeled N-terminus of Bassoon (Körber 2011) suggesting the possibility that Mover also binds to the N-terminus of Bassoon. In addition, the fluorescence signals of the Mover and Bassoon overlap only partially in confocal images. Though, the confocal resolution might not be sufficient to make precise conclusions as it is limited to $100-200 \mathrm{~nm}$. Unfortunately, to date, we did not get immuno-gold stainings with the 'commercial' Mover antibody in brainstem sections to work. Nevertheless, analysis of immuno-gold labelings with electron microscopy provides an optimal tool to confirm the localization of Mover to docked vesicles. 


\section{Summary}

The central auditory pathway contains highly specialized giant presynaptic nerve terminals specialized to preserve temporal information carried by acoustic signals (Oertel et al., 1999). One of them, the endbulbs of Held, are large and highly branched axosomatic endings arising from auditory nerve fibers that converge onto bushy cells in the anterior ventral cochlear nucleus (AVCN). In addition, bushy cells receive a number of inhibitory inputs from of non-cochlear origin. Due to their remarkable size these terminals are a useful model to investigate signal transmission but little is known about the underlying molecular mechanisms. The vertebratespecific presynaptic protein Mover was identified as an interaction partner of the active zone protein Bassoon and suggested to have a regulatory role in the control of release probability ( $\operatorname{Pr}$ ) (Kremer et al., 2007; Körber, 2011). Based on these findings the present study aimed to further investigate the localization and role of Mover with a particular focus endbulbs of Held. Mover immunosignals co-localized with Synapsin immunosignals confirming that Mover is associated with synaptic vesicles. Furthermore, immunofluorescence signals of Mover were present at endbulbs of Held as well as at inhibitory synapses around bushy cells. Mean fluorescence intensities of Mover signals in endbulbs of Held were broadly distributed over different cells but were similar between converging endbulbs onto one bushy cell. Similar findings have been reported for the Pr in endbulbs of Held (Yang and Xu-Friedman, 2009, 2012). The results from Mover immunofluorescence analysis presented here provide an, albeit indirect, correlation between the Mover level and $\operatorname{Pr}$ and support the suggestion for the role of Mover in regulation of Pr. In order to study whether Mover is regulated by activity in auditory nerve fibers (ANF) Mover fluorescence intensities were compared in wild-type and knock-out Otoferlin mice, the latter one are lacking activity in ANF. A reduction of Mover fluorescence intensities by $35 \%$ was found indicating an activity dependent regulation of Mover in endbulbs of Held. To further elucidate the role of Mover a Mover knock-out mouse as generated. Using electrophysiology and patch clamp recordings from bushy cells in auditory brainstem slices the synaptic transmission at the endbulbs of Held in Mover knock-out animals was studied. The absence of Mover in endbulbs of Held was validated with fluorescence stainings. Analysis of spontaneous miniature excitatory postsynaptic currents (mEPSCs) revealed an increased quantal size and area of mEPSCs in 
Mover knock-out animals. However, kinetics of mEPSCs remained unchanged suggesting that the amount of AMPA receptor is increased. Yet, further experiments have to be performed to study the consequences of these changes for synaptic transmission upon evoked action potentials. 


\section{References}

Ahmed, S. et al., 2013. Mover is a homomeric phospho-protein present on synaptic vesicles. PloS one, 8(5), p.e63474. Available at:

http://www.pubmedcentral.nih.gov/articlerender.fcgi?artid=3665746\&tool=pmcen trez\&rendertype=abstract [Accessed March 11, 2015].

Altrock, W.D. et al., 2003. Functional inactivation of a fraction of excitatory synapses in mice deficient for the active zone protein bassoon. Neuron, 37(5), pp.787800. Available at: http://www.ncbi.nlm.nih.gov/pubmed/12628169 [Accessed April 30, 2015].

Antonini, D. et al., 2008. Tprg, a gene predominantly expressed in skin, is a direct target of the transcription factor p63. The Journal of investigative dermatology, 128(7), pp.1676-85. Available at: http://www.ncbi.nlm.nih.gov/pubmed/18256694 [Accessed April 30, 2015].

Asako, M. et al., 2005. Deafness-related decreases in glycine-immunoreactive labeling in the rat cochlear nucleus. Journal of neuroscience research, 81(1), pp.102-9. Available at: http://www.ncbi.nlm.nih.gov/pubmed/15929063 [Accessed April 25, 2015].

Beurg, M. et al., 2010. Control of exocytosis by synaptotagmins and otoferlin in auditory hair cells. The Journal of neuroscience : the official journal of the Society for Neuroscience, 30(40), pp.13281-90. Available at: http://www.jneurosci.org/content/30/40/13281.long [Accessed January 29, 2015].

Blackburn, C.C. \& Sachs, M.B., 1990. The representations of the steady-state vowel sound /e/ in the discharge patterns of cat anteroventral cochlear nucleus neurons. Journal of neurophysiology, 63(5), pp.1191-212. Available at: http://www.ncbi.nlm.nih.gov/pubmed/2358869 [Accessed April 30, 2015].

Bolte, S. \& Cordelières, F.P., 2006. A guided tour into subcellular colocalization analysis in light microscopy. Journal of microscopy, 224(Pt 3), pp.213-32. Available at: http://www.ncbi.nlm.nih.gov/pubmed/17210054 [Accessed November 17, 2014].

Burré, J. et al., 2006. Analysis of the synaptic vesicle proteome using three gel-based protein separation techniques. Proteomics, 6(23), pp.6250-62. Available at: http://www.ncbi.nlm.nih.gov/pubmed/17080482 [Accessed March 10, 2015].

Campagnola, L. \& Manis, P.B., 2014. A Map of Functional Synaptic Connectivity in the Mouse Anteroventral Cochlear Nucleus. Journal of Neuroscience, 34(6), pp.2214-2230. Available at:

http://www.pubmedcentral.nih.gov/articlerender.fcgi?artid=3913869\&tool=pmcen trez\&rendertype=abstract [Accessed March 11, 2015].

Cant, N.B. \& Benson, C.G., 2003. Parallel auditory pathways: projection patterns of the different neuronal populations in the dorsal and ventral cochlear nuclei. Brain 
research bulletin, 60(5-6), pp.457-74. Available at: http://www.ncbi.nlm.nih.gov/pubmed/12787867 [Accessed March 11, 2015].

Cant, N.B. \& Casseday, J.H., 1986. Projections from the anteroventral cochlear nucleus to the lateral and medial superior olivary nuclei. The Journal of comparative neurology, 247(4), pp.457-476.

Cao, X.-J., McGinley, M.J. \& Oertel, D., 2008. Connections and synaptic function in the posteroventral cochlear nucleus of deaf jerker mice. The Journal of comparative neurology, 510(3), pp.297-308. Available at: http://www.pubmedcentral.nih.gov/articlerender.fcgi?artid=2553045\&tool=pmcen trez\&rendertype=abstract [Accessed March 10, 2015].

Cao, X.-J. \& Oertel, D., 2010. Auditory nerve fibers excite targets through synapses that vary in convergence, strength, and short-term plasticity. Journal of neurophysiology, 104(5), pp.2308-20. Available at: http://www.pubmedcentral.nih.gov/articlerender.fcgi?artid=3350034\&tool=pmcen trez\&rendertype=abstract [Accessed March 10, 2015].

Cao, X.-J., Shatadal, S. \& Oertel, D., 2007. Voltage-sensitive conductances of bushy cells of the Mammalian ventral cochlear nucleus. Journal of neurophysiology, 97(6), pp.3961-3975.

Chanda, S. \& Xu-Friedman, M. a, 2010. A low-affinity antagonist reveals saturation and desensitization in mature synapses in the auditory brain stem. Journal of neurophysiology, 103(4), pp.1915-26. Available at:

http://www.pubmedcentral.nih.gov/articlerender.fcgi?artid=2853296\&tool=pmcen trez\&rendertype=abstract [Accessed March 10, 2015].

Chaudhry, F.A. et al., 1998. The Vesicular GABA Transporter, VGAT, Localizes to Synaptic Vesicles in Sets of Glycinergic as Well as GABAergic Neurons. J. Neurosci., 18(23), pp.9733-9750. Available at: http://www.jneurosci.org/content/18/23/9733.long [Accessed April 18, 2015].

Dani, A. et al., 2010. Superresolution imaging of chemical synapses in the brain. Neuron, 68(5), pp.843-56. Available at:

http://www.pubmedcentral.nih.gov/articlerender.fcgi?artid=3057101\&tool=pmcen trez\&rendertype=abstract [Accessed March 3, 2015].

Dresbach, T. et al., 2003. Functional regions of the presynaptic cytomatrix protein Bassoon: Significance for synaptic targeting and cytomatrix anchoring. Molecular and Cellular Neuroscience, 23(2), pp.279-291.

Fay, R.R., 1988. Hearing in Vertebrates - a Psychophysics Databook, Hill-Fay Associates.

Frank, T. et al., 2010. Bassoon and the synaptic ribbon organize $\mathrm{Ca}^{2}+$ channels and vesicles to add release sites and promote refilling. Neuron, 68(4), pp.724-38.

Available at:

http://www.pubmedcentral.nih.gov/articlerender.fcgi?artid=3005353\&tool=pmcen trez\&rendertype=abstract [Accessed April 30, 2015]. 
Grothe, B., 2003. New roles for synaptic inhibition in sound localization. Nature reviews. Neuroscience, 4(7), pp.540-50. Available at: http://www.ncbi.nlm.nih.gov/pubmed/12838329 [Accessed April 30, 2015].

Grothe, B. \& Pecka, M., 2014. The natural history of sound localization in mammals-a story of neuronal inhibition. Frontiers in neural circuits, 8, p.116. Available at: http://www.pubmedcentral.nih.gov/articlerender.fcgi?artid=4181121\&tool=pmcen trez\&rendertype=abstract [Accessed March 26, 2015].

Grothe, B., Pecka, M. \& McAlpine, D., 2010. Mechanisms of sound localization in mammals. Physiological reviews, 90(3), pp.983-1012. Available at: http://physrev.physiology.org/content/90/3/983.abstract [Accessed March 26, 2015].

Grothe, B. \& Sanes, D.H., 1994. Synaptic inhibition influences the temporal coding properties of medial superior olivary neurons: an in vitro study. The Journal of neuroscience : the official journal of the Society for Neuroscience, 14(3 Pt 2), pp.1701-9. Available at: http://www.ncbi.nlm.nih.gov/pubmed/8126564 [Accessed April 30, 2015].

Hallermann, S. et al., 2010. Bassoon speeds vesicle reloading at a central excitatory synapse. Neuron, 68(4), pp.710-23. Available at:

http://www.pubmedcentral.nih.gov/articlerender.fcgi?artid=3004039\&tool=pmcen trez\&rendertype=abstract [Accessed March 31, 2015].

Held, H., 1893. Die zentrale Gehörleitung E. D. His, W. \& Bois-Reymond, ed., Leipziger Verlag von Veit und Comp, Leipzig.

Isaacson, J.S. \& Walmsley, B., 1996. Amplitude and time course of spontaneous and evoked excitatory postsynaptic currents in bushy cells of the anteroventral cochlear nucleus. Journal of neurophysiology, 76(3), pp.1566-71. Available at: http://www.ncbi.nlm.nih.gov/pubmed/8890276 [Accessed April 29, 2015].

Joris, P. \& Yin, T.C.T., 2007. A matter of time: internal delays in binaural processing. Trends in neurosciences, 30(2), pp.70-8. Available at: http://www.ncbi.nlm.nih.gov/pubmed/17188761 [Accessed April 28, 2015].

Joris, P.X. et al., 1994. Enhancement of neural synchronization in the anteroventral cochlear nucleus. I. Responses to tones at the characteristic frequency. Journal of neurophysiology, 71(3), pp.1022-1036.

Joris, P.X., Smith, P.H. \& Yin, T.C.T., 1998. Coincidence detection minireview in the auditory system: 50 years after \{Jeffress\}. Neuron, 21, pp.1235-1238.

Kolston, J. et al., 1992. An atlas of glycine- and GABA-like immunoreactivity and colocalization in the cochlear nuclear complex of the guinea pig. Anatomy and embryology, 186(5), pp.443-65. Available at: http://www.ncbi.nlm.nih.gov/pubmed/1443654 [Accessed April 30, 2015].

Kopp-Scheinpflug, C. et al., 2002. Interaction of Excitation and Inhibition in Anteroventral Cochlear Nucleus Neurons That Receive Large Endbulb Synaptic 
Endings. J. Neurosci., 22(24), pp.11004-11018. Available at: http://www.jneurosci.org/content/22/24/11004.long [Accessed April 30, 2015].

Körber, C., 2011. Functional characterization of the vertebrate-specific presynaptic protein Mover in the calyx of Held. Ruperto-Carola University of Heidelberg.

Kremer, T., 2008. Identification and characterisation of mover as a novel vertebratespecific presynaptic protein. Ruperto-Carola University of Heidelberg.

Kremer, T. et al., 2007. Mover is a novel vertebrate-specific presynaptic protein with differential distribution at subsets of CNS synapses. FEBS letters, 581(24), pp.4727-33. Available at: http://www.ncbi.nlm.nih.gov/pubmed/17869247 [Accessed March 10, 2015].

Kuenzel, T., Borst, J.G.G. \& van der Heijden, M., 2011. Factors controlling the inputoutput relationship of spherical bushy cells in the gerbil cochlear nucleus. The Journal of neuroscience : the official journal of the Society for Neuroscience, 31(11), pp.4260-73. Available at: http://www.ncbi.nlm.nih.gov/pubmed/21411667 [Accessed April 30, 2015].

Lauer, A.M. et al., 2013. Morphological characterization of bushy cells and their inputs in the laboratory mouse (Mus musculus) anteroventral cochlear nucleus. PloS one, 8(8), p.e73308. Available at: http://www.pubmedcentral.nih.gov/articlerender.fcgi?artid=3753269\&tool=pmcen trez\&rendertype=abstract [Accessed March 10, 2015].

Leao, R.N. et al., 2004. Reduced low-voltage activated K+ conductances and enhanced central excitability in a congenitally deaf $(\mathrm{dn} / \mathrm{dn})$ mouse. The Journal of physiology, 559(Pt 1), pp.25-33. Available at: http://www.pubmedcentral.nih.gov/articlerender.fcgi?artid=1665064\&tool=pmcen trez\&rendertype=abstract [Accessed April 25, 2015].

Liberman, M.C., 1991. Central projections of auditory-nerve fibers of differing spontaneous rate. I. Anteroventral cochlear nucleus. The Journal of comparative neurology, 313(2), pp.240-58. Available at:

http://www.ncbi.nlm.nih.gov/pubmed/1722487 [Accessed April 30, 2015].

Limbach, C. et al., 2011. Molecular in situ topology of Aczonin/Piccolo and associated proteins at the mammalian neurotransmitter release site. Proceedings of the National Academy of Sciences of the United States of America, 108(31), pp.E392-401. Available at: http://www.pubmedcentral.nih.gov/articlerender.fcgi?artid=3150911\&tool=pmcen trez\&rendertype=abstract [Accessed April 22, 2015] .

Lin, K.-H., Oleskevich, S. \& Taschenberger, H., 2011. Presynaptic Ca2+ influx and vesicle exocytosis at the mouse endbulb of Held: a comparison of two auditory nerve terminals. The Journal of physiology, 589(Pt 17), pp.4301-20. Available at:

http://www.pubmedcentral.nih.gov/articlerender.fcgi?artid=3180584\&tool=pmcen trez\&rendertype=abstract [Accessed March 10, 2015]. 
Lu, Y., Harris, J.A. \& Rubel, E.W., 2007. Development of spontaneous miniature EPSCs in mouse AVCN neurons during a critical period of afferent-dependent neuron survival. Journal of neurophysiology, 97(1), pp.635-46. Available at: http://www.pubmedcentral.nih.gov/articlerender.fcgi?artid=1774585\&tool=pmcen trez\&rendertype=abstract [Accessed March 23, 2015].

Mendoza Schulz, A. et al., 2014. Bassoon-disruption slows vesicle replenishment and induces homeostatic plasticity at a CNS synapse. The EMBO journal, 33(5), pp.512-27. Available at: http://www.ncbi.nlm.nih.gov/pubmed/24442636.

Mukherjee, K. et al., 2010. Piccolo and bassoon maintain synaptic vesicle clustering without directly participating in vesicle exocytosis. Proceedings of the National Academy of Sciences of the United States of America, 107(14), pp.6504-9. Available at: http://www.pubmedcentral.nih.gov/articlerender.fcgi?artid=2851964\&tool=pmcen trez\&rendertype=abstract [Accessed April 30, 2015].

Nerlich, J. et al., 2014. Activity-dependent modulation of inhibitory synaptic kinetics in the cochlear nucleus. Frontiers in neural circuits, 8(December), p.145. Available at:

http://www.pubmedcentral.nih.gov/articlerender.fcgi?artid=4274880\&tool=pmcen trez\&rendertype=abstract [Accessed March 10, 2015].

Nicol, M.J. \& Walmsley, B., 2002. Ultrastructural basis of synaptic transmission between endbulbs of Held and bushy cells in the rat cochlear nucleus. Journal of Physiology, pp.713-723.

O'Neil, J.N. et al., 2011. Synaptic morphology and the influence of auditory experience. Hearing research, 279(1-2), pp.118-30. Available at: http://www.pubmedcentral.nih.gov/articlerender.fcgi?artid=3116016\&tool=pmcen trez\&rendertype=abstract [Accessed March 11, 2015].

Oertel, D. et al., 2011. The multiple functions of T stellate/multipolar/chopper cells in the ventral cochlear nucleus. Hearing research, 276(1-2), pp.61-9. Available at: http://www.pubmedcentral.nih.gov/articlerender.fcgi?artid=3078527\&tool=pmcen trez\&rendertype=abstract [Accessed March 10, 2015].

Oertel, D., 1999. The role of timing in the brain stem auditory nuclei of vertebrates. Annual review of physiology, 61, pp.497-519. Available at: http://www.ncbi.nlm.nih.gov/pubmed/10099699.

Oleskevich, S., Clements, J. \& Walmsley, B., 2000. Release probability modulates short-term plasticity at a rat giant terminal. The Journal of physiology, $524 \mathrm{Pt} 2$, pp.513-23. Available at:

http://www.pubmedcentral.nih.gov/articlerender.fcgi?artid=2269875\&tool=pmcen trez\&rendertype=abstract [Accessed March 11, 2015].

Oleskevich, S. \& Walmsley, B., 2000. Phosphorylation regulates spontaneous and evoked transmitter release at a giant terminal in the rat auditory brainstem. The Journal of physiology, 526 Pt 2, pp.349-57. Available at: 
http://www.pubmedcentral.nih.gov/articlerender.fcgi?artid=2270026\&tool=pmcen trez\&rendertype=abstract [Accessed March 11, 2015].

Oleskevich, S. \& Walmsley, B., 2002. Synaptic transmission in the auditory brainstem of normal and congenitally deaf mice. The Journal of physiology, 540(Pt 2), pp.447-55. Available at:

http://www.pubmedcentral.nih.gov/articlerender. fcgi?artid=2290254\&tool=pmcen trez\&rendertype=abstract [Accessed March 23, 2015].

Oleskevich, S., Youssoufian, M. \& Walmsley, B., 2004. Presynaptic plasticity at two giant auditory synapses in normal and deaf mice. The Journal of physiology, 560(Pt 3), pp.709-19. Available at:

http://www.pubmedcentral.nih.gov/articlerender.fcgi?artid=1665284\&tool=pmcen trez\&rendertype=abstract [Accessed March 10, 2015].

Osen, K.K., 1969. Cytoarchitecture of the cochlear nuclei in the cat. The Journal of comparative neurology, 136(4), pp.453-84. Available at:

http://www.ncbi.nlm.nih.gov/pubmed/5801446 [Accessed April 30, 2015].

Pangrsic, T. et al., 2010. Hearing requires otoferlin-dependent efficient replenishment of synaptic vesicles in hair cells. Nature neuroscience, 13(7), pp.869-876.

Available at: http://dx.doi.org/10.1038/nn.2578.

Petralia, R.S. et al., 2000. Differential distribution of glutamate receptors in the cochlear nuclei. Hearing research, 147, pp.59-69.

Pliss, L., Yang, H. \& Xu-Friedman, M.A., 2009. Context-Dependent Effects of NMDA Receptors on Precise Timing Information at the Endbulb of Held in the Cochlear Nucleus. Journal of Neurophysiology, 102(5), pp.2627-2637. Available at: http://www.pubmedcentral.nih.gov/articlerender.fcgi?artid=2777834\&tool=pmcen trez\&rendertype=abstract [Accessed March 11, 2015].

Regehr, W.G., 2012. Short-term presynaptic plasticity. Cold Spring Harbor perspectives in biology, 4(7), p.a005702. Available at:

http://www.pubmedcentral.nih.gov/articlerender.fcgi?artid=3385958\&tool=pmcen trez\&rendertype=abstract [Accessed February 13, 2015].

Reisinger, E. et al., 2011. Probing the functional equivalence of otoferlin and synaptotagmin 1 in exocytosis. The Journal of neuroscience : the official journal of the Society for Neuroscience, 31(13), pp.4886-95. Available at: http://www.pubmedcentral.nih.gov/articlerender.fcgi?artid=3083821\&tool=pmcen trez\&rendertype=abstract [Accessed February 19, 2015].

Rhode, W.S. \& Smith, P.H., 1986. Encoding timing and intensity in the ventral cochlear nucleus of the cat. Journal of neurophysiology, 56(2), pp.261-86. Available at: http://www.ncbi.nlm.nih.gov/pubmed/3760921 [Accessed March 11, 2015].

Roux, I. et al., 2006. Otoferlin, defective in a human deafness form, is essential for exocytosis at the auditory ribbon synapse. Cell, 127(2), pp.277-89. Available at: 
http://www.cell.com/article/S0092867406012189/fulltext [Accessed January 9, 2015].

Ryugo, D.K. et al., 1998. Single unit recordings in the auditory nerve of congenitally deaf white cats: morphological correlates in the cochlea and cochlear nucleus. The Journal of comparative neurology, 397(4), pp.532-48. Available at: http://www.ncbi.nlm.nih.gov/pubmed/9699914 [Accessed April 30, 2015].

Ryugo, D.K. et al., 1997. Ultrastructural analysis of primary endings in deaf white cats: morphologic alterations in endbulbs of Held. The Journal of comparative neurology, 385(2), pp.230-44. Available at: http://www.ncbi.nlm.nih.gov/pubmed/9268125 [Accessed April 30, 2015].

Ryugo, D.K. \& Sent, S., 1991. Synaptic Connections of the Auditory Nerve in Cats: Relationship Between Endbulbs of Held and Spherical Bushy Cells. , 3053548.

Ryugo, D.K. \& Spirou, G.A., 2010. Auditory System: Giant Synaptic Terminals, Endbulbs, and Calyces. In Encyclopedia of Neuroscience. pp. 759-770.

Ryugo, D.K., Wu, M.M. \& Pongstaporn, T.A.N., 1996. Activity-Related Features of Synapse Morphology: A Study of Endbulbs of Held. , 158.

Schoch, S. \& Gundelfinger, E.D., 2006. Molecular organization of the presynaptic active zone. Cell and tissue research, 326(2), pp.379-91. Available at: http://www.ncbi.nlm.nih.gov/pubmed/16865347 [Accessed December 29, 2014].

Schofield, B.R., 1994. Projections to the cochlear nuclei from principal cells in the medial nucleus of the trapezoid body in guinea pigs. The Journal of comparative neurology, 344(1), pp.83-100. Available at: http://www.ncbi.nlm.nih.gov/pubmed/7520457 [Accessed April 30, 2015].

Schofield, B.R., 1991. Superior paraolivary nucleus in the pigmented guinea pig: separate classes of neurons project to the inferior colliculus and the cochlear nucleus. The Journal of comparative neurology, 312(1), pp.68-76. Available at: http://www.ncbi.nlm.nih.gov/pubmed/1744244 [Accessed April 30, 2015].

Sento, S. \& Ryugo, D.K., 1989. Endbulbs of held and spherical bushy cells in cats: morphological correlates with physiological properties. The Journal of comparative neurology, 280(4), pp.553-62. Available at: http://www.ncbi.nlm.nih.gov/pubmed/2708566 [Accessed April 30, 2015].

Shannon, R. V et al., 1995. Speech recognition with primarily temporal cues. Science (New York, N.Y.), 270(5234), pp.303-4. Available at: http://www.ncbi.nlm.nih.gov/pubmed/7569981 [Accessed March 17, 2015].

Shofner, W.P., 2008. Representation of the spectral dominance region of pitch in the steady-state temporal discharge patterns of cochlear nucleus units. The Journal of the Acoustical Society of America, 124(5), pp.3038-52. Available at: /pmc/articles/mid/NIHMS65790/?report=abstract [Accessed April 30, 2015]. 
Smith, P.H. et al., 1991. Projections of physiologically characterized globular bushy cell axons from the cochlear nucleus of the cat. The Journal of comparative neurology, 304(3), pp.387-407. Available at:

http://www.ncbi.nlm.nih.gov/pubmed/2022755 [Accessed April 30, 2015].

Smith, P.H. \& Rhode, W.S., 1989. Structural and functional properties distinguish two types of multipolar cells in the ventral cochlear nucleus. The Journal of comparative neurology, 282(4), pp.595-616. Available at: http://www.ncbi.nlm.nih.gov/pubmed/2723154 [Accessed April 30, 2015].

Spirou, G.A., Rager, J. \& Manis, P.B., 2005. Convergence of auditory-nerve fiber projections onto globular bushy cells. Neuroscience, 136(3), pp.843-863. Available at: http://www.ncbi.nlm.nih.gov/pubmed/16344156 [Accessed March 11, 2015].

Südhof, T.C., 2012. The presynaptic active zone. Neuron, 75(1), pp.11-25.

Turrigiano, G., 2012. Homeostatic synaptic plasticity: local and global mechanisms for stabilizing neuronal function. Cold Spring Harbor perspectives in biology, 4(1), p.a005736. Available at:

http://www.pubmedcentral.nih.gov/articlerender.fcgi?artid=3249629\&tool=pmcen trez\&rendertype=abstract [Accessed March 6, 2015].

Wang, Y. et al., 1998. Endbulb Synapses in the Anteroventral Cochlear Nucleus Express a Specific Subset of AMPA-Type Glutamate Receptor Subunits. The journal of neuroscience, 18(3), pp.1148-1160.

Wang, Y. \& Manis, P.B., 2008. Short-term synaptic depression and recovery at the mature mammalian endbulb of Held synapse in mice. Journal of neurophysiology, 100(3), pp.1255-64. Available at: http://www.pubmedcentral.nih.gov/articlerender.fcgi?artid=2544465\&tool=pmcen trez\&rendertype=abstract [Accessed March 10, 2015].

Wang, Y. \& Manis, P.B., 2005. Synaptic transmission at the cochlear nucleus endbulb synapse during age-related hearing loss in mice. Journal of neurophysiology, 94(3), pp.1814-24. Available at: http://www.pubmedcentral.nih.gov/articlerender.fcgi?artid=1941703\&tool=pmcen trez\&rendertype=abstract [Accessed April 22, 2015].

Wang, Y. \& Manis, P.B., 2006. Temporal Coding by Cochlear Nucleus Bushy Cells in DBA/2J Mice with Early Onset Hearing Loss. Journal of the Association for Research in Otolaryngology, 7(4), pp.412-424. Available at: http://www.pubmedcentral.nih.gov/articlerender.fcgi?artid=1785302\&tool=pmcen trez\&rendertype=abstract [Accessed March 11, 2015].

Wang, Y., Ren, C. \& Manis, P.B., 2010. Endbulb synaptic depression within the range of presynaptic spontaneous firing and its impact on the firing reliability of cochlear nucleus bushy neurons. Hearing research, 270(1-2), pp.101-9.

Available at:

http://www.pubmedcentral.nih.gov/articlerender.fcgi?artid=2997871\&tool=pmcen trez\&rendertype=abstract [Accessed March 10, 2015]. 
Wickesberg, R.E. \& Oertel, D., 1990. Delayed, frequency-specific inhibition in the cochlear nuclei of mice: a mechanism for monaural echo suppression. The Journal of neuroscience : the official journal of the Society for Neuroscience, 10(6), pp.1762-1768.

Wilhelm, B.G. et al., 2014. Composition of isolated synaptic boutons reveals the amounts of vesicle trafficking proteins. Science (New York, N.Y.), 344(6187), pp.1023-8. Available at: http://www.ncbi.nlm.nih.gov/pubmed/24876496.

Wright, S., Hwang, Y. \& Oertel, D., 2014. Synaptic transmission between end bulbs of Held and bushy cells in the cochlear nucleus of mice with a mutation in Otoferlin. Journal of Neurophysiology, 112(12), pp.3173-3188. Available at: http://jn.physiology.org/cgi/doi/10.1152/jn.00522.2014.

Xie, R. \& Manis, P.B., 2013. Glycinergic synaptic transmission in the cochlear nucleus of mice with normal hearing and age-related hearing loss. Journal of neurophysiology, 110(8), pp.1848-1859. Available at: http://www.ncbi.nlm.nih.gov/pubmed/23904491.

Xu-friedman, M.A. \& Regehr, W.G., 2004. Structural Contributions to Short-Term Synaptic Plasticity. Physiological reviews, pp.69-85.

Yang, H. \& Xu-Friedman, M. a, 2012. Emergence of coordinated plasticity in the cochlear nucleus and cerebellum. The Journal of neuroscience : the official journal of the Society for Neuroscience, 32(23), pp.7862-8. Available at: http://www.pubmedcentral.nih.gov/articlerender.fcgi?artid=3378049\&tool=pmcen trez\&rendertype=abstract [Accessed March 10, 2015].

Yang, H. \& Xu-Friedman, M. a, 2009. Impact of synaptic depression on spike timing at the endbulb of Held. Journal of neurophysiology, 102(3), pp.1699-710. Available at: http://www.pubmedcentral.nih.gov/articlerender.fcgi?artid=2894642\&tool=pmcen trez\&rendertype=abstract [Accessed March 10, 2015].

Yang, H. \& Xu-Friedman, M. a, 2008. Relative roles of different mechanisms of depression at the mouse endbulb of Held. Journal of neurophysiology, 99(5), pp.2510-21. Available at:

http://www.pubmedcentral.nih.gov/articlerender.fcgi?artid=2905879\&tool=pmcen trez\&rendertype=abstract [Accessed March 10, 2015]. 


\section{Appendix}

A

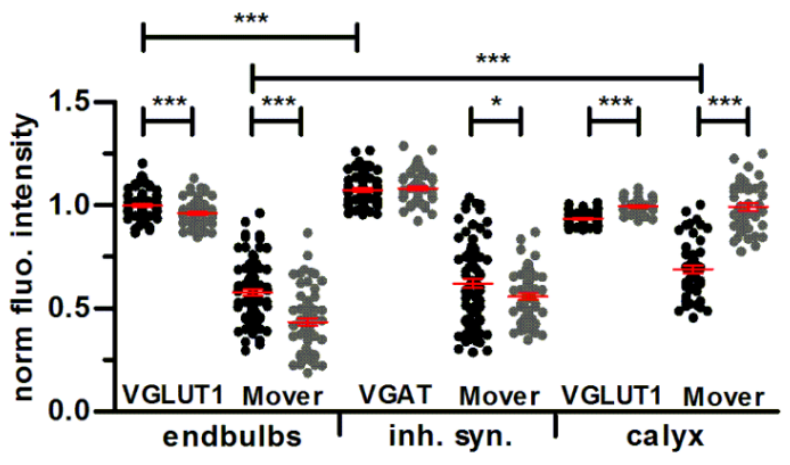

C

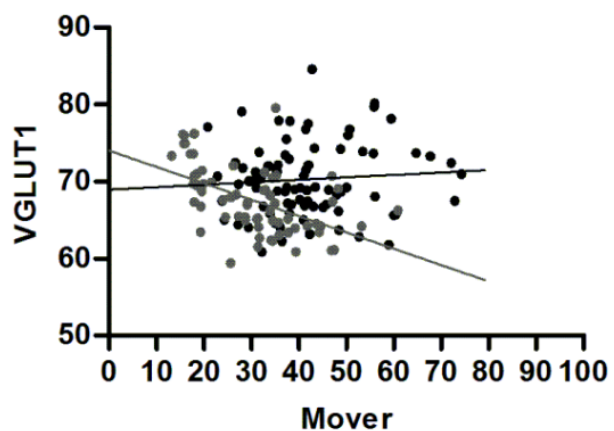

B

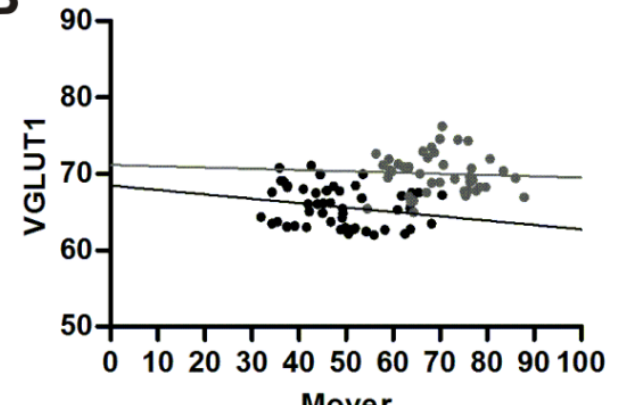

D

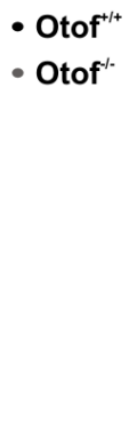

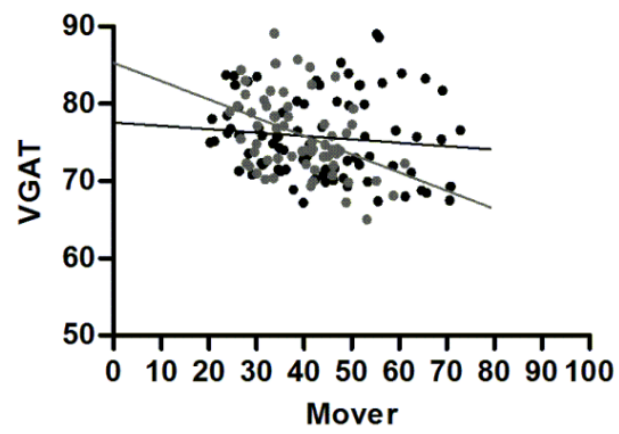

Figure 7.1 Correlation of measured immunofluorescence intensities in Otoferlin mice. A. Summary of analyzed fluorescence signals. Intensities are normalized against VGLUT1 intensities in wild-type endbulbs. B. Intensities of Mover and VGLUT1 signal do not correlate in calyx of Held of wild-type or knock-out Otoferlin mice. C and D. Mover signal intensities are negatively correlated with VGLUT1 and VGAT signal intensities in Otoferlin knock-out mice $\left(r^{2}=0.27\right.$ and $\left.r^{2}=0.14\right)$ but not in wild-type mice $\left(r^{2}=0.006\right.$ and $\left.r^{2}=0.01\right)$. 
A

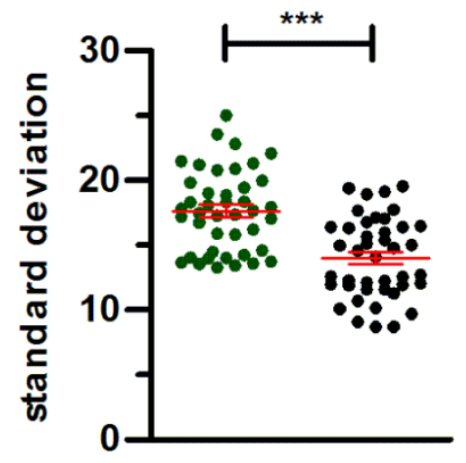

B

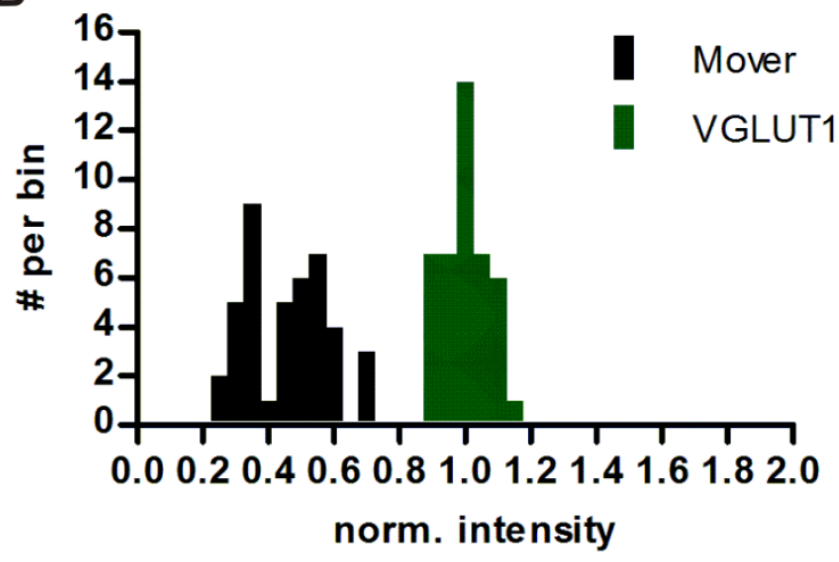

Figure 7.2 Standard deviation of mean intensities from Mover immunosignals in rat.

A. Standard deviations (SD) of the mean intensity of all regions of interest in a confocal image is lower for Mover signals than for VGLUT1 signal. B. Distribution of the mean intensities of analyzed images in broad for the Mover signals and more narrow for the VGLUT1 signals.

A

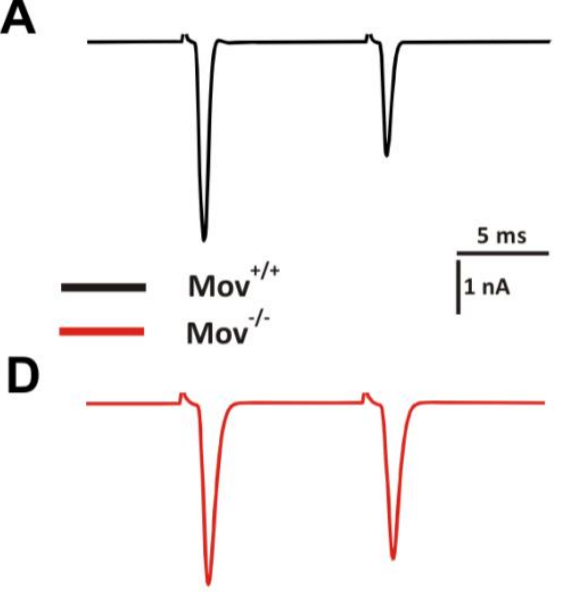

B

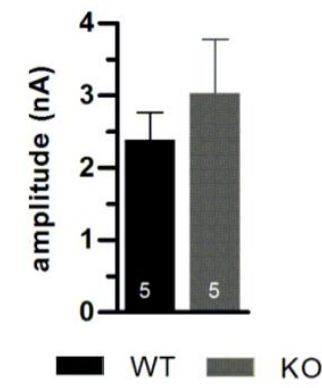

E

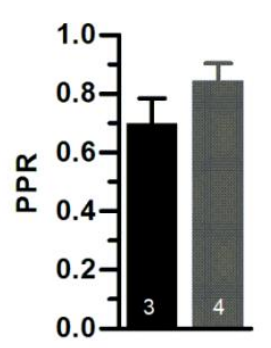

C

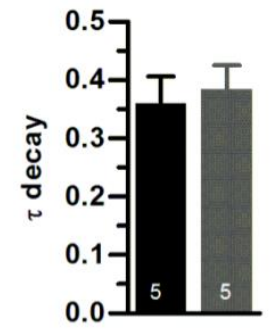

$\mathbf{F}$

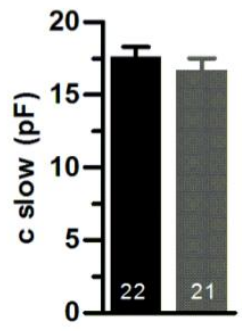

Figure 7.3 Evoked paired EPSCs in endbulbs of Mover knock-out mice.

A and D. Evoked paired EPSCs of an example cell in a wild-type (black) and knock-out animal red). B-C. Amplitude size (B) and kinetics such as decay time (C) are not affected. E. Paired-pulse ratio (PPR) serves as a mean for release probability. For evaluation of the PPR the amplitude of the second eEPSC is divided by the amplitude of the first eEPSC. PPR tends to be increased in endbulbs of knock-out mice. F. Cell size, approximated by the membrane capacitance, remained unchanged (16.68 $\pm 0.83, n=21$, versus $17.62 \pm 0.68$, $n=22 ; p=0.38$ ). 
Table. 7.1 Analysis of evoked EPSCs

\begin{tabular}{lccc}
\hline & $\begin{array}{c}\text { Mov }^{+/+} \\
\mathrm{n}=5\end{array}$ & $\begin{array}{c}\text { Mov }^{-1-} \\
\mathrm{n}=5\end{array}$ & p value \\
\hline Amplitude (nA) & $3.03 \pm 0.75$ & $2.38 \pm 0.39$ & 0.46 \\
Tau decay time (ms) & $0.36 \pm 0.05$ & $0.38 \pm 0.04$ & 0.70 \\
PPR (EPSC2/EPSC1) & $0.85 \pm 0.01$ & $0.70 \pm 0.09$ & 0.21 \\
\hline
\end{tabular}




\section{List of abbreviations}

ABR auditory brainstem

AMPA a-amino-3-hydroxy-5-

methyl- 4-

isoxazolepropionic acid

AVCN anteroventral cochlear

nucleus

AZ active zone

CAZ cytomatrix of the active

zone

CN cochlear nucleus

DCN dorsal cochlear nucleus

eEPSC evoked excitatory postsynaptic current

GBC globular bushy cell

ILD interaural level difference

ITD interaural time difference

KO knock-out

LNTB lateral nucleus of the trapezoid body

LSO lateral superior olive

mEPSC miniature excitatory postsynaptic current

MNTB medial nucleus of the trapezoid body

MSO medial superior olive

NMDA N-methyle-D-aspartate

MNTB medial nucleus of the

trapezoid body

MSO medial superior olive

PB phosphate buffer

PSD postsynaptic density

PVCN posteroventral cochlear

nucleus

$\mathrm{Pr} \quad$ release probability

q quantal size

$\mathrm{ROI} \quad$ region of interest

SBC spherical bushy cell

SPN superior olivary nucleus

SV synaptic vesicle

TTX tetrodotoxin

VCN ventral cochlear nucleus

VGAT vesicular GABA

transporter

VGLUT1 vesicular glutamate

transporter 1

VNTB ventral nucleus of the

WT wild- 


\section{Acknowledgements}

Ich danke,

Prof . Thomas Dresbach für die Möglichkeit in seinem Labor weiter im auditorischen System zu arbeiten und für sein Vertrauen und seinen Rückhalt die Jahre über. Ich schätze seine Begeisterung für die Wissenschaft und seine vielen, nie enden wollenden Ideen.

Prof. Tobias Moser und Prof. Nils Brose für Zeit und Rat als thesis committee Mitglieder. Besonders Tobias für die vielen Angebote Elektrophysiologie in seinem Labor zu nutzen/üben.

Dr. Donata Oertel for her hospitality in the lab and at home and for her time to share knowledge of and passion for cochlear nucleus cells. In particularly, I thank Sam Wright for being a great teacher for slice preparations and bushy cell recordings.

Irmgard Weiß für ihren Einsatz und die endlose Hilfe und Unterstützung bei Färbungen, besonders bei der Genotypisierung der Mover Mäuse und bei allen anderen Sachen, die mir das reibungslose Arbeiten im Labor erleichtert haben.

Dr. Ellen Reisinger für die Bereitstellung der Otoferlin Mäuse.

Dr. Carolin Wichmann für die Zeit und Mühe Immunogold-EM mit Mover zu probieren.

Dr. Nicola Strenzke für die ABR Messungen.

Julio and Tanvi for help and support with electrophysiology and Igor programming. Julio for comments on my thesis.

Alejandro für die Zusammenarbeit für sein paper und für das sich über die Schulter gucken lassen.

Andonia für das Korrekturlesen meiner Doktorarbeit.

Asha, Andonia, Tina, Julio, Moritz, Rebecca, Donatus, Nina and Jan for sharing lab time, lab fun and work discussions. It is due to you guys that I always liked to go to the lab.

meiner Familie, besonders meine Mama, meinen Großeltern und meiner Tante Christiane, für unaufhörliche und große Unterstützung im Allgemeinen und auf dem Weg zur Wissenschaftlerin.

meinen Freunden und meinem Freund für die gemeinsame Zeit und das Mich-auf-denBoden-des-normalen-(nicht wissenschaftlichen) Lebens-zurückholen. Besonders möchte ich mich bei Fam. Balles für die schöne gemeinsame Zeit und ihre Gastfreundschaft in Göttingen bedanken. Tausend Dank an meinen lieben Freund für die Liebe, Kraft und Unterstützung. 


\section{Curriculum Vitae}

Friederike Wetzel

PERSONAL INFORMATION

Date of Birth:

16.04.1986

Place of birth: Wernigerode, Germany

Citizenship: German

\section{EDUCATION}

05.2011 - present

PhD within the Göttingen Graduate School for Neurosciences, Biophysics, and Molecular Biosciences at the Georg-August University of Göttingen

Advisor: Prof. Thomas Dresbach, Department of Anatomy and Embryology, Group Synaptogenesis

$11.2010-03.2011$ student assistant, Group General Zoology and Neurobiology, Institute of Biology, University of Leipzig

$04.2010-11.2010$

diploma thesis: "Postnatal development of neuronal activity of spherical bushy cells"

Institute of Biology, Group General Zoology and Neurobiology, University of Leipzig

Advisor: Prof. Rudolf Rübsamen, Institute of Biology, University of Leipzig

10.2005-11.2010 Diploma degree program in Biology, University of Rostock

\section{PUBLICATION}

A. Mendoza Schulz, Z. Jing, J. M. Sánchez Caro, F. Wetzel, T. Dresbach, N. Strenzke, C. Wichmann, T. Moser "Bassoondisruption slows vesicle replenishment and induces homeostatic plasticity at a CNS synapse." EMBO Journal, 2014 Mar 3; 33(5):512-27. doi: 10.1002/embj.201385887 